UNIVERSIDADE DE SÃO PAULO

FFCLRP- DEPARTAMENTO DE PSICOLOGIA

PROGRAMA DE PÓS-GRADUAÇÃO EM PSICOLOGIA

RENATA TAMIE NAKAO

Variáveis sociodemográficas, clínicas e psicológicas associadas à adesão à hemodiálise

RIBEIRÃO PRETO - SP 

RENATA TAMIE NAKAO

\section{Variáveis sociodemográficas, clínicas e psicológicas associadas à adesão à hemodiálise}

Dissertação de Mestrado apresentada à Faculdade de Filosofia, Ciências e Letras de Ribeirão Preto da Universidade de São Paulo, como parte das exigências para a obtenção do título de Mestre em Ciências, Área de concentração: Psicologia.

Orientador: Prof. Dr. Ricardo Gorayeb 
Autorizo a reprodução e divulgação total ou parcial deste trabalho, por qualquer meio convencional ou eletrônico, para fins de estudo e pesquisa, desde que citada a fonte.

Nakao, Renata Tamie

Variáveis sociodemográficas, clínicas e psicológicas associadas à adesão à hemodiálise. Ribeirão Preto, 2013.

112p. : il. ; $30 \mathrm{~cm}$

Dissertação de Mestrado, apresentada à Faculdade de Filosofia, Ciências e Letras de Ribeirão Preto/USP. Área de concentração: Psicologia

Orientador: Gorayeb, Ricardo

1. Adesão ao tratamento. 2. Hemodiálise. 3. Depressão. 4. Ansiedade. 5. Apoio Social 
Nome: Renata Tamie Nakao

Título: Variáveis sociodemográficas, clínicas e psicológicas associadas à adesão à hemodiálise

Dissertação de Mestrado apresentada à Faculdade de Filosofia, Ciências e Letras de Ribeirão Preto da Universidade de São Paulo, para obtenção do título de Mestre em Ciências, Área de concentração: Psicologia.

Aprovada em:

Banca Examinadora

Prof. Dr.

Instituição:

Assinatura:

Prof. Dr.

Instituição:

Assinatura:

Prof. Dr.

Instituição:

Assinatura: 

Aos queridos pacientes da Unidade de Diálise do HCFMRPUSP, com carinho e admiração, por todas as lições de coragem, humildade e esperança. 



\section{AGRADECIMENTOS}

À minha família, pelos exemplos de dedicação ao trabalho e ao cuidado com o outro; pelo apoio carinhoso em todos os momentos, de alegrias e incertezas profissionais.

À querida Duda, pela dedicação ao cuidado da minha família por todos estes anos. Por ter acompanhado meu crescimento e minha formação, sempre com muito amor e generosidade.

Ao Daniel, pelo amor com que me acompanha em tudo que faço, pela compreensão e paciência com o cansaço dos finais de semana.

Ao Professor Ricardo Gorayeb, pela confiança sempre demonstrada e por todas as oportunidades de crescimento e desenvolvimento profissional que me proporciona.

Ao Professor José Abrão, pelo apoio prestado durante todo o período em que estive na Unidade de Diálise, pela disponibilidade sempre gentil e por todas as contribuições oferecidas para a confecção deste trabalho.

A todos os amigos do Serviço de Psicologia, pela convivência harmoniosa, pelos momentos de descontração e por toda ajuda que me deram durante a realização deste trabalho. Um agradecimento especial às grandes amigas Ana Luisa, Juliana, Flávia e Caroline, com quem dividi as dificuldades e com quem vivi os melhores momentos desta etapa.

Aos queridos amigos da Unidade de Diálise, de quem sinto tanta saudade. Obrigada pelo carinho com que me acolheram na equipe e pela colaboração com este trabalho. Foi muito bom estar com vocês!

Aos pacientes que participaram desta pesquisa, pela cooperação e por dividirem comigo histórias tão enriquecedoras. Espero um dia poder retribuir. Muito obrigada. 



\section{RESUMO}

NAKAO, R. T. Variáveis sociodemográficas, clínicas e psicológicas associadas à adesão à hemodiálise. 2013. 112f. Dissertação de Mestrado - Faculdade de Filosofia, Ciências e Letras de Ribeirão Preto, Universidade de São Paulo.

A adesão ao tratamento de pacientes em hemodiálise (HD) vem sendo estudada em função de seu impacto sobre o sucesso da terapêutica, a qualidade de vida e a mortalidade. Altas taxas de não adesão têm sido observadas, mas ainda não há investigações suficientes para gerar consenso quanto aos fatores relacionados a elas, especialmente no Brasil. $\mathrm{O}$ objetivo deste estudo descritivo de corte transversal foi avaliar a adesão ao tratamento de pacientes em HD no Hospital das Clínicas (HC) da Faculdade de Medicina de Ribeirão PretoUSP, e identificar relações entre adesão ao tratamento e variáveis sociodemográficas, clínicas e psicológicas. Participaram 64 pacientes, que responderam a uma entrevista semiestruturada, à Escala Hospitalar de Ansiedade e Depressão (HAD) e à Escala de Apoio Social (MOS). Foram coletados dados clínicos e medidas objetivas de adesão no prontuário dos participantes, que foram classificados como sem e com adesão aos diferentes aspectos do tratamento segundo dois critérios distintos: um utilizado no $\mathrm{HC}$ (Critério $\mathrm{HC}$ ) e outro descrito na literatura (Critério da Literatura). A amostra foi constituída por 51,56\% de homens, com média de idade de 50,11 anos e 46,87\% dos participantes eram analfabetos ou tinham Ensino Fundamental incompleto. O tempo médio de HD foi de 65,38 meses e, como doença de base, 34,38\% referiram Hipertensão Arterial e 28,13, Diabetes Mellitus. Dos entrevistados, 53,12\% não sabiam que sua doença de base poderia prejudicar os rins e $39,06 \%$ não realizavam ou realizavam parcialmente o tratamento de sua doença de base. Quanto aos aspectos psicológicos, $25 \%$ da amostra apresentaram sintomas de ansiedade, $12,5 \%$ de depressão e o escore médio na Escala de Apoio Social foi de 86,96. De acordo com o Critério HC, 68,7\% dos pacientes foram classificados como sem adesão ao tratamento e, segundo o Critério da Literatura, 15,62\% não aderiam ao tratamento. Encontrou-se evidência de associação entre sexo e adesão às sessões de HD e à dieta e medicação, e entre a escolaridade e a adesão dos pacientes ao tratamento. Observou-se, também, associação significante entre a história de adesão e os aspectos "Controle Hídrico", "Consultas" e "Geral" da adesão ao tratamento atual, indicando que os pacientes com adesão a estes três aspectos também aderiam ao tratamento da doença de base. Quando comparadas as variáveis psicológicas, encontrou-se uma porcentagem significantemente maior de pacientes sem sintomas de depressão no grupo sem adesão ao controle hídrico. As taxas de adesão obtidas com o Critério da Literatura foram superiores aos resultados de estudos anteriores. O Critério $\mathrm{HC}$ se mostrou mais rígido e a diferença entre eles revela a necessidade de se validar e padronizar parâmetros para avaliar adesão à hemodiálise. Discutem-se as associações encontradas com base nos estudos da literatura e nos princípios da Análise do Comportamento. A complexidade do tema foi evidenciada pelos resultados e sugere-se a realização de novos estudos, com diferentes delineamentos, que busquem ampliar o conhecimento da Psicologia voltada aos pacientes renais crônicos, para o desenvolvimento de estratégias de intervenção mais apropriadas e eficazes.

Palavras chave: Adesão ao tratamento; Hemodiálise; Depressão; Ansiedade; Apoio Social. 



\begin{abstract}
NAKAO, R. T. Sociodemographic, clinical and psychological factors associated to hemodialysis adherence. 2013. 112f. Dissertation - Faculdade de Filosofia, Ciências e Letras de Ribeirão Preto, Universidade de São Paulo.
\end{abstract}

Treatment adherence in patients undergoing hemodialysis (HD) has been studied due to its impact on the success of treatment, quality of life and mortality. High rates of noncompliance have been observed, but there is not enough investigation to generate consensus on factors related to them, mainly in Brazil. The aim of this cross-sectional descriptive study was to evaluate the adherence to treatment of HD patients at the Hospital das Clínicas (HC) of Ribeirão Preto Medical School- USP, and identify relationship between adherence and sociodemographic, clinical and psychological variables. Participated 64 patients and a semi structured interview, the Hospital Anxiety and Depression (HAD) and the Social Support Scales (MOS) were administrated. Clinical data and objective measures of adherence were collected in the medical records. Participants were classified as with and without adherence to different aspects of the treatment, according to two different criteria: one used in $\mathrm{HC}$ (HC Criterion) and another described in the literature (Literature Criterion). The sample consisted of $51.56 \%$ males, with a mean age of 50.11 years and $46.87 \%$ of the participants were illiterate or had incomplete primary education. Mean time on HD was 65.38 months, and as underlying disease, 34.38\% reported Hypertension and 28.13\%, Diabetes Mellitus. Of the respondents, $53.12 \%$ were unaware that their underlying disease could harm the kidney and $39.06 \%$ did not perform or performed partially its treatment. Regarding the psychological aspects, $25 \%$ of the sample presented anxiety symptoms, $12.5 \%$ depression and the Social Support Scale mean score was 86.96 . According to HC Criterion, $68.7 \%$ of patients were classified as non-adherent to treatment and, according to the Literature Criterion, $15.62 \%$ did not adhere to treatment. Evidence of association was found between gender and adherence to HD sessions and diet and medication, and between educational level and patient's adherence to treatment. There was also a significant association between history of adherence and the aspects "Fluid Restrictions", "Consultations" and "General" adherence to current treatment, indicating that patients with adherence to these three aspects also adhered to the treatment of the underlying disease. Regarding the psychological variables, it was found a significantly higher percentage of patients without symptoms of depression in the group with no adherence to fluid restrictions. Compliance rates using the Literature Criterion were higher than in previous studies. HC Criterion was more rigid and the difference between the two criteria points out the need to validate and standardize parameters for assessing adherence to hemodialysis. The associations founded were discussed based on literature studies and the principles of Behavioral Analysis. The complexity of the issue was highlighted by the results and it is suggested that further studies be realized, with different designs, seeking to expand the psychological knowledge on patients with renal disease, and to develop intervention strategies appropriate and effective.

Keywords: Adherence; Hemodialysis; Depression; Anxiety; Social Support. 



\section{LISTA DE FLUXOGRAMAS}

Fluxograma 1: Descrição do processo de formação da amostra do estudo 



\section{LISTA DE GRÁFICOS}

Gráfico 1. Aspectos do tratamento considerados como mais difíceis de aderir, segundo relato dos pacientes em hemodiálise $(n=64)$

Gráfico 2. Aspectos do tratamento considerados como mais fáceis de aderir, segundo relato dos pacientes em hemodiálise $(\mathrm{n}=64)$

Gráfico 3. Autoavaliação de adesão aos cinco aspectos do tratamento $(n=64)$ 53

Gráfico 4. Avaliação dos pacientes sobre o relacionamento com a equipe de profissionais da Unidade de Diálise $(n=64)$

Gráfico 5. Ansiedade e Depressão, avaliados com a Escala Hospitalar de Ansiedade e Depressão $(\mathrm{HAD})(\mathrm{n}=64)$ .55

Gráfico 6. Adesão ao tratamento em seus quatro aspectos e Adesão Geral de acordo com o Critério $\mathrm{HC}$ 56

Gráfico 7. Adesão ao tratamento em seus quatro aspectos e Adesão Geral de acordo com o Critério da Literatura 



\section{LISTA DE TABELAS}

Tabela 1 - Critérios para classificação dos participantes quanto à adesão

Tabela 2 - Categorias da força de concordância de acordo com o Coeficiente Kappa.

Tabela 3 - Características sociodemográficas da amostra de pacientes em hemodiálise $(n=64)$......

Tabela 4 - Doenças de base para a IRC da amostra de pacientes em hemodiálise $(n=64)$. .48

Tabela 5 - Conhecimento dos pacientes sobre sua doença e tratamento .49

Tabela 6 - Conhecimento sobre riscos da doença de base e história de adesão em uma amostra de pacientes em hemodiálise .50

Tabela 7 - Percepção de Apoio Social na amostra de pacientes em hemodiálise $(\mathrm{n}=64)$ 55

Tabela 8 - Concordância entre os critérios HC e Literatura segundo o Coeficiente de Kappa. 58

Tabela 9 - Comparação entre pacientes com e sem adesão ao tratamento em relação às variáveis sociodemográficas numéricas.

Tabela 10 - Variáveis sociodemográficas categóricas e adesão ao tratamento em uma amostra de pacientes em hemodiálise - dados percentuais

Tabela 11 - Associação entre adesão ao tratamento para doença de base e adesão ao tratamento atual em uma amostra de pacientes em hemodiálise - dados percentuais 62 
Tabela 12 - Associação entre variáveis psicológicas e adesão a tratamento em uma amostra de pacientes em hemodiálise - dados percentuais .63 


\section{SUMÁRIO}

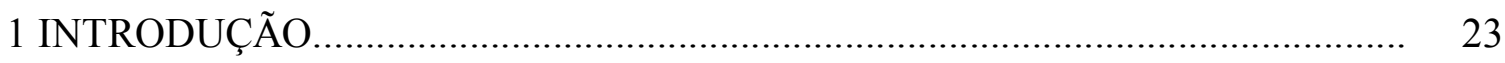

1.1. A doença renal: informações clínicas e dados epidemiológicos ............... 23

1.2. Aspectos psicológicos associados à hemodiálise ................................... 26

1.3. Adesão à hemodiálise: conceito, avaliação e associações........................ 30

2 OBJETIVOS

2.1. Objetivo Geral.............................................................................. 37

2.2. Objetivos Específicos....................................................................... 37

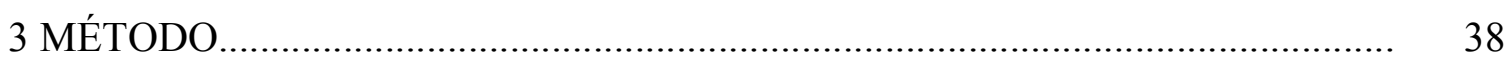

3.1. Local da Pesquisa.................................................................................... $\quad 38$

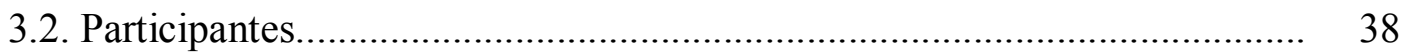

3.3. Materiais e Instrumentos...................................................................... $\quad 39$

3.3.1. Roteiro de Entrevista Semiestruturada.......................................... 39

3.3.2. Escala Hospitalar de Ansiedade e Depressão (HAD).................... 40

3.3.3. Escala de Apoio Social (MOS) .................................................. 40

3.3.4. Folha de registro das Medidas Fisiológicas.................................... 40

3.4. Estudo Piloto ..................................................................................... 41

3.5. Procedimento de Coleta de Dados ................................................................. 41

3.6. Critérios para Classificação dos Participantes quanto à Adesão ao

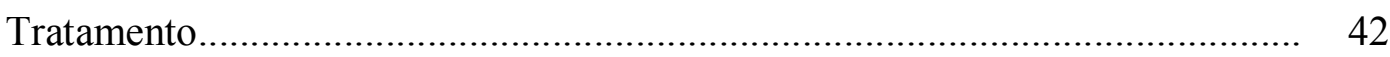

3.7. Procedimento de Análise de Dados ......................................................... 43

3.8. Aspectos Éticos ................................................................................ 45

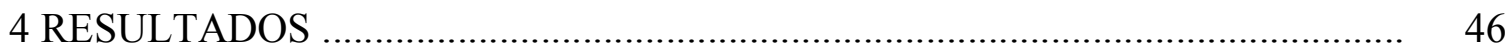

4.1. Caracterização da amostra .................................................................. 46

4.2. Conhecimento sobre a doença e o tratamento ....................................... 48

4.3. Conhecimento sobre riscos da doença de base e história de adesão........... 50

4.4. Facilitadores e obstáculos da adesão à hemodiálise ................................. 51

4.5. Autoavaliação de adesão e relacionamento com a equipe de saúde........... 53

4.6. Caracterização psicológica: ansiedade, depressão e apoio social .............. 54

4.7. Adesão ao tratamento: dados descritivos ................................................. 55 
4.8. Comparação entre o Critério HC e Critério da Literatura .......................... 57

4.9. Variáveis Sociodemográficas e Adesão ao Tratamento............................ 58

4.10. Variáveis Clínicas e Adesão ao Tratamento ........................................... 61

4.11. Conhecimento sobre a doença e o tratamento, história de adesão e adesão ao tratamento ................................................................................... 62

4.12. Variáveis Psicológicas e Adesão ao Tratamento ...................................... 62

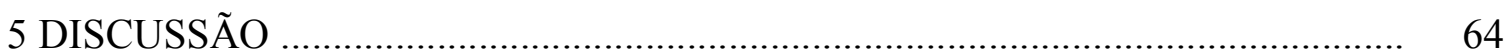

5.1. Primeiras considerações sobre as características sociodemográficas e

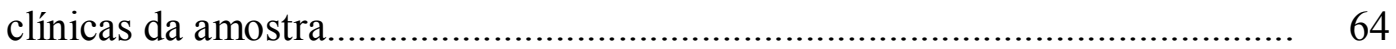

5.2. Sobre a relação entre conhecimento da doença e adesão ao tratamento..... 65

5.3. Adesão à hemodiálise: considerações sobre os critérios e comparação com resultados de outros estudos

5.4. A relação entre profissionais e pacientes como fator associado à adesão à hemodiálise

5.5 Fatores citados como facilitadores e obstáculos da adesão à hemodiálise: uma análise teórica e comparativa.

5.6. Análise de outras associações observadas: o impacto da idade e da questão de gênero sobre a adesão ao tratamento

5.7. Prevalência de sintomas de ansiedade e depressão e percepção de suporte social: o que os dados indicam?

5.8. Em busca do bem estar biopsicossocial: estratégias de intervenção com pacientes renais crônicos em hemodiálise 


\section{INTRODUÇÃO}

No último século, o avanço tecnológico no campo da saúde, o consequente aumento na expectativa de vida e a crescente prevalência das doenças crônicas relacionadas ao estilo de vida trouxeram aos profissionais da saúde um novo desafio: como ajudar as pessoas a adotarem e manterem mudanças no seu estilo de vida que promovam vitalidade, e ainda, como auxiliar os indivíduos a conviverem com enfermidades por toda a vida? Este desafio se baseia na premissa de que saúde não se resume à ausência de doença, mas sim ao bem estar físico, mental, social e espiritual, definida pela Organização Mundial de Saúde (Straub, 2005). Assim, cabe ao profissional da saúde e, particularmente, ao Psicólogo da saúde criar condições para que os indivíduos adotem padrões de comportamento mais saudáveis, no sentido de evitar que doenças se instalem ou prevenir o agravamento das doenças já instaladas. No contexto da doença crônica, isso se torna ainda mais importante pois a preocupação maior com a cura é substituída pela preocupação com a qualidade de vida do paciente, sendo este responsável por grande parte do sucesso de seu tratamento. Este trabalho se insere neste contexto e, mais especificamente, trata da doença renal crônica e de uma modalidade de tratamento, a hemodiálise, os quais serão apresentados a seguir.

\subsection{A doença renal: informações clínicas e dados epidemiológicos}

Os rins são órgãos vitais responsáveis por quatro funções no organismo: (1) a eliminação de toxinas do sangue por um sistema de filtração, (2) a regulação da formação dos ossos e da produção de glóbulos vermelhos, (3) a regulação da pressão sanguínea e (4) o controle do equilíbrio químico e de líquidos no corpo. Quando os rins apresentam problemas, eles deixam de desempenhar corretamente estas funções de forma aguda ou crônica (Sociedade Brasileira de Nefrologia, 2011a).

A Lesão Renal Aguda ocorre em pacientes com outras doenças graves, quando os rins param de funcionar de forma rápida, porém temporária. Na Insuficiência Renal Crônica (IRC) ocorre perda lenta, progressiva e irreversível das funções renais. Até que tenham perdido 50\% de sua função renal, os pacientes permanecem quase sem sintomas. Deste ponto até que os rins estejam funcionando de 10 a $12 \%$ da função normal, o tratamento é realizado a partir de medicamentos e adaptações na dieta (tratamento conservador). Quando a função renal se reduz abaixo destes valores, torna-se necessário o uso de outros métodos de tratamento, que 
substituem a função renal (tratamento substitutivo) (Sociedade Brasileira de Nefrologia, 2011a).

Existem três modalidades de tratamento substitutivo para a IRC: hemodiálise, diálise peritoneal e transplante renal. A hemodiálise, enquanto um procedimento de apoio à função renal, promove a retirada das substâncias tóxicas e do excesso de líquido, através da passagem do sangue por um filtro artificial (Thomas \& Alchieri, 2005). Esta modalidade é, em geral, realizada três vezes por semana, em sessões com duração média de três a quatro horas, com o auxílio de uma máquina, em clínicas especializadas neste tratamento. Para que o sangue passe pela máquina, é necessária a colocação de um cateter ou a confecção de uma fístula, que é um procedimento cirúrgico realizado mais comumente no braço, em que se liga uma veia a uma artéria, para permitir que estas fiquem mais calibrosas e, desta forma, forneçam o fluxo de sangue adequado para ser filtrado (Sociedade Brasileira de Nefrologia, 2011a).

$\mathrm{Na}$ diálise peritoneal, utiliza-se o peritônio (membrana que reveste os órgãos internos do abdômen) para realizar a "filtração" do sangue. Através da colocação de um cateter flexível no abdômen, é feita a infusão de um líquido na cavidade abdominal chamado banho de diálise. Este líquido entra em contato com o peritônio e, após um período de permanência na cavidade abdominal, fica saturado de substâncias tóxicas, e é então retirado, sendo feita em seguida a infusão de novo banho de diálise. Este procedimento é feito de forma contínua e no domicílio do próprio paciente (Sociedade Brasileira de Nefrologia, 2011a).

Já o transplante renal é um procedimento cirúrgico em que se implanta um rim sadio em um indivíduo portador de IRC e, a partir de então, este novo rim passará a desempenhar as funções que os rins doentes não puderam manter (Associação Brasileira de Transplante de Órgãos, 2011)

De acordo com os últimos censos divulgados pela Sociedade Brasileira de Nefrologia, estima-se que no ano de 2011 cerca de 91.300 pacientes estavam em diálise no Brasil, e o número estimado de pacientes que iniciaram o tratamento no ano de 2010 foi 18.972 (Sociedade Brasileira de Nefrologia, 2011b; Sesso, Lopes, Thomé, Lugon \& dos Santos, 2011). A taxa de prevalência do tratamento dialítico em 2010 foi de 483 pacientes por milhão (ppm), sendo maior nas regiões Sudeste (591 ppm), Sul (513 ppm) e Centro-Oeste (501 ppm). Em relação à modalidade de diálise, cerca de 90\% dos pacientes analisados no Censo de 2010 realizavam hemodiálise nas diversas unidades que responderam ao questionário (Sesso et al., 2011).

Dentre as doenças que levam à IRC, as três mais comuns são a Hipertensão Arterial Sistêmica (HAS), o Diabetes Mellitus (DM) e a Glomerulonefrite. Sabe-se que o tratamento 
adequado destas doenças pode prevenir o aparecimento de doenças renais e evitar a necessidade de diálise. Além destas, existem outras causas conhecidas da IRC, tais como a presença de rins policísticos, a pielonefrite e doenças congênitas. Considerando a doença de base, o Censo de 2011 indicou que 35,1\% dos pacientes em diálise naquele ano possuíam diagnóstico anterior de HAS, 28,4\% de DM, 11,4\% de Glomerulonefrite, 3,8\% de rins policísticos e 12\% de outras doenças (Sociedade Brasileira de Nefrologia, 2011b).

O número de pacientes com algum grau de déficit de função renal no Brasil não é exatamente conhecido, mas foi estimado a partir de um estudo populacional realizado na cidade de Bambuí, no interior do estado de Minas Gerais, em que foram avaliados os níveis de creatinina sérica da população de idosos e de uma amostra da população de adultos do município. Os resultados mostraram que, na população adulta, a prevalência de creatinina sérica elevada foi de 0,48\% e, em idosos (acima de 60 anos de idade), este nível chegou a 5,09\% (Passos, Barreto, Lima-Costa \& BHAS Group, 2003). Em projeção para a população brasileira, a taxa de pacientes com disfunção renal chegaria a 1,4 milhões de pessoas (Romão Junior, 2004).

A prevalência da IRC também pode ser estimada a partir dos números de suas principais doenças de base. Em uma publicação do Centro de Vigilância Epidemiológica da Secretaria de Estado da Saúde sobre a doença renal crônica no Brasil (2006), calculou-se que aproximadamente $25 \%$ da população adulta brasileira tenha hipertensão arterial, ou seja, cerca de 26 milhões de indivíduos. Destes, não mais do que 15\% teriam a pressão arterial devidamente controlada, portanto, os demais têm maior potencial para evoluírem com IRC. Ainda de acordo com esta publicação, a prevalência de DM é de 7,5\% da população adulta. Desta forma, cerca de 7,7 milhões de indivíduos teriam DM, sendo que mais de 30\% destes teriam potencial para desenvolver IRC (Secretaria de Estado da Saúde, 2006).

Estes dados ilustram o que é chamado de novo cenário da saúde brasileira, no qual as doenças crônicas não transmissíveis (DCNT) se tornaram prioridade das políticas públicas por corresponderem à maior parcela de óbitos e de despesas com assistência hospitalar no Sistema Único de Saúde (SUS), totalizando cerca de 75\% dos gastos com atenção à saúde (Ministério da Saúde, 2009).

Configuram-se, assim, novos desafios para os programas de saúde pública encontrarem mecanismos para o enfrentamento das DCNT, dentre elas a doença renal, considerando que estas acarretam um forte impacto na qualidade de vida dos indivíduos afetados, causam morte prematura e geram grandes e subestimados efeitos econômicos adversos para as famílias, comunidades e sociedade em geral (Ministério da Saúde, 2009). 


\subsection{Aspectos psicológicos associados à hemodiálise}

Apesar dos importantes avanços tecnológicos no tratamento da doença renal crônica e do aumento da sobrevida destes pacientes, nenhuma das modalidades existentes é curativa. Ou seja, lidar com a cronicidade da doença e com as limitações impostas pelo tratamento torna-se necessário para os pacientes em terapias substitutivas e oferece importante impacto psicológico para estes indivíduos.

O tratamento hemodialítico, em particular, é responsável por um cotidiano monótono e restrito, em que as atividades dos pacientes se tornam limitadas, favorecendo o sedentarismo e a deficiência funcional (Law, 2002). É bastante comum que o início da hemodiálise esteja associado a perdas importantes nestas pessoas, como perda da sensação de bem-estar, da função sexual, do emprego, de atividades de lazer, perda de tempo e do senso de utilidade e autonomia (Borges \& Martins, 2001; Zimmermann, Carvalho \& Mari, 2004; Martins \& Cesarino, 2005). Isso porque o paciente em hemodiálise precisa comparecer à clínica de tratamento por três dias na semana e permanecer por cerca de quatro horas em um procedimento doloroso e sujeito a intercorrências, como câimbras e alterações na pressão arterial. Além disso, o tratamento requer o controle constante da alimentação e da ingestão de líquidos, o que aumenta seu caráter restritivo e impõe ao indivíduo a necessidade de adaptação a um novo estilo de vida (Madeiro, Machado, Bonfim, Braqueais \& Lima, 2010).

Todas estas restrições afetam necessidades humanas básicas e podem desencadear sentimentos de incapacidade, inutilidade e fraqueza, impossibilidade diante de situações adversas, revolta, indignação e conformismo (Menezes, Maia \& Lima Junior, 2007). É, inclusive, esperado que manifestações depressivas sejam apresentadas nos períodos iniciais do tratamento, tendo em vista que estas respostas podem funcionar como adaptativas frente aos sentimentos de insegurança e perdas (Thomas \& Alchieri, 2005; Zimmermann et al., 2004).

Isto se torna um problema, entretanto, quando manifestações depressivas permanecem no indivíduo por um período maior do que a fase de adaptação ao tratamento. Configura-se, então, um transtorno depressivo, ou depressão. Trata-se do transtorno psicológico mais comum em pacientes em hemodiálise, ainda que sua prevalência não esteja bem estabelecida nesta população (Kimmel, 2001).

Um estudo de revisão publicado em 2004 na Revista de Psiquiatria do Rio Grande do Sul identificou que os dados relativos à depressão em pacientes renais crônicos são contraditórios, principalmente em função da diversidade das populações estudadas, das 
diferenças entre as equipes médicas, da heterogeneidade dos critérios diagnósticos e da variedade de instrumentos de medida usados (Zimmerman et al., 2004).

Uma pesquisa realizada com pacientes de sete centros de hemodiálise nos Estados Unidos avaliou depressão em 100 pacientes, utilizando dois instrumentos de autorrelato sobre presença de sintomas depressivos: o Brief Symptom Inventory ï Depression Subscale (BSI), que se concentra na medida dos sintomas psicológicos da depressão, excluindo as manifestações físicas do transtorno, e o Inventário Beck de Depressão (BDI). Foi observado que um terço dos pacientes avaliados apresentava sintomas depressivos a partir da análise do BDI e dois terços dos pacientes demonstraram presença de sintomas depressivos quando da análise do BSI (Khalil, Frazier, Lennie \& Sawaya, 2011). Estes dados demonstram como a variedade de instrumentos utilizados para medir a presença de depressão pode interferir na determinação de sua prevalência.

Ainda com o uso do BDI, Koo et al. (2003) encontraram prevalência de 56,5\% de depressão em uma amostra de 62 pacientes coreanos em hemodiálise. Em uma amostra de 63 pacientes idosos (acima de 65 anos de idade) na Turquia, foi observada prevalência de $25 \%$ de depressão (Turkmen et al., 2012). Além disso, quando comparados com portadores de outras doenças crônicas, os pacientes renais crônicos em hemodiálise apresentaram de 1,5 a 3 vezes mais chances de ser internados em função de um transtorno psiquiátrico, especialmente a depressão (Kimmel, Thamer, Richard \& Ray, 1998a).

No Brasil, Macuglia, Caillava, Teixeira e Giacomoni (2010) aplicaram a Escala Hospitalar de Ansiedade e Depressão (HAD) em 49 pacientes em hemodiálise e constataram que $28,6 \%$ de sua amostra apresentaram grau leve ou moderado de depressão, sendo o sexo feminino o mais afetado. Com o uso do Inventário Beck de Depressão, Nifa e Rudnicki (2010) observaram sintomas leves em $23,3 \%$ de sua amostra e sintomas moderados de depressão em $10 \%$, sendo que $66,7 \%$ dos participantes apresentaram um nível mínimo de depressão.

Outro estudo brasileiro, realizado com 58 pacientes em hemodiálise de uma clínica do sul do país, obteve $44 \%$ de prevalência de depressão nesta amostra de pacientes. Os dados foram coletados com o uso do BDI e os autores realizaram uma análise da pontuação item a item para determinar quais características estavam mais relacionadas com o quadro de sintomas depressivos significativos nesta população. Encontrou-se que os itens dificuldade para dormir, cansaço, incapacidade de tomar decisões, insatisfação, diminuição da libido e preocupação com a saúde foram os que mais contribuíram para o escore final (Finger et al., 2011). Tais características fornecem informações interessantes sobre o perfil da depressão nos 
pacientes renais crônicos e podem ser úteis para direcionar as intervenções psicológicas neste contexto.

Como se pode observar, os dados referentes à depressão em pacientes submetidos à hemodiálise são diversos. A prevalência observada, no entanto, se dá em níveis sempre elevados, variando de 25 a mais de $60 \%$ das amostras estudadas, em estudos nacionais e internacionais. Tal relevância clínica levou a depressão a se tornar o fator mais estudado dentre os indivíduos portadores de doença renal crônica, tendo em vista a possibilidade de tratamento desses quadros (Zimmermann et al., 2004).

Outros transtornos psicológicos podem também ser observados nos pacientes renais crônicos que se tratam com hemodiálise, sendo a ansiedade bastante importante entre eles. Apesar de sua importância, os dados referentes à ocorrência de ansiedade e ao seu impacto na vida e no tratamento destes doentes são ainda escassos e, comumente, os transtornos ansiosos são considerados como parte dos quadros depressivos, ao invés de serem tratados como uma condição independente (Cukor, Coplan, Brown, Friedman, Newville, Safier, et al., 2008). Assim como para a depressão, a variabilidade de ferramentas usadas para o diagnóstico de transtornos ansiosos, bem como as diferentes notas de corte consideradas nos estudos têm dificultado o consenso no que diz respeito à sua prevalência. Há, porém, dados na literatura que sugerem que entre 30 e $40 \%$ de pacientes em hemodiálise apresentam sintomas de ansiedade (Feroze, Martin, Kalantar-Zadeh, Kim, Reina-Patton, Kopple, et al., 2012; Taskapan, Ates, Kaya, Emul, Kaya, Taskapan, et al., 2005).

Não há, também, concordância em relação à adequação de alguns instrumentos psicométricos comumente utilizados para o diagnóstico de transtornos ansiosos em pacientes renais crônicos. Em um estudo realizado em um centro de hemodiálise urbano nos Estados Unidos, Cukor et al. (2008) avaliaram um grupo de 70 pacientes randomicamente selecionados. Utilizaram a Entrevista Clínica Estruturada para Diagnóstico do Eixo I do DSM-IV (SCID-I), a Escala Hospitalar de Ansiedade e Depressão (HAD) e o Formulário Abreviado de Qualidade de Vida para Doentes Renais e encontraram que a concordância entre o diagnóstico obtido pelo SCID-I e os escores obtidos a partir da HAD não foi significante, indicando que a HAD parece ter um fraco poder preditivo para o diagnóstico de ansiedade em pacientes com doença renal crônica. Neste estudo, os resultados do SCID- I revelaram presença de diagnóstico do Eixo I do DSM-IV em 71\% da amostra, sendo que 45,7\% dos participantes atingiram critério para o diagnóstico de transtorno de ansiedade e $40 \%$, para transtornos de humor. Além disso, observou-se associação negativa entre a presença de 
ansiedade e a percepção de qualidade de vida na amostra de pacientes estudada (Cukor et al., 2008).

Outro aspecto que parece influenciar no prognóstico e na qualidade de vida de pacientes em hemodiálise é o nível de suporte social percebido. Definido como "a qualidade do suporte emocional disponível a partir das relações estabelecidas nas redes sociais" (Rudnicki, 2007), sua presença vem sendo associada a melhores condições de saúde física e mental, em indivíduos saudáveis ou portadores de doenças.

Um estudo multicêntrico realizado com 32.332 pacientes em hemodiálise em 12 países avaliou a influência do suporte social na mortalidade, adesão às recomendações médicas e qualidade de vida, especialmente em relação a aspectos físicos (Untas et al., 2011). Como resultados, encontrou-se que níveis mais baixos de apoio social foram associados ao maior risco de mortalidade e à menor adesão ao tratamento, principalmente no que diz respeito à duração da sessão dialítica e ao ganho de peso interdialítico. Adicionalmente, os autores identificaram associação entre baixo suporte social e redução na qualidade de vida, especialmente no aspecto físico (Untas et al., 2011).

Também estudando a associação entre qualidade de vida e suporte social, Rambod e Rafii (2010) avaliaram 202 pacientes iranianos em hemodiálise no ano de 2007. Foi encontrada associação significante entre o nível de suporte social percebido e aspectos da qualidade de vida como: funcionamento da saúde, aspectos socioeconômicos, espiritualidade e relacionamento familiar. Os dados revelam a importância de se considerar a percepção de apoio social quando se fala em qualidade de vida em pacientes renais crônicos submetidos a hemodiálise (Rambod \& Rafii, 2010).

O suporte social em pacientes renais crônicos tem sido associado, também, a outras variáveis como características sociodemográficas, espiritualidade, modalidade de tratamento e número de internações, resposta clínica muito importante em pacientes renais crônicos (Platinga et al., 2010; Spinale et al., 2008).

No Brasil, pouca atenção tem sido dada aos efeitos de uma rede de suporte social forte ou frágil na vida de pacientes em hemodiálise. Estudos que avaliam esta variável são escassos e, muitas vezes, utilizam abordagens que não possibilitam a generalização dos resultados. São exemplos disto os estudos de Sandri e Schmitz (2011), e de Schwartz et al. (2009). Ambos se utilizaram da abordagem qualitativa e, apesar de seus dados não poderem ser generalizados para toda a população de pacientes renais crônicos, obtiveram resultados que valorizam a importância do apoio social no processo de enfrentamento da doença e do tratamento. 
Um estudo realizado com pacientes renais crônicos em hemodiálise no estado do Rio Grande do Sul investigou a relação entre apoio social, estressores percebidos e características demográficas com a qualidade de vida (Rudnicki, 2007). Foram utilizados um Questionário de Dados Sociodemográficos, Escala de Apoio Social e o Índice de Qualidade de Vida e Estressores Relacionados à Hemodiálise. Como resultados, encontrou-se diferença nos níveis de qualidade de vida em relação ao sexo, sendo o sexo masculino com melhor índice. Além disso, a autora encontrou associação entre estressores e o tratamento hemodialítico, bem como entre apoio social (nas dimensões tamanho da rede de apoio e satisfação com o apoio percebido) e os índices de qualidade de vida (Rudnicki, 2007).

Observa-se, até aqui, que variáveis psicológicas parecem ter importante influência sobre a qualidade de vida dos pacientes renais crônicos em tratamento dialítico, bem como sobre respostas clínicas, como hospitalização e mortalidade. Isso porque distúrbios de ordem psicológica, como ansiedade e depressão, podem influenciar a forma como o indivíduo se coloca diante da doença e determinar se seu comportamento será compatível ou não com as recomendações médicas, ou seja, determinar sua adesão ao tratamento, variável da qual trataremos a seguir.

\subsection{Adesão à hemodiálise: conceito, avaliação e associações}

O conceito de "adesão ao tratamento" vem sendo discutido entre os profissionais da área da saúde e, ainda hoje, não há um consenso sobre sua definição (Gusmão \& Mion Jr., 2006). Inicialmente, definia-se adesão como "o grau em que um paciente seguia as instruções médicas" (Organização Mundial da Saúde, 2003). No entanto, o termo "médicas" pareceu insuficiente para descrever toda a gama de intervenções utilizadas, especialmente, no tratamento das doenças crônicas. Além disso, o termo "instruções" dava a conotação de que o paciente seria passivo, simples receptor dos conselhos do médico, ao invés de um agente ativo e colaborativo no processo de seu tratamento. Foi a partir destes questionamentos que, em 2003, a Organização Mundial de Saúde (OMS) divulgou a definição mais abrangente e atual do termo adesão ao tratamento:

o grau em que o comportamento de uma pessoa, representado pela ingestão de medicação, o seguimento da dieta e/ou as mudanças no estilo de vida, corresponde e concorda com as recomendações de um profissional da saúde. (p.3) 
Apesar de outros autores terem apresentado diferentes definições para este termo (Gusmão \& Mion Jr, 2006; Miller, Hill, Kottke \& Ockene, 1997), neste trabalho, teremos como base o conceito definido pela OMS acima apresentado. Isso porque ele parece se adequar de forma bastante apropriada ao tratamento da doença renal crônica, que necessariamente envolve muitos comportamentos (uso de medicação, seguimento da dieta, mudança de hábitos, etc.) e, no geral, conta com uma equipe de saúde multiprofissional, cujas orientações vão além dos fatores estritamente médicos do tratamento.

Em relação à hemodiálise, vêm sendo observados baixos níveis de adesão relacionados ao importante sofrimento psicológico vivido por estes pacientes e à alta complexidade do tratamento. A literatura sugere que entre $30 \%$ e $50 \%$ dos pacientes renais crônicos não aderem ao tratamento de hemodiálise, e isto pode estar associado com uma série de pequenas e grandes complicações médicas, bem como uma diminuição da sobrevivência destes indivíduos (Kutner, Zhang, McClellan \& Cole, 2002; Pedroso \& Sbardelloto, 2008).

Um estudo publicado no Journal of Nephrology da Sociedade Italiana de Nefrologia (2012) investigou a associação entre a adesão ao tratamento dialítico e o risco de hospitalização nestes pacientes. Foram analisados 559 pacientes durante cinco anos e, ajustando-se a amostra em relação às comorbidades da doença renal (DM, doença coronariana, entre outras), observou-se aumento no risco de hospitalização associado ao aumento da porcentagem de ganho de peso interdialítico e ao aumento nos níveis de fósforo nos exames laboratoriais dos participantes, indicadores frequentes de adesão ao tratamento à hemodiálise (Vaiciuniene, Kuzminskis, Ziginskiene, Skarupskiene \& Bumblyte, 2012).

Em função de suas complicações clínicas, diversos estudos têm sido realizados nas últimas décadas, buscando-se encontrar possíveis determinantes do comportamento aderente ou não aderente à hemodiálise ou, ao menos, identificar fatores clínicos e psicológicos associados. No entanto, devido à alta complexidade do tratamento e às várias alterações comportamentais requeridas do paciente renal crônico, a maioria dos estudos se volta para a análise de um dos aspectos do tratamento (adesão à medicação, adesão ao controle hídrico ou adesão à dieta, por exemplo), o que acaba por dificultar o estabelecimento de conclusões gerais.

Um dos fatores mais estudados é a adesão ao uso dos medicamentos no tratamento de doentes renais crônicos. Muitas são as drogas utilizadas por estes pacientes e grande parte delas deve ser ingerida diariamente. As principais são os hipotensores, os vasodilatadores coronarianos, protetores gástricos, antianêmicos e medicamentos para evitar a hipocalcemia e para repor a perda de ferro no sangue residual (Terra et al., 2010). Em um estudo de revisão 
de literatura, identificou-se que as taxas de não adesão ao tratamento farmacológico variam de 3 a $80 \%$, sendo que mais da metade dos estudos revisados encontraram taxas de não adesão maiores que 50\% (Schmid, Hartmann \& Schiffl, 2009). Alguns fatores parecem dificultar a adesão ao uso de medicamentos em pacientes portadores de doenças crônicas, tais como a quantidade de medicamentos, suas reações adversas, a incompatibilidade entre os fármacos, e dificuldades na compreensão das metas da terapia e dos efeitos de seu uso inadequado (De Figueiredo, Sinkoc, Tomazim, Gallani \& Colombrini, 2001).

Um estudo epidemiológico realizado com 30 pacientes em hemodiálise objetivou, a partir do uso de uma entrevista semiestruturada, avaliar a adesão ao tratamento farmacológico de uso diário. Observou-se que todos os pacientes entrevistados faziam uso diário de medicações, mas 16,66\% deles afirmaram já ter interrompido o uso por conta própria em função de efeitos adversos e de achar que não havia a necessidade de tomar todos os dias (Terra et al., 2010). Outro resultado interessante deste estudo é que apenas $40 \%$ dos participantes referiram conhecer todos os medicamentos que usavam, sendo que $40 \%$ afirmaram conhecer apenas alguns e $20 \%$ disseram que desconheciam a razão do uso de todos os medicamentos. Diante destes dados, os autores discutiram que a adesão ao tratamento farmacológico envolve, além de fatores terapêuticos, fatores educativos relacionados aos pacientes (Terra et al., 2010). Ou seja, conhecer os motivos que levam à necessidade de determinado medicamento, seus possíveis efeitos adversos e os riscos advindos da interrupção não programada parece contribuir para a melhoria na adesão deste aspecto do tratamento da doença crônica.

Ainda sobre este aspecto, Sgnaolim, Prado e Figueiredo (2011) utilizaram uma Escala de Adesão para identificar a adesão ao tratamento farmacológico em uma amostra de 65 pacientes em hemodiálise e encontraram que 55,4\% dos pacientes da amostra não aderiam ao tratamento. Neste estudo, uma variável associada à adesão foi idade, sendo que os indivíduos com mais de 60 anos se mostraram com mais adesão. Observou-se, também, que o baixo nível de conhecimento sobre os medicamentos utilizados pôde funcionar como obstáculo da adesão ao tratamento, sendo a orientação promovida pela equipe multiprofissional uma estratégia possível para a promoção de adesão nestes pacientes (Sgnaolim et al., 2011).

Também buscando associar o nível de conhecimento à adesão ao tratamento, Nerbass et al. (2010) encontraram resultados controversos. Estudando especificamente o tratamento da hiperfosfatemia (nível elevado de fosfato no sangue) em pacientes dialíticos, os autores observaram um bom nível de conhecimento sobre as conseqüências e o tratamento deste distúrbio e, no entanto, altas taxas de não adesão ao uso do medicamento específico (quelante) 
foram encontradas (54\%). Os autores apresentam dados contraditórios na literatura e apontam que a relação entre o nível de conhecimento e o comportamento de aderir ao tratamento ainda não é bem estabelecida (Nerbass et al., 2010).

A contradição entre os dados encontrados na literatura e a amplitude do intervalo das taxas de adesão e não adesão observadas podem estar relacionadas com a variedade de parâmetros e ferramentas utilizadas. Os pesquisadores desta área têm se utilizado de autorrelato dos pacientes, escalas de avaliação, entrevistas estruturadas e, até mesmo, medidas objetivas, como o nível de fósforo no sangue (Schmid et al., 2009). Porém, segundo a OMS, não há, ainda hoje, um bom método padronizado para avaliação do uso de medicamentos, já que todos os métodos possuem limitações relacionadas à sensibilidade e especificidade (Magacho, Ribeiro, Chaobah \& Bastos, 2011). Mostra-se necessária a realização de novos estudos, que busquem padronizar estratégias de avaliação desta variável, para que se possa comparar resultados e obter dados mais conclusivos no que diz respeito à adesão ao tratamento farmacológico em doentes renais crônicos em hemodiálise.

Outro aspecto que tem recebido atenção dos pesquisadores da área é a adesão ao controle hídrico e à dieta em pacientes em hemodiálise. Para medir esta variável, indicadores biológicos e bioquímicos vêm sendo frequentemente usados, sendo combinados a medidas de autorrelato, como entrevistas e instrumentos padronizados. Esta combinação, de acordo com Kugler, Vlaminck, Haverich e Maes (2005), é o melhor e mais confiável método de acessar a adesão ao controle hídrico e à dieta nos doentes renais.

Dentre os indicadores biológicos para adesão ao controle hídrico, o mais importante é o ganho de peso interdialítico (GPID). Este índice se refere à diferença entre o peso préhemodiálise no dia da avaliação e o peso do paciente após a sessão de hemodiálise anterior. Apesar da unanimidade existente de que quanto maior for o valor do GPID, maiores as chances da ocorrência de complicações como hipertensão, insuficiência cardíaca e morte, não há uma nota de corte estabelecida para se distinguir um paciente com adesão de outro, sem (Nerbass et al., 2011; Kugler et al., 2005).

Além disso, não há concordância no que diz respeito à nota de corte para os indicadores bioquímicos de adesão à dieta (níveis séricos de potássio, fósforo e albumina) (Kugler et al., 2005). Em 1986, a discussão em torno destes valores já existia e em um artigo de revisão publicado no Journal of Psychosomatic Research, Manley e Sweeney (1986) apresentaram diversas notas de corte existentes na literatura daquela época e discutiram, ao final do estudo, que possivelmente os valores determinados até então para os níveis de potássio e para o GPID eram muito baixos. Ainda hoje, a discordância se mantém, mas o que 
se vê com mais frequência é, para a medida de GPID, a utilização do parâmetro de $5 \%$ do peso seco (ou seja, o peso ideal que deve ser atingido ao término de cada sessão de hemodiálise) para classificar pacientes com e sem adesão e, para os níveis de fósforo no sangue $\left(\mathrm{PO}_{4}\right)$, o valor de 7,5 mg/dl. Em relação ao comparecimento para as sessões dialíticas, tem-se como parâmetro na literatura que pacientes com até duas faltas por mês podem ser considerados aderentes (Kutner et al., 2002; Thomas \& Alchieri, 2005; Nerbass et al., 2011).

Em estudos recentes, observa-se que a não adesão à dieta e ao controle hídrico neste grupo de pacientes tem estado entre dois e $82 \%$, taxas encontradas com o uso de parâmetros e metodologias diferentes (Kugler, Maeding \& Russell, 2011; Nerbass et al., 2011; IborraMoltó, López-Roin \& Pastor, 2012; Kugler et al., 2005).

Um estudo multicêntrico realizado em unidades de hemodiálise da Bélgica e Alemanha descreveu a prevalência da não adesão à dieta prescrita e ao controle hídrico em uma amostra de 916 pacientes. Foram coletadas medidas objetivas (exames laboratoriais e medidas biológicas) e subjetivas (autorrelato dos pacientes sobre seu próprio comportamento nos últimos 14 dias). Os resultados mostraram que $81,4 \%$ dos pacientes não aderiam à dieta prescrita pela equipe e $74,6 \%$ não aderiam ao controle hídrico indicado. Além disso, observou-se que a idade e o tempo de hemodiálise estavam positivamente relacionados com o grau de adesão ao tratamento nesta amostra. Observou-se, também, que o nível de suporte social estava associado com a adesão ao controle hídrico e que o relato dos participantes sobre seu comportamento foi adequado em relação às medidas objetivas (Kugler et at., 2005).

Esta associação entre o relato dos pacientes e as medidas objetivas de adesão também foi observada por Iborra-Moltó, López-Roig e Pastor (2012). Estes autores descreveram as taxas de adesão às restrições hídricas utilizando dois parâmetros: um, chamado critério clássico, considera aderente o paciente com GPID inferior a 1quilograma, e o outro, um critério proposto pelos autores, considerava o GPID ajustado ao peso seco de cada paciente, sendo que os valores de GPID aceitáveis dependem da faixa de peso seco em que o indivíduo se encontra. Foram encontradas taxas de adesão distintas quando usados os dois critérios, sendo $61 \%$ de adesão para o critério clássico e $73 \%$ de adesão quando utilizado o critério ajustado ao peso seco. Quando comparadas variáveis clínicas e demográficas, estes autores também observaram associação positiva entre adesão e idade, sendo que os pacientes mais jovens aderiam menos ao tratamento, e associação negativa entre adesão e peso seco, níveis séricos de potássio e tempo de hemodiálise (Iborra-Moltó et al., 2012).

No Brasil, um estudo transversal realizado com 278 pacientes em hemodiálise de seis centros de diálise no sul do país avaliou fatores relacionados com o GPID, tendo como 
parâmetro de adesão o GPID inferior a $5 \%$ do peso seco. Do total de participantes, $24 \%$ tinham GPID elevado e, quando comparados com o grupo de pacientes com GPID adequado, obtiveram níveis de PA sistólica pré-diálise mais elevados, menor idade e menor índice de massa corpórea (Nerbass et al.; 2011).

Além de variáveis clínicas e demográficas, também tem se buscado associações entre a adesão e não adesão dos pacientes em hemodiálise e variáveis psicológicas. Em estudos da literatura estrangeira, a presença de sintomas depressivos, a forma de percepção da doença e o nível de saúde mental são variáveis que vem sendo relacionadas com a não adesão dos pacientes ao tratamento (Kimmel et al., 1998b; Zimmermann et al., 2004; Cé, Kamile, Ceza \& Filla, 2008). Observa-se que pacientes com sintomas depressivos e sentimentos de incontrolabilidade sobre seu futuro e sua doença possuem maiores chances de não aderir ao tratamento (Kutner et al, 2002). Um estudo de revisão sobre os efeitos de sintomas depressivos sobre a adesão à dieta de pacientes em hemodiálise avaliou 44 pesquisas da literatura e encontrou, praticamente em todos os artigos revisados, uma associação entre sintomas depressivos e não adesão à dieta (Khalil \& Frazier, 2010).

Além disso, associações entre qualidade da relação do paciente com a equipe médica, percepção de suporte social e respostas de adesão ao tratamento têm sido analisadas no âmbito da doença renal crônica (Kovac, Patel, Peterson \& Kimmel, 2002; Cicolini, Palma, Simonetta \& Di Nicola, 2012). Untas, Rascle, Idier, Lasseur e Combe (2012) investigaram a interferência das relações familiares no ajustamento de 120 pacientes franceses ao tratamento dialítico. Os dados possibilitaram a categorização de três perfis de relacionamento familiar, a saber: famílias conflituosas, comunicativas e apoiadoras. Os pacientes classificados no primeiro perfil de família (conflituosas) se autoavaliaram como menos aderentes à dieta do que os pacientes das famílias comunicativas e apoiadoras, sugerindo o risco deste tipo de relacionamento familiar e levantando a necessidade da identificação precoce para ajudar na adaptação destas famílias à nova realidade da doença crônica (Untas et al., 2012).

Em um estudo de revisão bibliográfica realizado no Brasil em 2008, a carência de pesquisas sobre a adesão à hemodiálise fez com que os pesquisadores optassem por recorrer à bibliografia geral sobre adesão no tratamento de outras doenças crônicas. Como resultado, foram identificados nove fatores que influenciam a adesão terapêutica de pacientes portadores de doenças crônicas: confiança na equipe, redes de apoio, nível de escolaridade, aceitação da doença, efeitos colaterais da terapêutica, falta de acesso aos medicamentos, tratamento longo, esquema terapêutico complexo e ausência de sintomas (Maldaner, Beuter, Brondani, Budó \& Pauletto, 2008). 
Também com o objetivo de compreender os aspectos relacionados à adesão ao tratamento, Madeiro et al. (2010) obtiveram o relato de pacientes em hemodiálise sobre as principais dificuldades e os fatores promotores da adesão. Como facilitadores, os fatores mais citados foram medo da morte, fé em Deus e esperança de um transplante renal, conformação e suporte familiar. As maiores dificuldades referidas pelos pacientes foram problemas com o transporte até as clínicas de tratamento, a freqüência e o tempo destinado às sessões de hemodiálise e a dor ocasionada pela punção da fístula arteriovenosa. Também foi lembrado pelos pacientes que outro obstáculo para a adesão ao tratamento é o não cumprimento das necessidades humanas básicas, como o conforto, sono, repouso, ingestão hídrica e lazer (Madeiro et al., 2010).

$\mathrm{O}$ estudo dos fatores associados à adesão ao tratamento dos pacientes renais crônicos parece ter grande relevância, pois possibilita o direcionamento da assistência em saúde para condutas que auxiliem a melhor adaptação destes indivíduos à sua nova condição, desenvolvendo suas capacidades e, assim, minimizando o impacto da doença e do tratamento em sua vida (Resende, Santos, Souza \& Marques, 2007). Busca-se, portanto, que a hemodiálise não funcione somente como forma de prolongar a vida do paciente portador de IRC, mas que possibilite a extensão de vida com qualidade (Thomas \& Alchieri, 2005).

Diante disto, é assumida neste trabalho a tarefa de discriminar quais variáveis estão associadas à adesão do paciente ao tratamento de hemodiálise, sejam sociodemográficas, clínicas ou psicológicas. Isto será útil para embasar intervenções que, além de aumentar as taxas de adesão e, assim, promover o sucesso do tratamento, busquem minimizar o sofrimento emocional destas pessoas para que, assim, elas possam realizar suas escolhas de saúde ou doença de forma consciente, autônoma e responsável. 


\section{OBJETIVOS}

\subsection{Objetivo geral}

Avaliar a adesão ao tratamento de pacientes renais crônicos em hemodiálise no Hospital das Clínicas da Faculdade de Medicina de Ribeirão Preto da Universidade de São Paulo (HCFMRP - USP) e identificar possíveis relações entre a adesão ou não adesão ao tratamento e variáveis sociodemográficas, clínicas e psicológicas.

\subsection{Objetivos específicos}

- Descrever características sociodemográficas e clínicas da amostra;

- Investigar:

a) conhecimento dos pacientes acerca de sua doença e tratamento;

b) a avaliação que os pacientes fazem acerca de sua adesão ou não adesão frente ao tratamento;

c) os fatores que, do ponto de vista dos pacientes, facilitam e dificultam a adesão à hemodiálise;

d) a avaliação dos pacientes sobre seu relacionamento com a equipe de saúde da Unidade.

- Avaliar a presença de sintomas de ansiedade e depressão;

- Mensurar a percepção de apoio social;

- Identificar a frequência de pacientes com e sem adesão ao tratamento a partir de critérios específicos (número de faltas às sessões de hemodiálise e às consultas, GPID e resultados de exames bioquímicos);

- Estudar a relação entre adesão ao tratamento e:

a) Características sociodemográficas e clínicas;

b) Conhecimento dos pacientes sobre sua doença e tratamento;

c) Variáveis psicológicas (depressão, ansiedade e apoio social). 


\section{MÉTODO}

Trata-se de uma pesquisa quantitativa descritiva de corte transversal, com amostra de conveniência de pacientes renais crônicos da Unidade de Diálise do HCFMRP-USP.

\subsection{Local da Pesquisa}

A coleta de dados foi realizada na Unidade de Diálise do HCFMRP, instituição vinculada à Universidade de São Paulo (USP) e beneficiária do Sistema Único de Saúde (SUS). A Unidade de Diálise possui capacidade para atender 108 pacientes em hemodiálise, sendo que 12 destas vagas são reservadas para crianças.

\subsection{Participantes}

Foram convidados a participar do estudo os pacientes que realizavam hemodiálise nesta Unidade e que satisfaziam os critérios descritos abaixo.

\section{Critérios de Inclusão:}

- Pacientes portadores de IRC que realizam hemodiálise há, no mínimo, seis meses;

- Indivíduos com idade igual ou superior a 18 anos, de ambos os sexos;

\section{Critério de Exclusão:}

- Pacientes institucionalizados;

- Pacientes que se mostrem incapazes, por alguma deficiência ou dificuldade cognitiva, de compreender as perguntas efetuadas e/ou que não possam respondêlas de forma verbal, clara e consistente.

No total, participaram da pesquisa 64 pacientes. O número de pacientes avaliados, excluídos e convidados a participar do estudo, bem como o número final de participantes estão descritos no Fluxograma 1. 
Fluxograma 1. Descrição do processo de formação da amostra do estudo

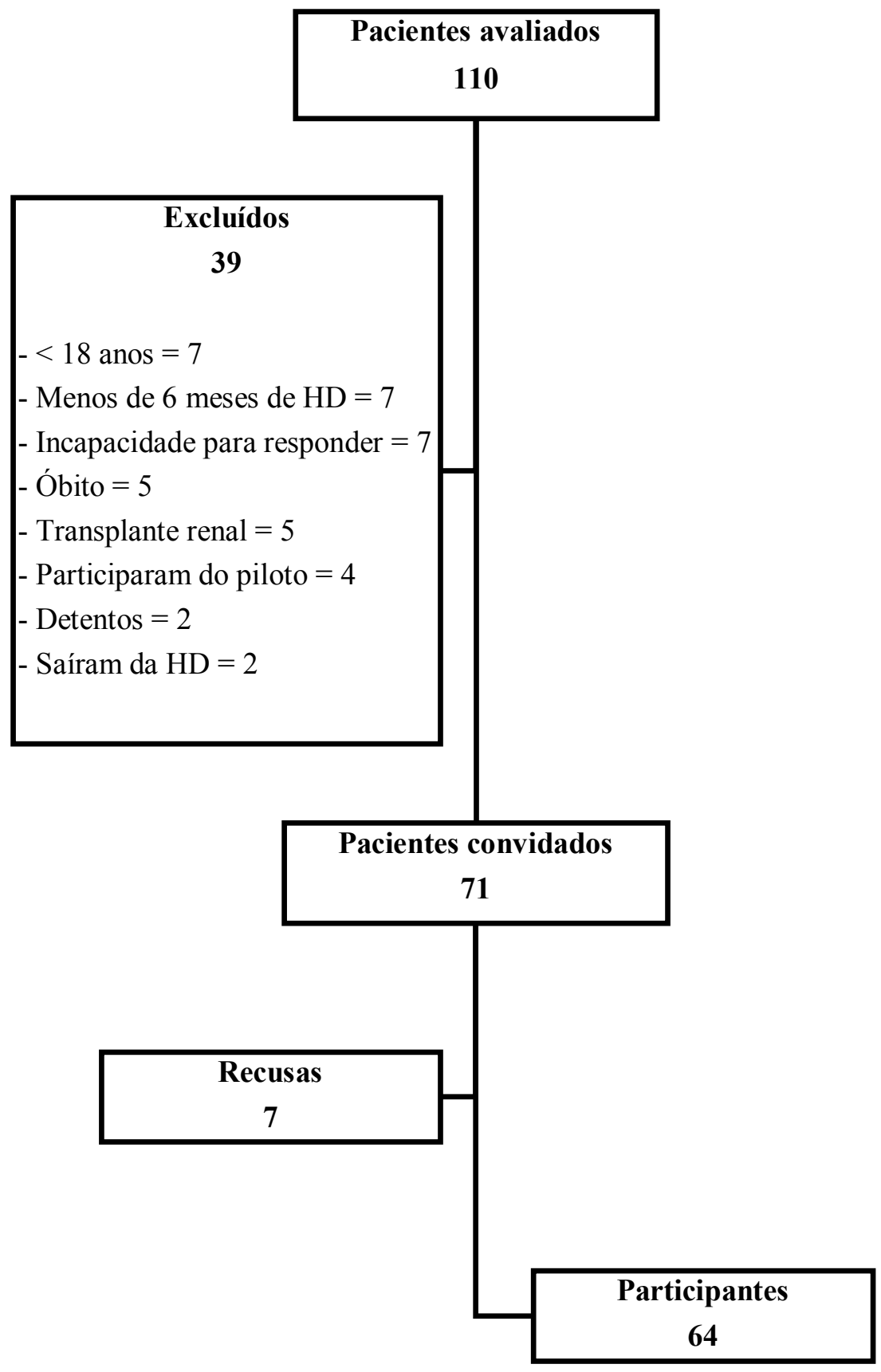

\subsection{Materiais e Instrumentos}

\subsubsection{Roteiro de Entrevista Semiestruturada}

Elaborado pelos pesquisadores para este estudo, teve como objetivos: (a) coletar dados sociodemográficos (sexo, idade, escolaridade, religiosidade, estado civil, renda familiar, situação empregatícia); (b) obter informações sobre nível de conhecimento dos participantes 
acerca da sua doença e tratamento; (c) obter relato dos pacientes sobre nível de adesão ao tratamento, bem como sobre facilitadores e obstáculos à adesão, percebidos por eles, e (d) investigar a avaliação realizada pelos participantes de seu relacionamento com a equipe de saúde da Unidade (Apêndice A).

\subsubsection{Escala Hospitalar de Ansiedade e Depressão (HAD)}

Tem como objetivo avaliar graus leves de transtornos de humor em ambientes não psiquiátricos e em situações de comorbidades física. Foi elaborado por Zigmond e Snaith (1983), e traduzido e adaptado para o português por Botega et al. em 1995 para pacientes internados em enfermarias, e em 1998 para pacientes ambulatoriais (Botega, Pondé, Medeiros, Lima \& Guerreiro, 1998). Possui 14 itens, dos quais sete são voltados para a avaliação da ansiedade (HAD - A) e sete avaliam sintomas de depressão (HAD - D). Cada um dos seus itens pode ser pontuado de 0 a 3, compondo uma pontuação máxima de 21 pontos para cada escala. A nota de corte estabelecida pelos autores é de oito pontos, sendo que os indivíduos com pontuação acima deste valor são considerados com "presença de sintomas" e, abaixo ou igual a este valor, "ausência de sintomas" (Anexo 1).

\subsubsection{Escala de Apoio Social - MOS (Medical Outcomes Study)}

Originalmente elaborada para o Medical Outcomes Study (MOS) por Sherbourne e Stewart (1991), foi traduzida, adaptada e validada para a população brasileira por Griep, Chor, Faerstein e Lopes (2003). Trata-se de uma escala tipo Likert, com 19 perguntas para as quais o participante possui cinco opções de resposta: 1 ("nunca"); 2 ("raramente"); 3 (“às vezes"); 4 ("quase sempre") e 5 ("sempre"). O instrumento abrange três dimensões do apoio social: (a) interação social positival apoio afeitvo - disponibilidade de pessoas para se divertir ou relaxar e demonstrações físicas de amor e afeto -, (b) apoio emocional/ de informação expressões de afeto positivo, compreensão e sentimentos de confiança e disponibilidade de pessoas para obtenção de conselhos ou orientações - e (c) material - provisão de recursos práticos e ajuda material (Griep, Chor, Faerstein, Werneck e Lopes, 2005) (Anexo 2).

\subsubsection{Folha de registro das medidas fisiológicas}


Foram registrados dados colhidos do prontuário médico dos participantes, a saber: principais intercorrências durante a diálise, data e motivo da última internação, número de faltas à sessão hemodialítica, ganho de peso interdialítico e resultados dos exames bioquímicos de fósforo. Consideraram-se as informações relativas aos três meses anteriores à data da coleta, para evitar que a ocorrência de alguma complicação médica, que possa ter alterado o estado clínico do participante em um determinado mês, enviesasse a interpretação dos dados (Apêndice B).

\subsection{Estudo Piloto}

Antes de iniciar a coleta de dados para esta pesquisa, foi realizado um estudo piloto com o objetivo de verificar a adequação do roteiro de entrevista semiestruturada, bem como a viabilidade da coleta de dados durante a sessão de hemodiálise dos pacientes. Para isto, foram selecionados aleatoriamente quatro pacientes da Unidade de Diálise do HCFMRP-USP, que se submeteram ao mesmo procedimento que está descrito a seguir. Após a análise das quatro entrevistas, foram realizados alguns ajustes no roteiro de entrevista, no sentido de facilitar a compreensão dos participantes.

\subsection{Procedimento de Coleta dos Dados}

O contato com os pacientes foi realizado nas salas da Unidade de Diálise, durante as sessões de hemodiálise. O paciente permaneceu sentado na poltrona ao lado da máquina de diálise e o pesquisador sentou-se em uma cadeira ao seu lado, de forma a não prejudicar o andamento da diálise. A equipe de enfermagem presente na sala foi comunicada sobre os objetivos do contato e solicitou-se aos profissionais o menor grau de interferência possível, respeitadas as necessidades do paciente, para que fossem garantidos o sigilo e a privacidade do participante.

O convite ao paciente se iniciou com a explicação dos objetivos do estudo e o fornecimento de informações importantes a respeito de sua participação, contidas no Termo de Consentimento Livre e Esclarecido (Apêndice C). Após aceitar participar da pesquisa e assinar o Termo, a coleta de seus dados foi realizada na seguinte ordem: (1) realização da entrevista semiestruturada, (2) aplicação da Escala Hospitalar de Ansiedade e Depressão (HAD), (3) aplicação da Escala de Apoio Social (MOS) e (4) consulta ao prontuário médico para obtenção dos dados clínicos. Esta ordem foi previamente definida, tendo em vista a 
redução do desconforto e constrangimento dos participantes. Para isso, a coleta se iniciou com questões mais objetivas do roteiro de entrevista semiestruturada, para que o paciente pudesse se familiarizar com o pesquisador e com a situação de coleta, e finalizou-se com a aplicação dos instrumentos, que abrangem questões mais íntimas sobre sentimentos e pensamentos. Optou-se por aplicar a HAD antes por ser este um instrumento mais longo. Assim, ao final da coleta, quando o paciente já pudesse sentir-se cansado, restou somente a Escala de Apoio Social, cuja aplicação costuma ser rápida e simples.

Todas as questões e alternativas de respostas dos instrumentos padronizados foram lidas para o paciente, que respondia oralmente qual era sua opção. Em função da dificuldade de leitura e compreensão de alguns pacientes, preferiu-se adotar este padrão, ainda que os testes utilizados permitam a autoaplicação dos sujeitos.

A entrevista foi gravada por um gravador de voz digital para facilitar a posterior análise dos dados. O tempo de duração para a realização da entrevista e aplicação dos instrumentos psicológicos foi em média de 40 minutos, variando em alguns casos de acordo com a necessidade de cada participante.

A capacidade cognitiva dos pacientes foi avaliada durante o procedimento de coleta de dados, quando não havia nenhum diagnóstico prévio conhecido. Quando foi identificada, durante a realização da entrevista, alguma dificuldade cognitiva no paciente que impedia a compreensão adequada das questões, a entrevista foi conduzida até o final e os dados foram posteriormente descartados.

A coleta de dados do estudo se estendeu por seis meses, de maio a outubro de 2012, período em que todos os pacientes que satisfaziam os critérios de inclusão foram contatados e convidados a participar da pesquisa.

\subsection{Critérios para Classificação dos Participantes quanto à Adesão ao Tratamento}

Para classificar os participantes quanto à adesão ao tratamento, foram utilizados dois critérios distintos: um deles, chamado "Critério da Literatura", foi o mais frequentemente utilizado em estudos anteriores e o outro, denominado "Critério HC", descreve as exigências estabelecidas pela equipe de saúde da Unidade de Diálise do HCFMRP-USP, onde os dados foram coletados. A descrição dos dois critérios se encontra na Tabela 1. 
Tabela 1- Critérios para classificação dos participantes quanto à adesão

\begin{tabular}{|c|c|c|c|c|}
\hline & \multicolumn{2}{|c|}{ CRITÉRIO LITERATURA } & \multicolumn{2}{|c|}{ CRITÉRIO HC } \\
\hline & Aderente & Não aderente & Aderente & Não aderente \\
\hline $\begin{array}{l}\text { N. de faltas às } \\
\text { sessões }\end{array}$ & Até 6 & $>6$ & 0 ou 1 & $>1$ \\
\hline$G P I D$ & $\begin{array}{l}\text { Média menor ou } \\
\text { igual a } 5 \% \text { do PS }\end{array}$ & $\begin{array}{c}\text { Média maior que } 5 \% \\
\text { do PS }\end{array}$ & $\begin{array}{l}\text { I- Média de até } 5 \% \\
\text { do PS no fim de } \\
\text { semana E } \\
\text { II- até } 3 \% \text { do PS } \\
\text { durante a semana E } \\
\text { III- mais que } 50 \% \\
\text { de dias com GPID } \\
\text { adequado }\end{array}$ & $\begin{array}{l}\text { I-Média de mais que } \\
5 \% \text { do PS no fim de } \\
\text { semana OU } \\
\text { II- Mais que } 3 \% \text { do } \\
\text { PS durante a semana } \\
\text { OU } \\
\text { III- menos que } 50 \% \\
\text { de dias com GPID } \\
\text { adequado }\end{array}$ \\
\hline $\mathrm{PO}_{4}(\mathrm{mg} / \mathrm{dl})$ & Até 7,5 & $>7,5$ & Até 5,5 & $>5,5$ \\
\hline $\begin{array}{l}\text { N. de faltas às } \\
\text { consultas médicas }\end{array}$ & - & - & Até 1 & $>1$ \\
\hline
\end{tabular}

GPID: Ganho de Peso Interdialítico

PS : Peso Seco

$\mathrm{PO}_{4}$ : nível sérico de fósforo

O número de faltas às sessões de hemodiálise foi utilizado para determinar a adesão à hemodiálise (HD). Para classificar os participantes em relação à adesão ao controle hídrico, utilizaram-se os valores de GPID e, para a adesão à dieta e medicação, os valores dos exames de $\mathrm{PO}_{4}$. Por fim, o número de faltas às consultas médicas foi usado para definir se os pacientes tinham adesão às consultas. Os participantes também foram classificados como com ou sem adesão ao tratamento como um todo, o que foi denominado "Adesão Geral”. Para ser considerado "com adesão", considerou-se necessário que o pacientes tivesse atingido o critério para adesão em todos os aspectos do tratamento, sendo que a falta de adesão a um dos quatro aspectos citados (hemodiálise, controle hídrico, dieta e medicação e consultas) era suficiente para um paciente ser classificado como "sem adesão".

\subsection{Procedimento de Análise dos Dados}

$\mathrm{Na}$ análise dos dados foi utilizada a abordagem quantitativa, realizando-se inicialmente análise estatística descritiva, com cálculo de porcentagens, médias, medianas e medidas de variabilidade. Para a comparação entre os grupos em relação às variáveis quantitativas, foi aplicado o teste de Mann-Whitney para amostras independentes, que é uma técnica não paramétrica utilizada para comparar distribuições de dois grupos. Sendo assim, ela não requer suposições quanto à distribuição dos dados (Conover, 1980). Os resultados 
foram obtidos com o auxilio do software $\mathrm{SAS}{ }^{\circledR}$ 9, através do pacote destinado a calcular os testes não paramétricos PROC NPAR1WAY. O teste exato de Fisher foi utilizado para verificar a associação entre as variáveis categóricas. Adotou-se como índice de significância o valor de alfa igual a 0,05 .

Para avaliar a concordância entre os critérios HC e Literatura, foi utilizado o Coeficiente Kappa, introduzido por Cohen (1960). Este coeficiente mede o grau de concordância entre testes quando as variáveis são categóricas. Para tais análises, foi utilizado o software SAS 9.0. O Coeficiente Kappa, representado pela letra grega $\kappa$, indica a extensão para qual a probabilidade observacional de concordância (Пo) está em excesso à probabilidade de concordância hipoteticamente oriunda do acaso (Пe) (Landis \& Koch, 1977; Agresti, 1990). Tal coeficiente é calculado pela fórmula:

$$
\kappa=\frac{\Pi_{0}-\Pi_{e}}{1-\Pi_{f}}
$$

Quando Пo vale 1, $\kappa$ assume seu valor máximo, 1, o que corresponde a uma perfeita concordância. Um Coeficiente Kappa igual a zero indica que a concordância é igual àquela esperada pelo acaso. Valores negativos ocorrem quando a concordância é mais fraca do que a esperada pelo acaso, mas segundo Agresti (1990), isto raramente ocorre. Landis e Koch (1977) fornecem as seguintes categorizações para o Coeficiente Kappa:

Tabela 2 - Categorias da força de concordância de acordo com o Coeficiente Kappa

\begin{tabular}{cc}
\hline Coeficiente Kappa & Força da concordância \\
\hline Menor que zero & poor (pobre) \\
\hline $0,00-0,20$ & slight (desprezível) \\
\hline $0,21-0,40$ & fair (suave) \\
\hline $0,41-0,60$ & moderate (moderada) \\
\hline $0,61-0,80$ & substantial (substancial, grande) \\
\hline $0,81-1,00$ & almost perfect (quase perfeita) \\
\hline
\end{tabular}

Os dados dos instrumentos padronizados (HAD e Escala de Apoio Social - MOS) foram analisados de acordo com os critérios estabelecidos pelos autores dos instrumentos.

As respostas às perguntas da entrevista semiestruturada foram categorizadas de acordo com o conteúdo principal das falas dos participantes, utilizando-se o método quantitativointerpretativo, proposto por Biasoli-Alves (1998). A categorização leva em conta os critérios de (1) exaustividade, abrangendo todo tipo de resposta obtida, (2) exclusividade, com o uso de categorias diferentes entre si e (3) manutenção de um mesmo nível de inferência e/ou interpretação dos comportamentos. Tendo isto feito, retorna-se à quantificação dos resultados 
através de cálculos de frequência, porcentagens, etc. Trata-se de um sistema de análise de dados que busca identificar o significado que a fala ou comportamento do informante podem assumir no contexto e na abordagem conceitual do estudo. As questões cujas respostas foram categorizadas a partir deste sistema e alguns exemplos de respostas para cada categoria estão no Apêndice D.

\subsection{Aspectos Éticos}

A coleta de dados teve início após a aprovação da pesquisa pelo Comitê de Ética em Pesquisa da Faculdade de Filosofia, Ciências e Letras de Ribeirão Preto da Universidade de São Paulo (FFCLRP-USP), sob o número de processo 601/2011-2011.1.2238.59.7 (Anexo 3), e a declaração de concordância emitida pelo Comitê de Ética do HCFMRP - USP (Anexo 4). Os pacientes participaram da pesquisa mediante interesse pessoal e assinatura do Termo de Consentimento Livre e Esclarecido (Apêndice C), elaborado seguindo as orientações da Resolução 196 do Conselho Nacional de Saúde (CONEP/96) para pesquisa com seres humanos.

Caso fosse identificado qualquer problema que demandasse acompanhamento psicológico, este foi fornecido pelo psicólogo que atua na Unidade de Diálise. 


\section{RESULTADOS}

Inicialmente, serão apresentados os dados descritivos coletados na entrevista semiestruturada, a saber:

(1) caracterização sociodemográfica e clínica da amostra de pacientes em hemodiálise na Unidade de Diálise do HCFMRP-USP,

(2) nível de conhecimento dos participantes acerca da doença e do tratamento,

(3) relato sobre história de adesão,

(4) facilitadores e obstáculos para a adesão relatados pelos pacientes,

(5) autoavaliação de adesão e avaliação do relacionamento com a equipe de saúde.

Em seguida, estarão descritos os resultados referentes às variáveis psicológicas estudadas, obtidas com a aplicação dos instrumentos padronizados e os dados que descrevem a adesão dos pacientes ao tratamento. Após estes dados descritivos, serão apresentados os resultados referentes aos testes estatísticos, que descrevem evidências de associação e diferenças na comparação entre as variáveis.

\subsection{Caracterização da amostra}

A Tabela 3 apresenta, em frequência e porcentagem, a distribuição dos pacientes da amostra em relação às características sociodemográficas. Tais dados foram referidos pelos participantes durante a entrevista semiestruturada. 
Tabela 3 - Características sociodemográficas da amostra de pacientes em hemodiálise $(n=64)$

\begin{tabular}{|c|c|c|c|}
\hline VARIÁVEL & & Freq. & $\%$ \\
\hline \multirow{2}{*}{ Sexo } & Masculino & 33 & 51,56 \\
\hline & Feminino & 31 & 48,44 \\
\hline \multirow{3}{*}{ Idade } & Até 40 anos & 18 & 28,12 \\
\hline & De 40 a 60 anos & 31 & 48,44 \\
\hline & Mais de 60 anos & 15 & 23,44 \\
\hline \multirow{3}{*}{ Escolaridade } & Analfabeto ou Fund. Incompleto & 30 & 46,87 \\
\hline & Fund. Completo ou Médio Incompleto & 12 & 18,75 \\
\hline & Médio Completo ou mais & 22 & 34,38 \\
\hline \multirow{2}{*}{ Estado Civil } & Com companheiro & 37 & 57,81 \\
\hline & Sem companheiro & 27 & 42,19 \\
\hline \multirow{4}{*}{ Cidade de procedência } & Ribeirão Preto & 46 & 71,88 \\
\hline & Até $50 \mathrm{~km}$ & 8 & 12,5 \\
\hline & de 50 a $100 \mathrm{~km}$ & 8 & 12,5 \\
\hline & Mais que $100 \mathrm{~km}$ & 2 & 3,12 \\
\hline \multirow{2}{*}{ Religiosidade } & Sim & 57 & 89,06 \\
\hline & Não & 7 & 10,94 \\
\hline \multirow{2}{*}{ Situação Empregatícia } & Trabalha & 14 & 21,87 \\
\hline & Não trabalha & 50 & 78,13 \\
\hline \multirow{4}{*}{ Renda Mensal Per Capita } & Menos que $1 \mathrm{SM}$ & 26 & 40,62 \\
\hline & De 1 a 2 SM & 26 & 40,62 \\
\hline & Mais que $2 \mathrm{SM}$ & 11 & 17,19 \\
\hline & Não sabe & 1 & 1,57 \\
\hline
\end{tabular}

Com relação às características clínicas, os participantes da amostra estavam em hemodiálise, em média, há 65,38 meses $(\mathrm{DP}=71,31$; Mediana=43,5), sendo que o tempo de hemodiálise variou de 7 a 330 meses. As informações referentes às doenças de base para a IRC estão descritas na Tabela 4. Doenças como Lúpus, Síndrome de Berger, Glomeruloesclerose Segmentar Focal (GESF), Nefrite e Pielonefrite foram agrupadas na categoria "Glomerulonefrites crônicas". Em "Doenças Congênitas" estão as malformações congênitas, como a Bexiga Neurogênica. Na categoria "Outras", encontram-se as doenças que tiveram baixa frequência nesta amostra, como Câncer Renal e Mieloma. 
Tabela 4 - Doenças de base para a IRC da amostra de pacientes em hemodiálise ( $\mathrm{n}=64)$

\begin{tabular}{lcc}
\hline \multicolumn{1}{c}{ DOENÇA DE BASE } & Freq. & $\%$ \\
\hline Hipertensão Arterial & 22 & 34,38 \\
Diabetes Mellitus & 18 & 28,13 \\
Glomerulonefrites crônicas & 18 & 28,13 \\
Rins Policísticos & 4 & 6,25 \\
Doença congênita & 4 & 6,25 \\
Outras & 9 & 14,06 \\
\hline
\end{tabular}

Foram coletados, também, dados referentes à ocorrência de intercorrências durante as sessões de hemodiálise e internações associadas à IRC no período analisado. Apenas cinco pacientes apresentaram intercorrências durante as sessões do tratamento, sendo elas: câimbras, alterações na pressão arterial e dispneia. Em relação à internação, nenhum paciente da amostra passou por internações relacionadas à IRC no período de três meses anteriores à data da coleta. Em função desta baixa frequência, os dados referentes a estas variáveis clínicas não foram analisados.

\subsection{Conhecimento sobre a doença e o tratamento}

Os resultados apresentados a seguir são referentes às questões da entrevista semiestruturada que investigavam o nível de conhecimento dos pacientes sobre sua doença e tratamento. Com este objetivo, foi solicitado ao paciente que explicasse ao pesquisador, com suas palavras, o que é a Insuficiência Renal Crônica e quais comportamentos estavam envolvidos no tratamento desta doença. As respostas foram categorizadas em relação ao seu conteúdo, sendo que uma mesma resposta poderia ser dividida e classificada em mais de uma categoria.

Para definir se uma explicação foi "satisfatória", criou-se um critério baseado na experiência dos pesquisadores e ajustado para o grau instrucional da amostra estudada. Para a explicação sobre a IRC, considerou-se necessário que, na resposta, fossem citadas ao menos duas das seguintes categorias: (1) rins não funcionam, (2) rins não filtram as impurezas do sangue e (3) rins não produzem hormônios e substâncias para sangue e ossos. Para a explicação sobre o tratamento, considerou-se necessária a presença de relatos referentes a, no mínimo, quatro das seguintes categorias: (1) controlar a alimentação, (2) fazer hemodiálise / comparecer às sessões, (3) controlar a ingestão de líquidos, (4) tomar as medicações e (5) 
comparecer às consultas médicas. Os dados de frequência e porcentagem de cada categoria encontram-se na Tabela 5.

Tabela 5 - Conhecimento dos pacientes sobre sua doença e tratamento

\begin{tabular}{|c|c|c|c|}
\hline & CATEGORIA & Freq. & $\%$ \\
\hline \multirow{8}{*}{ Explicação da IRC } & Rins não funcionam & 43 & 67,19 \\
\hline & Rins não filtram impurezas do sangue & 41 & 64,06 \\
\hline & Explicação baseada no tratamento & 31 & 48,44 \\
\hline & Rins não produzem hormônios e substâncias para sangue e ossos & 10 & 15,62 \\
\hline & Não sabe explicar & 10 & 15,62 \\
\hline & Explicação baseada nos sintomas & 8 & 12,5 \\
\hline & Explicação errada & 4 & 6,25 \\
\hline & Outros & 9 & 14,06 \\
\hline \multirow{2}{*}{$\begin{array}{c}\text { Classificação da explicação } \\
\text { da IRC }\end{array}$} & Satisfatória & 35 & 54,69 \\
\hline & Insatisfatória & 29 & 45,31 \\
\hline \multirow{9}{*}{ Explicação do tratamento } & Controlar alimentação & 60 & 93,75 \\
\hline & Fazer hemodiálise/comparecer às sessões & 58 & 90,62 \\
\hline & Controlar a ingestão de líquidos & 49 & 76,56 \\
\hline & Tomar as medicações & 34 & 53,12 \\
\hline & Cuidar da fístula & 7 & 10,94 \\
\hline & Comparecer às consultas médicas & 6 & 9,37 \\
\hline & Fazer exercício físico & 5 & 7,81 \\
\hline & Não sabe explicar & 1 & 1,56 \\
\hline & Outros & 12 & 18,75 \\
\hline Classificação da explicação & Insatisfatória & 37 & 57,81 \\
\hline do tratamento & Satisfatória & 27 & 42,19 \\
\hline
\end{tabular}

Observa-se que, com a adoção deste critério, mais da metade dos participantes apresentaram uma explicação satisfatória sobre sua doença renal, embora uma porcentagem importante da amostra tenha referido não saber explicar $(15,62 \%)$ ou tenha apresentado uma resposta errada $(6,25 \%)$. Em relação à explicação sobre o tratamento, a maioria dos pacientes $(57,81 \%)$ teve sua resposta considerada insatisfatória, sendo que as categorias "controlar a alimentação" e "fazer hemodiálise / comparecer às sessões" foram as mais citadas. 


\subsection{Conhecimento sobre riscos da doença de base e história de adesão}

Também na entrevista, foi perguntado aos participantes se eles sabiam que sua doença de base poderia prejudicar os rins e as respostas foram agrupadas em quatro categorias. Além das categorias "sim" e "não", houve relatos de que não havia nenhuma doença de base diagnosticada e, por isso, a resposta não cabia, além dos relatos de que o paciente era criança quando soube que era portador de uma doença e, por isso, não soube responder se sabia que esta doença oferecia risco para seus rins.

As respostas à pergunta "Você realizava o tratamento de sua doença que ocasionou a necessidade de hemodiálise da forma como o médico orientava?" foram classificadas também em quatro categorias: (1) sim, (2) não, (3) parcialmente e (4) não tinha tratamento prescrito. Esta última categoria se refere aos pacientes que relataram já ter iniciado a hemodiálise antes mesmo que ter sido recomendado qualquer tratamento anterior. Alguns deles atribuíram este fato a um erro médico, referindo, por exemplo, que recebiam medicação para os picos hipertensivos, mas não lhes era oferecido acompanhamento médico.

$\mathrm{Na}$ Tabela 6, estão apresentados os dados referentes a estas duas questões.

Tabela 6 - Conhecimento sobre riscos da doença de base e história de adesão em uma amostra de pacientes em hemodiálise

\begin{tabular}{|c|c|c|c|}
\hline & CATEGORIA & Freq. & $\%$ \\
\hline \multirow{4}{*}{$\begin{array}{l}\text { Sabia que a doença de base } \\
\text { podia prejudicar os rins? }\end{array}$} & Não & 34 & 53,12 \\
\hline & Sim & 20 & 31,25 \\
\hline & Não tinha o diagnóstico & 7 & 10,94 \\
\hline & Era criança & 3 & 4,69 \\
\hline \multirow{4}{*}{ Realizava o tratamento? } & Sim & 21 & 32,81 \\
\hline & Não tinha tratamento prescrito / Foi direto para HD / & 18 & 28,13 \\
\hline & Não & 13 & 20,31 \\
\hline & Parcialmente & 12 & 18,75 \\
\hline
\end{tabular}

Vale ressaltar a parcela importante da amostra que referiu não saber do risco oferecido por sua doença de base $(53,12 \%)$. Além disso, quando questionados sobre o tratamento para a doença de base, 18 participantes $(28,13 \%)$ referiram não ter tratamento prescrito, sendo a hemodiálise o primeiro tratamento realizado. 


\subsection{Facilitadores e obstáculos da adesão à hemodiálise}

No Gráfico 1 estão representados os resultados referentes à opinião dos pacientes sobre qual é o aspecto mais difícil do tratamento dialítico. Como se pode observar, os dois aspectos considerados mais difíceis pelos pacientes foram o controle da ingestão de líquidos e o controle da alimentação, sendo referidos por $40,62 \%$ e $28,12 \%$ dos pacientes, respectivamente.

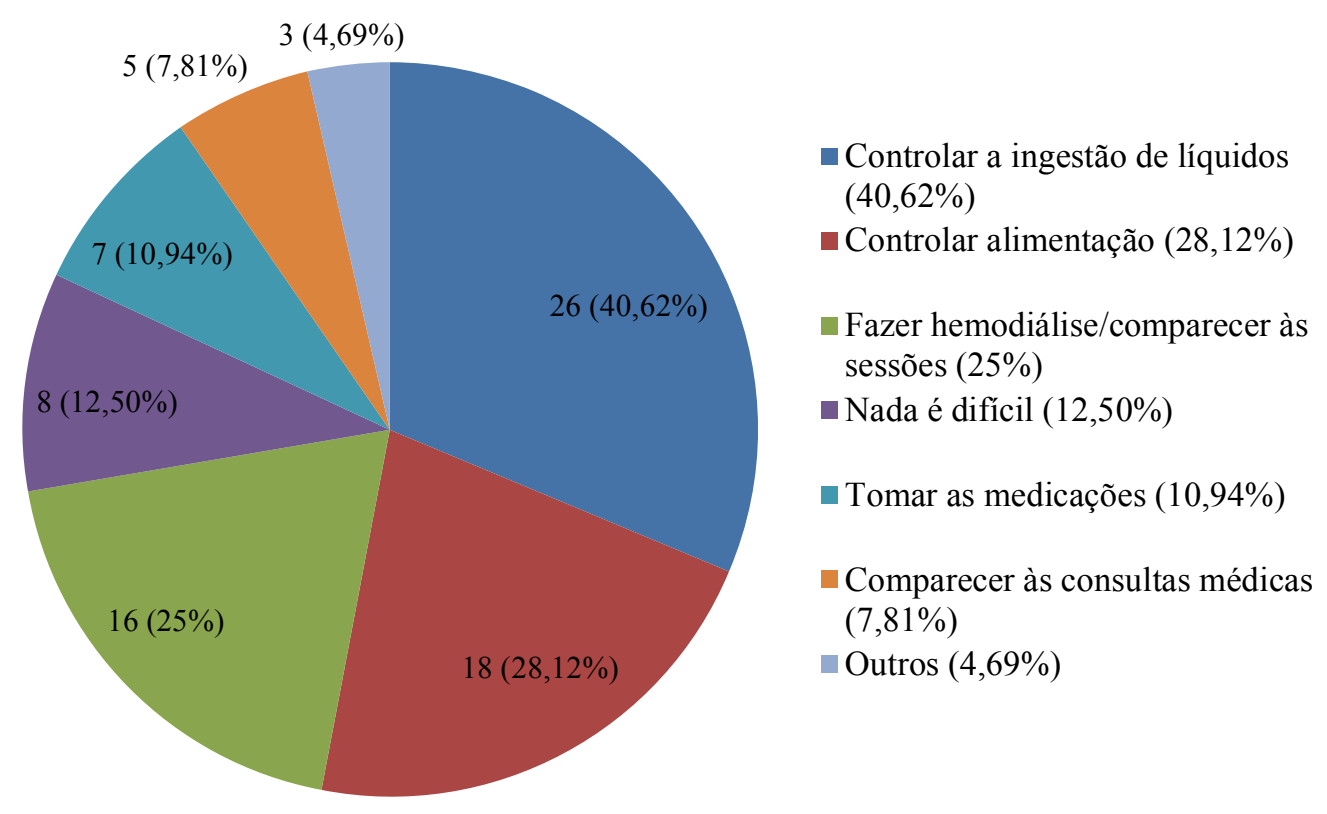

Gráfico 1. Aspectos do tratamento considerados como mais difíceis de aderir, segundo relato dos pacientes em hemodiálise $(\mathrm{n}=64)$

Quando perguntados sobre o que torna este aspecto o mais difícil de aderir, 25 pacientes $(39,06 \%)$ responderam fatores classificados como "aspectos físicos/ fisiológicos", como sentir muita sede ou fome, calor e clima seco. Além disso, 16 pacientes (25\%) destacaram como obstáculos para a adesão a estes aspectos a existência de hábitos anteriores inadequados, ou muito diferentes daqueles desejáveis atualmente. Outros 12 pacientes $(18,75 \%)$ responderam que o que dificulta a adesão são características do próprio tratamento, como o grande tempo dispendido para vir à clínica de hemodiálise, ou a grande quantidade de remédios prescritos. Também foi relatado por 10 pacientes $(15,62 \%)$ que dificuldades externas, como poucos recursos financeiros ou dificuldade para agendar o transporte público, funcionam como obstáculos à adesão ao tratamento. Por último, sendo referidos por sete 
participantes (10,94\%), sentimentos negativos como solidão, desânimo e tristeza foram considerados como obstáculos para o seguimento adequado do tratamento.

Com relação aos aspectos do tratamento considerados mais fáceis de aderir, segundo o relato dos pacientes, o mais citado foi fazer hemodiálise / comparecer às sessões (28 pacientes; 43,75\%). Em segundo lugar, foi citado por 23 participantes $(35,94 \%)$ o controle da alimentação. Estes dados estão representados no Gráfico 2.

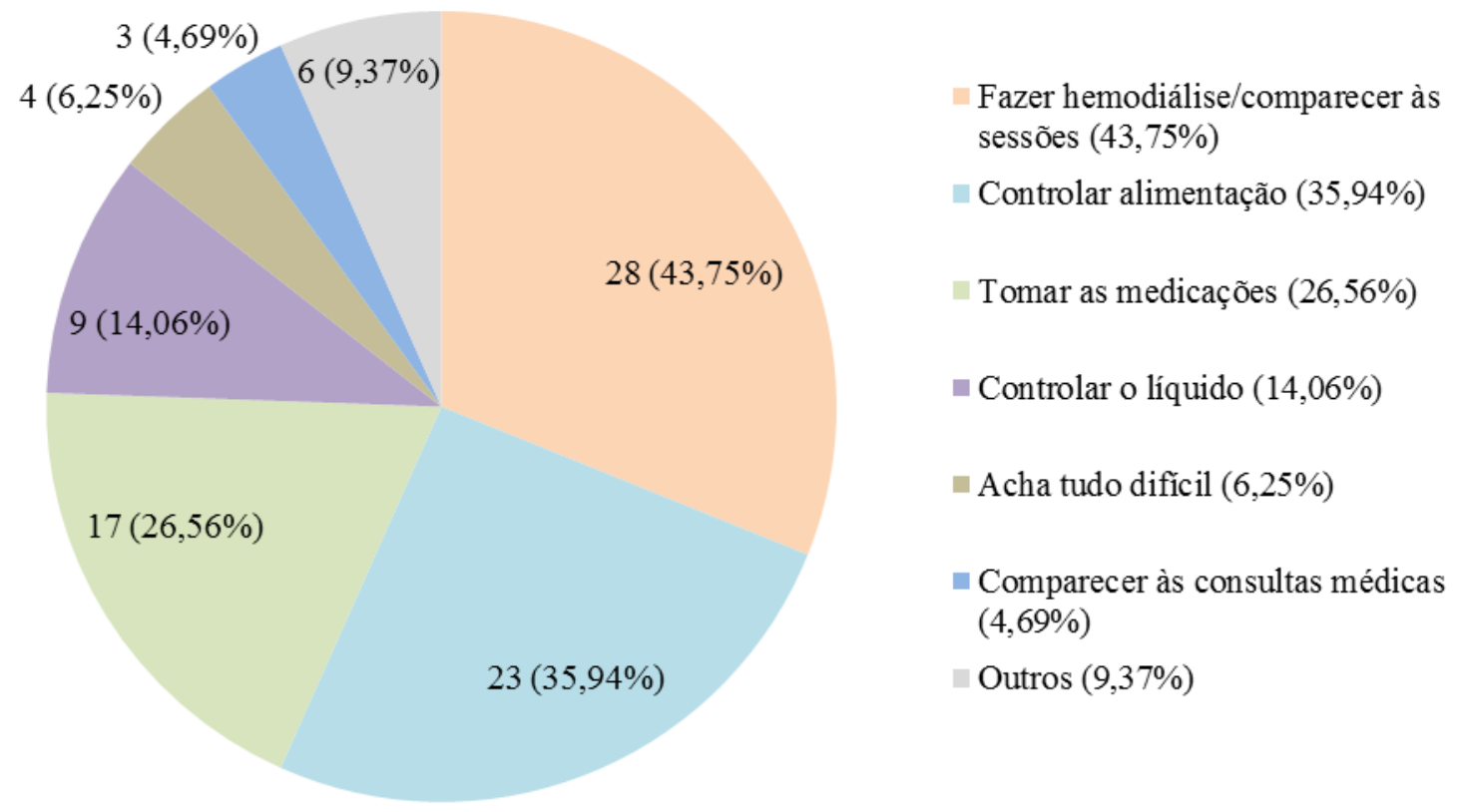

Gráfico 2. Aspectos do tratamento considerados como mais fáceis de aderir, segundo relato dos pacientes em hemodiálise $(\mathrm{n}=64)$

Quando questionados sobre o que torna isto o aspecto mais fácil de aderir, 16 pacientes $(25 \%)$ responderam que é o fato de, se não aderir, vão ocorrer consequência aversivas, negativas para o próprio paciente. Desta forma, $25 \%$ dos participantes parecem aderir ao tratamento para se esquivar dos agravos da doença. Além disso, 20,31\% dos pacientes $(n=13)$ referiram que o que facilita sua adesão é a aceitação que têm da doença e $18,75(\mathrm{n}=12)$ identificaram como facilitador o apoio social que recebem, tanto de familiares e amigos, quanto dos profissionais da equipe da unidade de diálise. Dos entrevistados, nove pacientes $(14,06 \%)$ referiram se utilizar de estratégias comportamentais, como o uso de uma garrafa de medição para controlar a ingestão de líquidos, ou a substituição de temperos industrializados por temperos naturais no preparo dos alimentos. A mesma quantidade de 
pacientes $(14,06 \%)$ referiu que o que facilita a adesão é a sensação de bem estar que o tratamento traz, além do desejo de ficar ou se manter bem. Finalmente, cinco pacientes da amostra $(7,81 \%)$ responderam que ter bom conhecimento sobre a doença e os riscos envolvidos na não adesão facilita a adesão ao tratamento, especialmente nos aspectos citados.

\subsection{Autoavaliação de adesão e relacionamento com a equipe de saúde}

Serão apresentados a seguir os dados descritivos referentes à autoavaliação dos pacientes em relação à adesão aos diferentes aspectos do tratamento e os resultados da avaliação que os participantes fizeram sobre seu relacionamento com a equipe de saúde, ambas realizadas em uma escala de notas de 0 a 5.

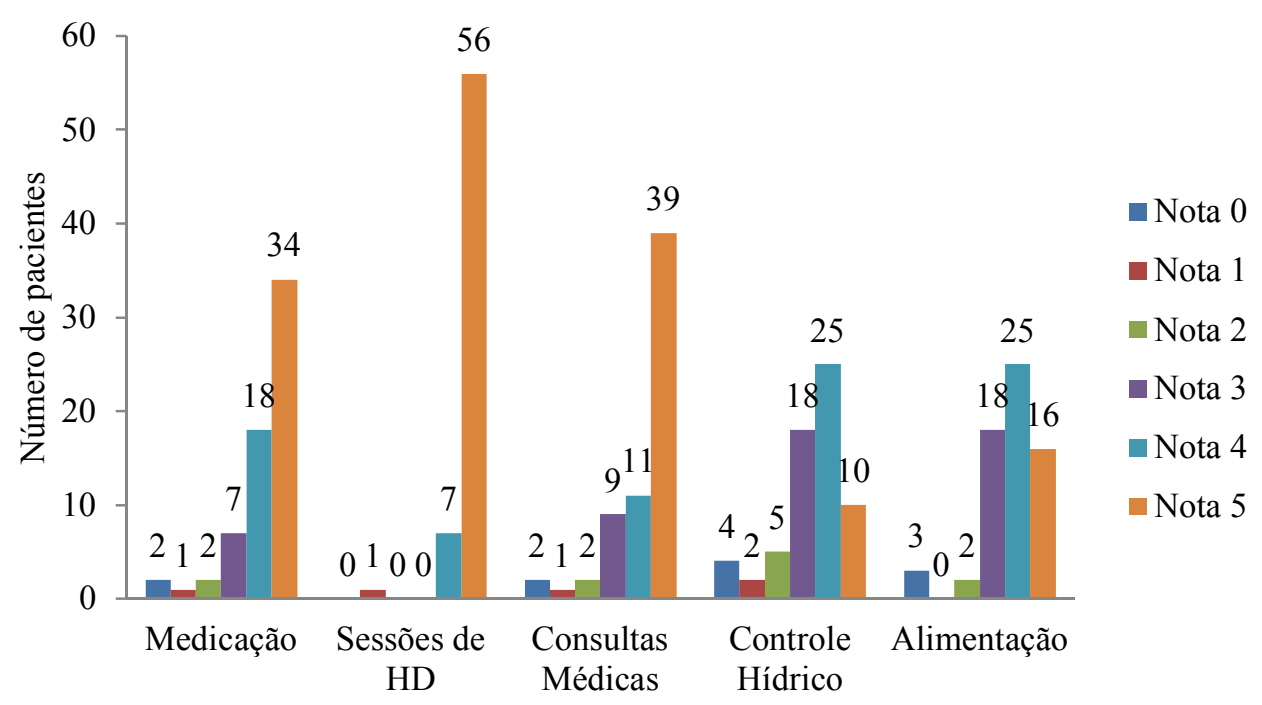

Gráfico 3. Autoavaliação de adesão aos cinco aspectos do tratamento (n=64)

No geral, observa-se que os pacientes realizaram uma autoavaliação positiva quanto à adesão aos diferentes aspectos do tratamento, já que a concentração de pacientes que atribuíram notas 4 e 5 ao seu comportamento foi maior. O aspecto do tratamento em que os participantes melhor se avaliaram foi o de comparecimento às sessões de hemodiálise (HD), para o qual 56 dos 64 pacientes (87,5\%) atribuíram nota máxima (5). Os aspectos "Controle Hídrico" e "Alimentação" foram os únicos em que o predomínio não foi da nota máxima; nestes dois aspectos, a maioria dos participantes atribuiu notas 3 ou 4 ao seu comportamento.

No Gráfico 4 estão representados os resultados da avaliação que os pacientes realizaram sobre seu relacionamento com a equipe de profissionais da Unidade de Diálise. 


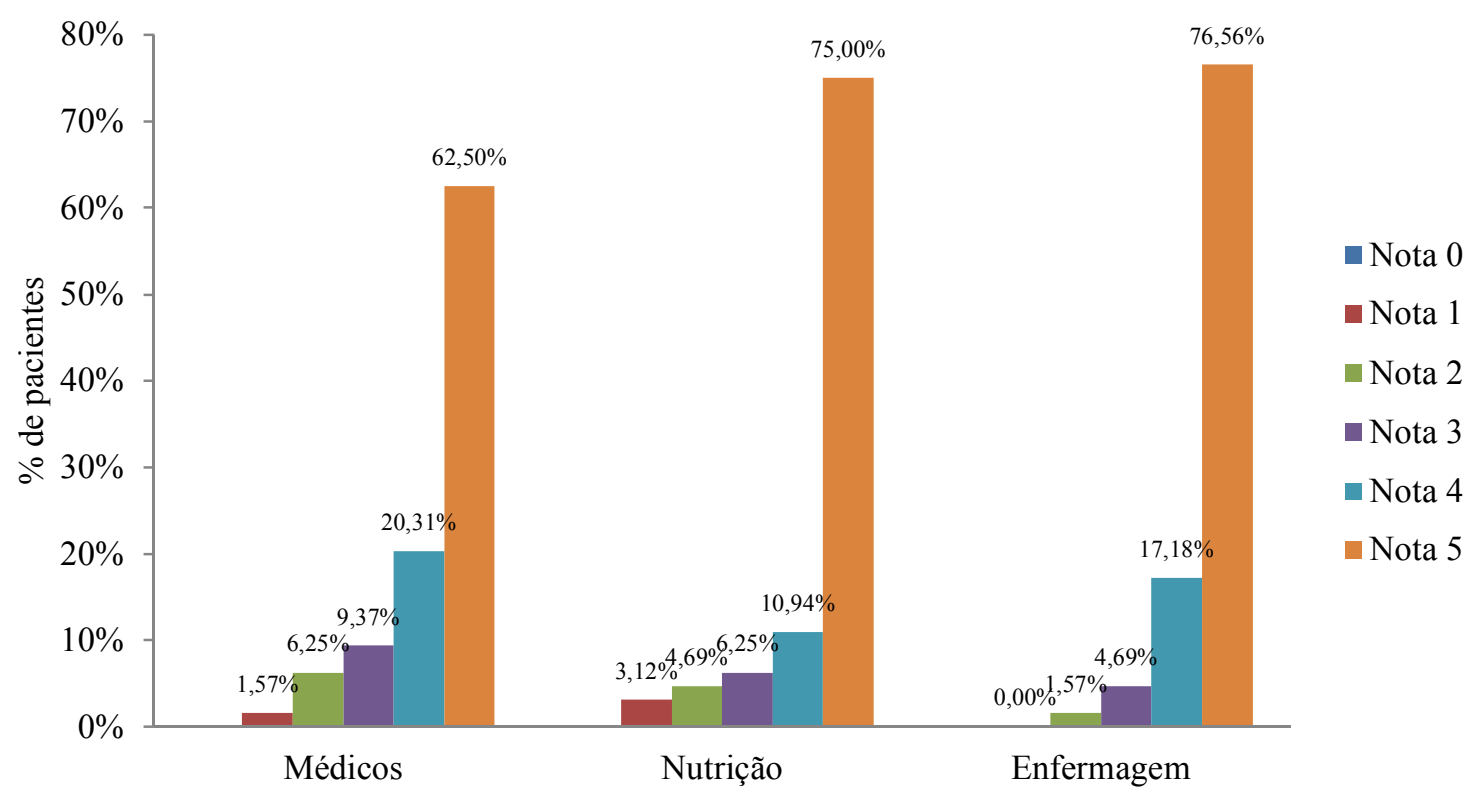

Gráfico 4. Avaliação dos pacientes sobre o relacionamento com a equipe de profissionais da Unidade de Diálise $(\mathrm{n}=64)$

De forma geral, os pacientes da amostra avaliaram positivamente o relacionamento com os profissionais da saúde, sendo que a nenhuma das categorias de profissionais foi atribuída nota zero. Observa-se que o grupo de profissionais com o qual os pacientes referiram melhor relacionamento foi o da Enfermagem, em que 76,56\% (n=49) dos participantes atribuíram nota máxima. Para $75 \%$ dos participantes $(n=48)$, seu relacionamento com a equipe de Nutrição da Unidade é excelente (nota 5) e para 62,5\% (n=40) esta nota reflete o relacionamento que têm com os médicos da Unidade.

\subsection{Caracterização psicológica: ansiedade, depressão e apoio social}

A presença de sintomas de ansiedade e depressão está representada no Gráfico 5. Os resultados foram obtidos com o uso da Escala Hospitalar de Ansiedade e Depressão (HAD) e separados em duas categorias - presença e ausência - a partir da nota de corte definida pelos autores do instrumento. 


\section{Ansiedade}

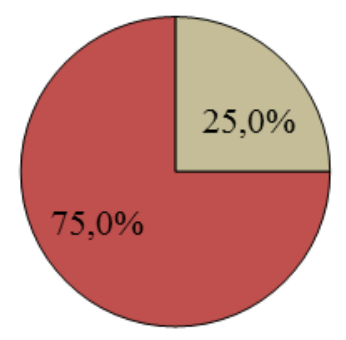

\section{Depressão}

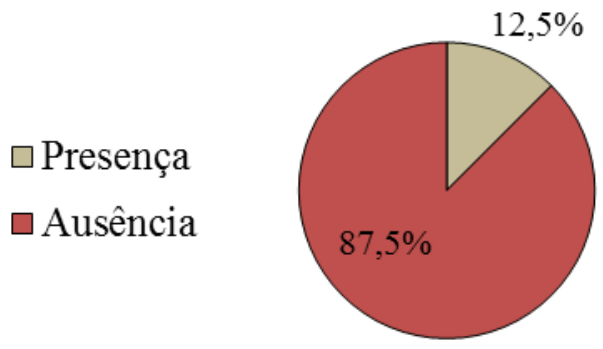

Gráfico 5. Ansiedade e Depressão, avaliados com a Escala Hospitalar de Ansiedade e Depressão $(\mathrm{HAD})(\mathrm{n}=64)$

Dentre os participantes, $25 \%(n=16)$ apresentaram sintomas de ansiedade e $12,5 \%$ $(n=8)$ obtiveram pontuação referente à presença de sintomas de depressão.

Com relação à percepção de apoio social, as médias e medidas de variabilidade de cada tipo de apoio, mensurado pela Escala de Apoio Social (MOS), estão apresentados na Tabela 7.

Tabela 7 - Percepção de Apoio Social na amostra de pacientes em hemodiálise ( $\mathrm{n}=64)$

\begin{tabular}{cccccccc}
\hline DIMENSÕES & Média & DP & Mínimo & $1^{\circ}$ Quartil & Mediana & $3^{\circ}$ Quartil & Máximo \\
\hline Material & 87,27 & 19,72 & 25 & 82,5 & 100 & 100 & 100 \\
Emocional/ Informação & 84,84 & 19,62 & 22,5 & 72,5 & 95 & 100 & 100 \\
Afetivo/ Interação Positiva & 89,20 & 17,05 & 25,71 & 84,29 & 97,14 & 100 & 100 \\
Geral & 86,96 & 17,05 & 24,21 & 78,95 & 96,32 & 100 & 100 \\
\hline
\end{tabular}

Como se observa na Tabela 7, a dimensão de apoio social com maior média entre os participantes foi a de Apoio Afetivo / Interação Positiva e a dimensão com média mais baixa foi a de Apoio Emocional / Informação. A diferença entre os valores, no entanto, é pequena e indica que o apoio social percebido pelos pacientes da amostra se distribui bem dentre as diferentes dimensões.

\subsection{Adesão ao tratamento: dados descritivos}

Os resultados referentes à adesão ao tratamento foram obtidos a partir das medidas objetivas de exames bioquímicos e medidas biológicas. Para classificar os participantes como 
“com adesão" ou "sem adesão" para cada aspecto do tratamento e adesão geral, utilizaram-se dois critérios (como descrito no item 3.6 da seção Método).

Primeiramente, serão apresentados os resultados obtidos com a utilização do Critério HC.

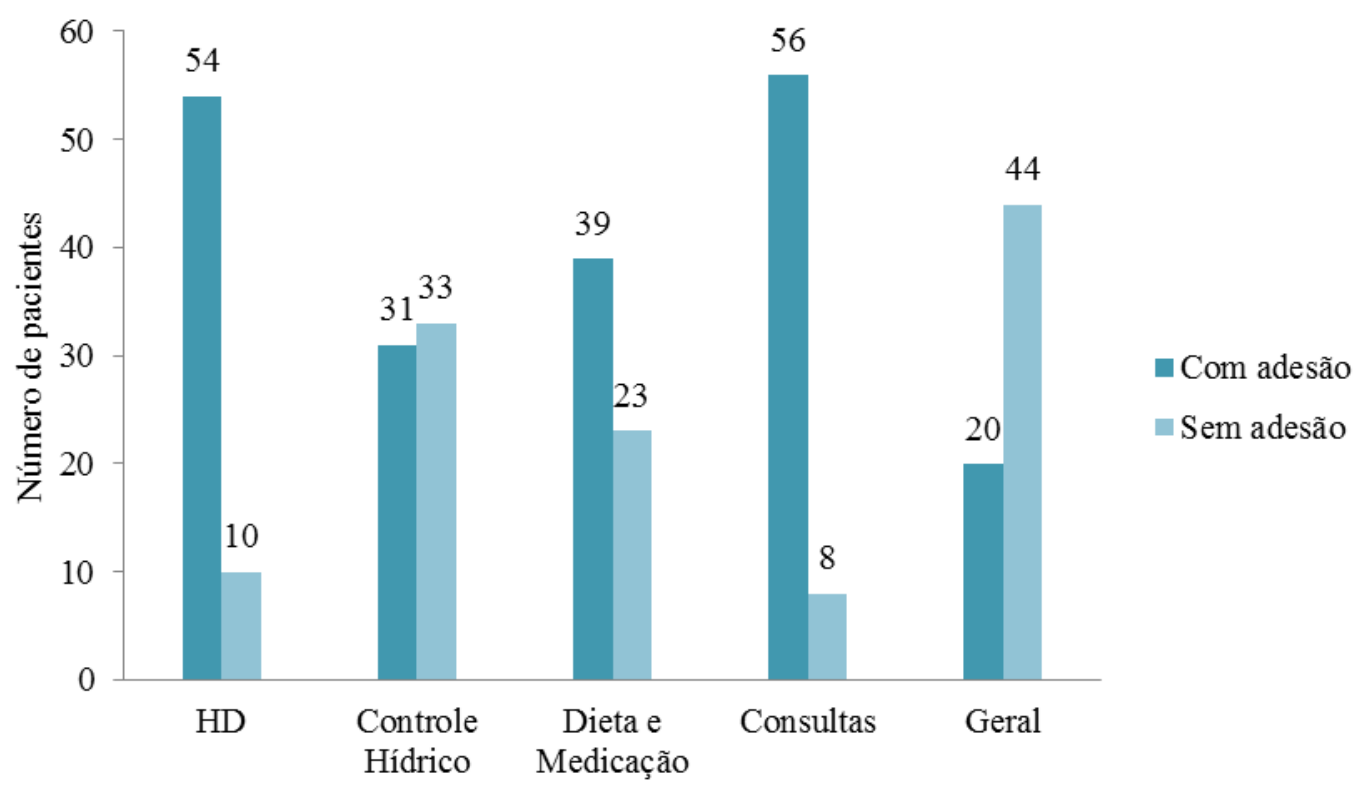

Gráfico 6. Adesão ao tratamento em seus quatro aspectos e Adesão Geral de acordo com o Critério HC

O Gráfico 6 indica que, segundo os critérios estabelecidos na Unidade de Diálise onde a pesquisa foi realizada (Critério HC), 44 pacientes $(68,7 \%)$ foram considerados como "sem adesão" ao tratamento como um todo (Adesão Geral). Apesar disso, observando cada aspecto do tratamento separadamente, houve prevalência de pacientes com adesão, exceto no aspecto Controle Hídrico, em que o número de pacientes sem adesão foi maior $(51,6 \%$; $n=33)$.

Os resultados obtidos a partir da utilização do Critério da Literatura são diferentes dos obtidos com o Critério HC, e estão apresentados no Gráfico 7. 


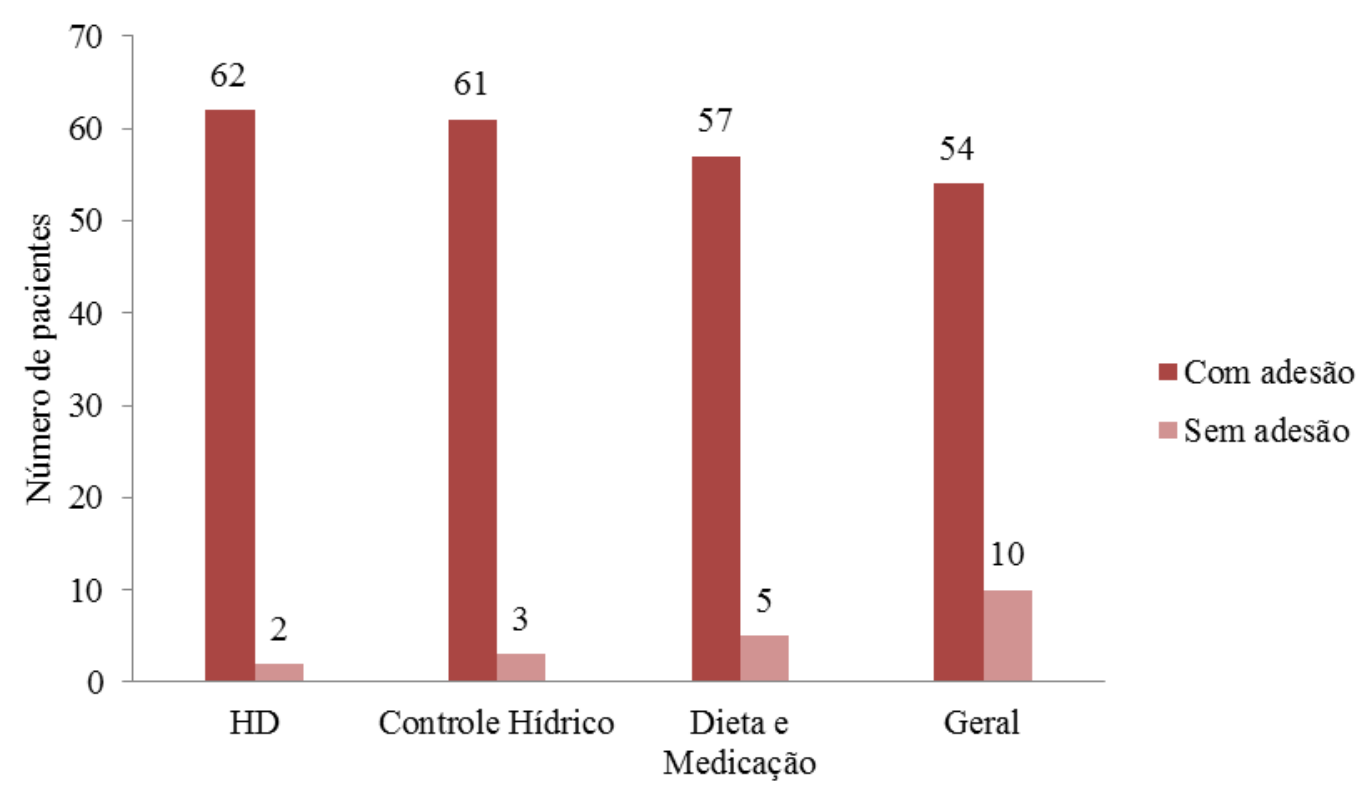

Gráfico 7. Adesão ao tratamento em seus quatro aspectos e Adesão Geral de acordo com o Critério da Literatura

De acordo com o critério para adesão estabelecido na literatura, a taxa de adesão ao tratamento como um todo nesta amostra foi de 84,38\% (n=54). Em relação aos diferentes aspectos do tratamento, em todos eles também houve prevalência de pacientes com adesão, sendo a diferença maior do que aquela observada no Critério HC. Observa-se que, às sessões de diálise, 62 pacientes (96,88\%) demonstraram aderir e, ao controle hídrico, 61 (95,31\%) foram considerados com adesão.

\subsection{Comparação entre o Critério HC e Critério da Literatura}

Os resultados do teste de concordância entre os critérios $\mathrm{HC}$ e Literatura estão descritos na Tabela 8. Observa-se que a concordância entre os critérios do $\mathrm{HC}$ e da Literatura é, em todos os aspectos do tratamento, desprezível ou suave. Portanto, parece não haver concordância entre os critérios, o que significa dizer que os critérios adotados na literatura tendem a classificar como com adesão pacientes que, pelo critério do $\mathrm{HC}$, eram classificados como sem adesão. 
Tabela 8 -Concordância entre os critérios HC e Literatura segundo o Coeficiente de Kappa

\begin{tabular}{ccccc}
\hline $\begin{array}{c}\text { Aspectos do } \\
\text { tratamento }\end{array}$ & Kappa & $\begin{array}{c}\text { Limite Inferior } \\
\text { de Confiança } \\
95 \%\end{array}$ & $\begin{array}{c}\text { Limite } \\
\text { Superior de } \\
\text { Confiança } 95 \%\end{array}$ & $\begin{array}{c}\text { Força da } \\
\text { concordância }\end{array}$ \\
\hline HD & 0,3 & $-0,03$ & 0,62 & suave \\
Controle Hídrico & 0,09 & $-0,01$ & 0,19 & desprezível \\
Dieta e Medicação & 0,26 & 0,07 & 0,45 & suave \\
Geral & 0,16 & 0,05 & 0,26 & desprezível \\
\hline $\mathrm{p}=0,02$ & & & &
\end{tabular}

Em relação à HD, dos dez participantes que haviam sido classificados como sem adesão segundo o Critério HC, oito foram classificados como com adesão no Critério da Literatura, indicando o motivo da concordância encontrada ter sido suave. Sobre o controle hídrico, dos 33 pacientes que eram sem adesão de acordo com o critério do HC, 30 foram classificados como com adesão no Critério da Literatura, justificando a concordância desprezível. Em relação à dieta e medicação, 37,1\% dos participantes foram considerados sem adesão segundo o Critério $\mathrm{HC}$, enquanto que 8,06\% foram considerados sem adesão de acordo com o Critério da Literatura. Por fim, quanto à adesão geral, 34 pacientes que foram classificados como sem adesão no Critério HC atingiram o critério para adesão no Critério da Literatura, indicando a discordância entre os critérios. Em todos os casos, nenhum paciente foi classificado como sem adesão segundo o Critério da Literatura e com adesão no Critério $\mathrm{HC}$, demonstrando ser este mais rígido do que o da literatura.

\subsection{Variáveis Sociodemográficas e Adesão ao Tratamento}

As variáveis sociodemográficas foram analisadas em relação à adesão ao tratamento de duas formas distintas. Primeiramente, serão apresentados os resultados referentes aos testes de comparação entre a distribuição dos grupos em relação às variáveis sociodemográficas numéricas: anos de idade, quilômetros de distância da cidade de procedência e valor, em reais, da renda mensal per capita. Em seguida, serão descritos os resultados do teste Exato de Fisher, que buscou evidências de associação entre a adesão ao tratamento e as variáveis sociodemográficas categóricas: sexo, nível de escolaridade, estado civil, religiosidade e situação empregatícia.

A Tabela 9 mostra os resultados da comparação entre a distribuição das variáveis sociodemográficas numéricas dentre os participantes classificados sem e com adesão, obtidos a partir do teste de Mann-Whitney para amostras independentes. Observa-se que houve 
diferença estatisticamente significante entre a idade dos grupos com e sem adesão ao controle hídrico e ao tratamento como um todo, indicando que os pacientes com adesão têm idade superior aos pacientes que não aderem a estes aspectos do tratamento.

Tabela 9 - Comparação entre pacientes com e sem adesão ao tratamento em relação às variáveis sociodemográficas numéricas

\begin{tabular}{|c|c|c|c|c|c|}
\hline & ADESÃO & & Idade & $\begin{array}{c}\text { Cidade de } \\
\text { procedência }\end{array}$ & $\begin{array}{c}\text { Renda Mensal } \\
\text { per capita }\end{array}$ \\
\hline \multirow{4}{*}{ HD } & \multirow{2}{*}{ Sem } & Mediana & 41,5 & 0 & 625 \\
\hline & & Mín-Máx & $18-73$ & $0-83$ & $83,3-1500$ \\
\hline & \multirow{2}{*}{ Com } & Mediana & 53,5 & 0 & 700 \\
\hline & & Mín-Máx & $24-80$ & $0-108$ & $207,3-5000$ \\
\hline \multirow{4}{*}{ Controle Hídrico } & \multirow{2}{*}{ Sem } & Mediana & $46^{*}$ & 0 & 875 \\
\hline & & Mín-Máx & $18-78^{*}$ & $0-108$ & $83,3-3000$ \\
\hline & \multirow{2}{*}{ Com } & Mediana & $56^{*}$ & 0 & 666,7 \\
\hline & & Mín-Máx & $32-80^{*}$ & $0-83$ & $426,7-5000$ \\
\hline \multirow{4}{*}{ Dieta e Medicação } & \multirow{2}{*}{ Sem } & Mediana & 46 & 0 & 850 \\
\hline & & Mín-Máx & $25-68$ & $0-108$ & $207,3-5000$ \\
\hline & \multirow{2}{*}{ Com } & Mediana & 56 & 0 & 626 \\
\hline & & Mín-Máx & $18-80$ & $0-83$ & $83,3-3000$ \\
\hline \multirow{4}{*}{ Consultas } & \multirow{2}{*}{ Sem } & Mediana & 40,5 & 0 & 557,2 \\
\hline & & Mín-Máx & $18-62$ & $0-108$ & $83,3-3000$ \\
\hline & \multirow{2}{*}{ Com } & Mediana & 53,5 & 0 & 700 \\
\hline & & Mín-Máx & $24-80$ & $0-105$ & $133,3-5000$ \\
\hline \multirow{4}{*}{ Geral } & \multirow{2}{*}{ Sem } & Mediana & $48^{*}$ & 0 & 800,5 \\
\hline & & Mín-Máx & $18-78^{*}$ & $0-108$ & $83,3-5000$ \\
\hline & \multirow{2}{*}{ Com } & Mediana & $56,5^{*}$ & 0 & 630 \\
\hline & & Mín-Máx & $32-80 *$ & $0-83$ & $233,3-3000$ \\
\hline
\end{tabular}

A seguir, serão apresentados os resultados referentes ao Teste Exato de Fisher, que verificou a associação entre as variáveis sociodemográficas categóricas em relação à adesão ao tratamento. Os dados estão descritos em seus valores percentuais, sendo destacados com um asterisco quando foi encontrado nível de significância menor ou igual a 0,05. 


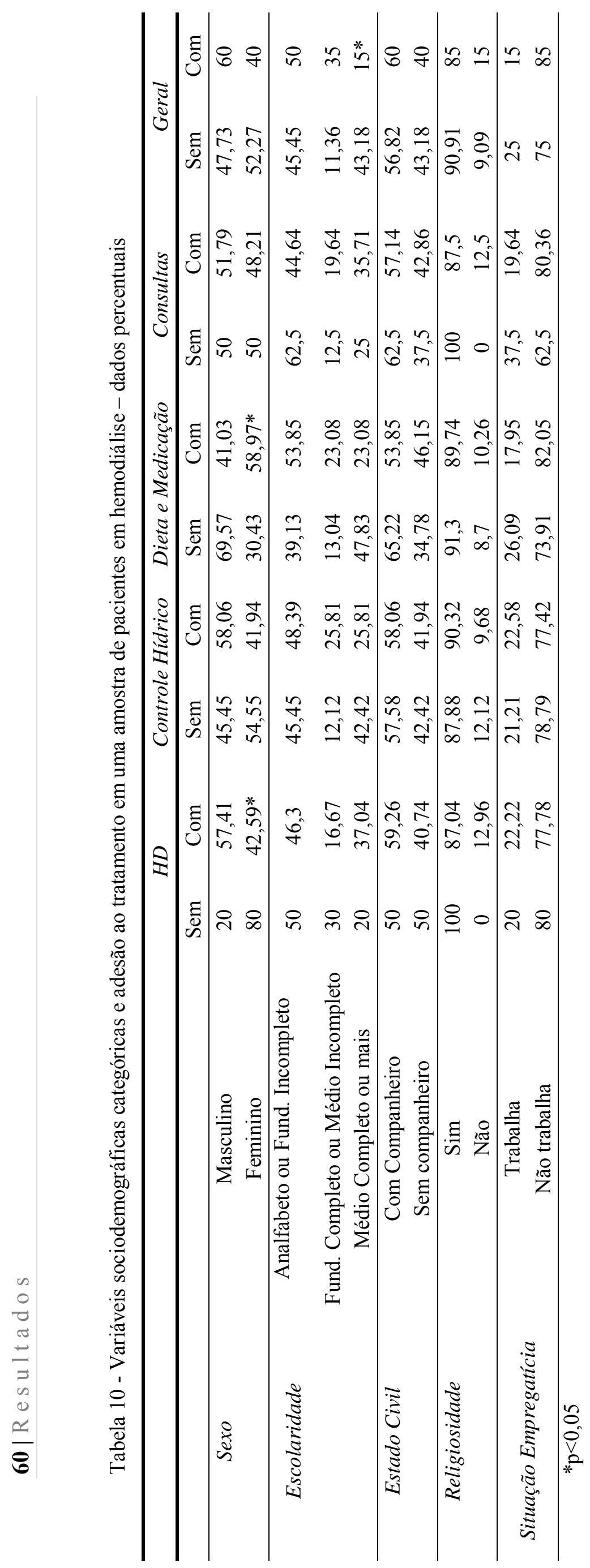


Quando são observados os dados relativos à adesão à HD, pode-se dizer que houve evidência de associação entre a variável sexo, nos grupos sem e com adesão, ou seja, ser de um determinado sexo parece pré-determinar se um paciente vai ou não aderir à HD. Embora o teste utilizado não permita este tipo de conclusão, pode-se sugerir, a partir dos dados descritivos, que pacientes do sexo masculino têm mais chances de aderir à HD do que as mulheres.

Com relação ao aspecto do tratamento "Dieta e Medicação", também se encontrou evidência de associação na variável sexo. Parece que, ao contrário do que acontece com a adesão à $\mathrm{HD}$, pacientes do sexo feminino possuem maiores chances de aderir à dieta $\mathrm{e}$ medicação quando comparadas aos homens.

Por fim, em relação ao aspecto Geral do tratamento, verificou-se evidência de associação entre a escolaridade e a adesão dos pacientes ao tratamento como um todo. Os dados sugerem que indivíduos com Ensino Médio completo ou Ensino Superior - completo ou incompleto - aderem menos ao tratamento como um todo e que, indivíduos com Ensino Fundamental completo ou Ensino Médio incompleto aderem mais ao tratamento.

\subsection{Variáveis Clínicas e Adesão ao Tratamento}

Foi investigada a existência de diferença significante entre o tempo de hemodiálise nos grupos de pacientes com e sem adesão aos diferentes aspectos do tratamento. Verificou-se que, somente no aspecto "Adesão à HD”, houve diferença estatisticamente significante entre o tempo de hemodiálise dos pacientes com adesão e sem adesão, sendo que os pacientes com adesão faziam hemodiálise há mais tempo (Mediana: 46 meses, Mínimo: 7, Máximo: 330) do que os pacientes sem adesão (Mediana: 28 meses, Mínimo: 7, Máximo: 53), sendo $\mathrm{p}=0,05$.

Com relação à doença de base, o teste Exato de Fisher foi utilizado para verificar a existência de associação entre as variáveis. Observou-se evidência de associação entre a doença congênita e a adesão à dieta e medicação $(\mathrm{p}=0,05)$, sendo que, dentre os participantes com adesão à dieta e medicação, nenhum possuía doença congênita e, dentre o grupo sem adesão, 13,04\% eram portadores deste tipo de doença. 
4.11. Conhecimento sobre a doença e o tratamento, história de adesão e adesão ao tratamento

Em relação à explicação que os participantes deram sobre sua doença e tratamento, foi encontrada associação significante entre a explicação sobre o tratamento e a adesão ao controle hídrico $(p=0,01)$. Curiosamente, os participantes que forneceram ao pesquisador uma explicação satisfatória sobre o tratamento aderiram menos ao controle hídrico e os participantes que deram uma explicação insatisfatória aderiram mais. Não foi encontrada evidência de associação entre os outros aspectos da adesão ao tratamento e a explicação sobre a doença e o tratamento.

Observou-se, também, associação significante entre a história de adesão e os aspectos "Controle Hídrico" e "Consultas" e "Geral" da adesão ao tratamento atual. Ou seja, entre os pacientes com adesão a estes três aspectos, foi observada maior porcentagem de pacientes que também aderiam ao tratamento da doença de base (Tabela 11).

Tabela 11 - Associação entre adesão ao tratamento para doença de base e adesão ao tratamento atual em uma amostra de pacientes em hemodiálise - dados percentuais

\begin{tabular}{lcccccc}
\hline \multicolumn{1}{c}{ Realizava tratamento? } & \multicolumn{2}{c}{ Controle Hídrico } & \multicolumn{2}{c}{ Consultas } & \multicolumn{2}{c}{ Geral } \\
\hline & Sem & Com & Sem & Com & Sem & Com \\
\hline Sim & 18,18 & 48,39 & 0 & 37,5 & 22,73 & 55 \\
Não & 21,21 & 19,35 & 0 & 23,21 & 18,18 & 25 \\
Parcialmente & 27,27 & 9,68 & 12,5 & 19,64 & 22,73 & 10 \\
Não tinha tratamento prescrito & 33,33 & 22,58 & 87,5 & 19,64 & 36,36 & 10 \\
\hline \multicolumn{2}{c}{$\mathrm{p}=0,05 *$} & $\mathrm{p}<0,01 *$ & $\mathrm{p}=0,03 *$ \\
\hline
\end{tabular}

${ }^{*} \mathrm{p} \leq 0,05$

\subsection{Variáveis Psicológicas e Adesão ao Tratamento}

Abaixo serão descritos os dados resultantes do teste que investigou associações entre as variáveis psicológicas, mensuradas pelos instrumentos padronizados, e a adesão ao tratamento, em seus quatro aspectos e no aspecto geral. 
Tabela 12 - Associação entre variáveis psicológicas e adesão a tratamento em uma amostra de pacientes em hemodiálise - dados percentuais

\begin{tabular}{|c|c|c|c|c|c|c|c|c|c|c|c|}
\hline & & \multicolumn{2}{|c|}{$H D$} & \multicolumn{2}{|c|}{ Controle Hídrico } & \multicolumn{2}{|c|}{ Dieta e Medicação } & \multicolumn{2}{|c|}{ Consultas } & \multicolumn{2}{|c|}{ Geral } \\
\hline & & Sem & Com & Sem & Com & Sem & Com & Sem & Com & Sem & Com \\
\hline \multirow{3}{*}{ 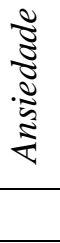 } & Ausente & 80 & 74,07 & 84,85 & 64,52 & 69,57 & 76,92 & 62,5 & 76,79 & 79,55 & 65 \\
\hline & Presente & 20 & 25,93 & 15,15 & 35,48 & 30,43 & 23,08 & 37,5 & 23,21 & 20,45 & 35 \\
\hline & & \multicolumn{2}{|c|}{$\mathrm{p}=0,99$} & \multicolumn{2}{|c|}{$\mathrm{p}=0,08$} & \multicolumn{2}{|c|}{$\mathrm{p}=0,56$} & \multicolumn{2}{|c|}{$\mathrm{p}=0,40$} & \multicolumn{2}{|c|}{$\mathrm{p}=0,23$} \\
\hline \multirow{3}{*}{ 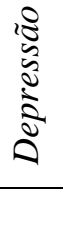 } & Ausente & 80 & 88,89 & 96,97 & 77,42 & 91,3 & 84,62 & 100 & 85,71 & 93,18 & 75 \\
\hline & Presente & 20 & 11,11 & 3,03 & 22,58 & 8,7 & 15,38 & 0 & 14,29 & 6,82 & 25 \\
\hline & & \multicolumn{2}{|c|}{$\mathrm{p}=0,60$} & \multicolumn{2}{|c|}{$\mathrm{p}=0,02 *$} & \multicolumn{2}{|c|}{$p=0,70$} & \multicolumn{2}{|c|}{$\mathrm{p}=0,58$} & \multicolumn{2}{|c|}{$\mathrm{p}=0,10$} \\
\hline
\end{tabular}

${ }^{*} \mathrm{p} \leq 0,05$

Observa-se que somente foi encontrada evidência de associação entre a variável depressão e a adesão ao controle hídrico, indicando que no grupo de pacientes sem adesão a este aspecto do tratamento, uma porcentagem significantemente maior de pacientes não apresentaram sintomas de depressão segundo a HAD.

Por fim, foram comparados os escores gerais obtidos na Escala de Apoio Social pelos pacientes dos grupos com e sem adesão ao tratamento. Não foi verificada evidência de diferença nos aspectos "Adesão ao Controle Hídrico", "Adesão à Dieta e Medicação", “Adesão às Consultas" e "Adesão Geral". No entanto, no que diz respeito à adesão à HD, foi observada diferença estatisticamente significante entre os grupos, sendo que os participantes com adesão à HD apresentaram escore de apoio social geral superior ao escore obtido no grupo sem adesão (Mediana 96,84 versus 81,05). 


\section{DISCUSSÃO}

\subsection{Primeiras considerações sobre as características sociodemográficas e clínicas da amostra}

As características sociodemográficas dos participantes deste estudo se assemelham às características observadas em outras amostras de pacientes renais crônicos em hemodiálise no Brasil (Macuglia et al., 2010; Sesso et al., 2011; Cavalcante et al., 2013). Nota-se uma distribuição semelhante entre os sexos, com leve predomínio de pacientes do sexo masculino. Há, também, maior frequência de pacientes com baixa escolaridade e baixa renda mensal, características também observadas na Pesquisa Nacional por Amostra de Domicílios (PNAD), realizada pelo Instituto Brasileiro de Geografia e Estatística em 2003, sobre o perfil sociodemográfico dos pacientes atendidos pelo SUS (Ribeiro, Barata, Almeida \& Silva, 2006). Tais características indicam que o SUS, enquanto política pública, permite aos grupos com pior inserção social o acesso aos serviços de saúde, cumprindo a expectativa prevista em sua elaboração.

Entretanto, o predomínio de pacientes dialíticos em pior condição econômica também traz à tona outra questão importante: a evolução da doença renal ao estágio mais avançado pode estar relacionada a piores condições de cuidado à saúde desta população no nível primário de atenção, antes do agravamento da doença. É possível que pacientes mais pobres e menos instruídos tenham maiores chances de ser portadores de doenças como HAS, principal doença de base para a IRC, bem como de possuir baixo controle sobre esta doença.

Estudos descritivos realizados em diferentes regiões do Brasil observaram que a prevalência de HAS aumenta à medida que os anos de estudo decrescem (Hartman, Dias-daCosta, Olinto, Pattussi \& Tramontini, 2007; Castro, Moncau \& Marcopito, 2006; Gus, Harzheim, Zaslavsky, Medina \& Gus, 2004). Ainda sobre as características de hipertensos, Carlos, Palha, Veiga e Beccaria (2008) descreveram o perfil de uma amostra de 343 pacientes hipertensos tratados em um núcleo de saúde da família do interior do estado de São Paulo e revelaram que $72,86 \%$ deste grupo eram analfabetos ou possuíam o $1^{\circ}$ grau de escolaridade.

Além de um fator que parece influenciar a prevalência da HAS, o baixo status socioeconômico também afeta o controle da doença. Girotto, Andrade, Cabrera e Matsuo (2013) avaliaram 385 pacientes hipertensos do sul do Brasil e identificaram que pacientes com menor escolaridade eram menos aderentes às atividades físicas regulares do que pacientes com escolaridade igual ou superior à $4^{\mathrm{a}}$. série. Outro estudo, realizado em 2001 
também no sul do país, associou a maior probabilidade de abandono ao tratamento antihipertensivo à escolaridade inferior ou igual a cinco anos de estudo (Busnello et al., 2001). Ou seja, a baixa escolaridade - frequentemente acompanhada de uma condição econômica desfavorável - parece exercer influência sobre a saúde dos indivíduos, bem como sobre o sucesso do tratamento.

Ainda que as razões que permeiam esta relação não estejam totalmente esclarecidas, pode-se imaginar que fatores como dificuldade de acesso aos serviços de saúde, aos medicamentos e baixa compreensão sobre sua doença podem levar à não adesão dos pacientes ao tratamento e exercer papel importante no impacto da escolaridade na evolução do quadro de saúde destes indivíduos. Neste estudo, 24,38\% dos pacientes relataram a HAS como doença de base para sua IRC e 39,06\% responderam que não realizavam o tratamento de sua doença de base - dentre elas a HAS - da forma com o profissional da saúde orientava. Notase que, para uma parcela significante da amostra, a evolução da doença de base para a fase avançada da IRC pode ter sido ocasionada - ou, ao menos, favorecida - pela baixa adesão ao tratamento prescrito.

Embora os dados não permitam este tipo de conclusão, um resultado interessante, que à primeira vista parece estar associado à elevada frequência de pacientes pouco aderentes ao tratamento da doença de base, é a elevada porcentagem de pacientes que relataram não saber que sua doença poderia prejudicar os rins $(53,12 \%)$. Porém, a análise de estudos anteriores realizados com pacientes hipertensos e diabéticos demonstra que esta relação pode não ser tão óbvia como parece.

\subsection{Sobre a relação entre conhecimento da doença e adesão ao tratamento}

Strelec, Pierin e Mion Jr. (2003) buscaram relacionar o controle da pressão arterial com o conhecimento dos pacientes sobre a HAS e observaram fraca associação entre conhecimento satisfatório em relação à doença e tratamento e o bom controle da pressão arterial. Um estudo realizado em Minas Gerais com 164 pacientes diabéticos também avaliou a associação entre o conhecimento sobre as complicações do DM descompensado e a adesão ao tratamento não farmacológico para a doença. Como resultado, os autores obtiveram que o conhecimento sobre as complicações do DM, caso o tratamento não fosse realizado adequadamente, estava inversamente relacionado com a adesão ao tratamento. Ou seja, pacientes com maior conhecimento tinham menor chance de aderir ao tratamento não farmacológico para o DM (Assunção \& Ursine, 2008). 
Vale ressaltar que estão sendo discutidos aspectos relacionados ao tratamento das doenças tidas como doenças de base para a IRC, e não da doença renal propriamente dita. Isso porque chama a atenção o predomínio de pacientes que desenvolvem a doença renal em sua fase avançada como complicação de doenças controláveis, cuja evolução negativa poderia ter sido evitada. No entanto, quando se observam os dados da presente pesquisa, referentes ao conhecimento dos pacientes sobre o tratamento de hemodiálise e a adesão, este contrassenso se mantém.

Não foi encontrada associação significante entre o conhecimento dos participantes sobre a doença e o tratamento e a adesão aos aspectos: HD, Dieta e Medicação, Consultas e Geral. Somente observou-se associação estatisticamente significante entre a explicação sobre o tratamento e a adesão ao controle hídrico, sendo que pacientes com explicação satisfatória sobre o tratamento aderiram menos ao controle hídrico. Ao contrário, pacientes que demonstraram conhecimento insatisfatório aderiram mais ao controle hídrico. Além disso, foi observada associação entre a escolaridade e a adesão ao tratamento, sendo que pacientes com maior nível de escolaridade aderiam menos ao tratamento do que pacientes com nível de escolaridade inferior. Embora o nível de escolaridade por si só não prediga conhecimento sobre a doença, é possível imaginar que pacientes com mais anos de estudo possuam melhores condições de comunicação e compreensão das orientações médicas, atingindo mais conhecimento sobre sua doença.

Também no contexto da doença renal crônica, muitos estudos avaliaram a relação entre nível de conhecimento e a adesão dos pacientes ao tratamento da hiperfosfatemia transtorno em que há nível elevado de fósforo no sangue, relacionado a complicações cardiovasculares, hiperparatireoidismo e distúrbio mineral ósseo em pacientes em diálise (Nerbass et al., 2010). Os resultados obtidos revelaram controvérsias sobre a relação entre conhecimento e adesão ao tratamento.

Por um lado, Thomas et al. (2001), em estudo com 276 pacientes norte-americanos em hemodiálise, observaram que o bom nível de conhecimento sobre o tratamento foi um fator que aumentou as chances de adesão à dieta prescrita. Stamatakis, Pecora e Gunel (1997) compararam o conhecimento sobre hiperfosfatemia entre pacientes com nível moderado e severo deste distúrbio e concluíram que o grupo de pacientes com hiperfosfatemia moderada demonstrou maior pontuação nos testes de conhecimento do que os pacientes com hiperfosfatemia severa, sugerindo que o aumento no conhecimento sobre a doença pode contribuir para o melhor controle desta. Por outro lado, Durose, Holdsworth, Watson e Przygrodzka (2004) e Nerbass et al. (2010) não encontraram esta relação. Ao contrário disto, 
observaram que pacientes com melhor conhecimento sobre as restrições na dieta e as consequências da doença mal controlada aderiram menos à dieta prescrita e as restrições de fósforo, sódio e líquidos.

Nota-se que, embora a adesão ao tratamento dependa do conhecimento e das informações que o paciente possui sobre sua doença, isto não funciona por si só como um fator preditor de adesão (Assunção \& Ursine, 2008). Isso porque a adesão ao tratamento é um constructo complexo, de sofisticado funcionamento e que requer extensa análise. É constituída por um conjunto de comportamentos diferentes, nem sempre relacionados entre si. Tais comportamentos, chamados comportamentos de autocuidado, são considerados operantes e, assim, segundo os princípios da Análise do Comportamento, são controlados por eventos ambientais, sendo que diferentes contingências de reforçamento controlam diferentes comportamentos de autocuidado (Malerbi, 2000).

Orientar um paciente sobre quais comportamentos devem ser emitidos para que sua doença seja controlada e informar sobre as consequências que pode sofrer caso não siga estas orientações são ações importantes, pois descrevem ao paciente as contingências que estão operando sobre seu comportamento (estímulo antecedente / resposta / consequência). Para que haja a mudança comportamental, esta descrição é imprescindível. Ou seja, o paciente, para mudar de comportamento e passar a seguir o tratamento adequadamente, precisa em primeiro lugar compreender o que ele deve fazer, diante de qual situação, para alcançar (ou evitar) uma certa consequência.

Mas somente esta orientação não é suficiente, pois funciona como regra, isto é, uma descrição da contingência pela qual um indivíduo ainda vai passar (Guedes, 2001). Dizer ao paciente como ele deve se comportar é inserir uma regra e esperar que ele a siga, sem que sinta "na pele" as consequências de seu comportamento. O problema é que isso só ocorrerá se, em sua história de vida, o paciente possuir experiências de ter seguido outras regras e ter obtido boas consequências por isso (Malerbi, 2000). Caso isso não tenha ocorrido, possivelmente a orientação não surtirá o efeito esperado. Sendo assim, cabe ao profissional da saúde identificar se regras são capazes de controlar o comportamento daquele paciente, e isso só é possível com a análise de sua história.

Portanto, transmitir instruções contribui para ampliar o conhecimento dos pacientes sobre seu tratamento e sua doença, mas parece não ser suficiente para se alcançar a mudança comportamental e a adesão ao tratamento desejadas pela equipe de saúde. As intervenções devem ter a adição de elementos psicoterapêuticos em sua formulação, no sentido de auxiliar o paciente a reconhecer quais são suas dificuldades e capacidades, desenvolver habilidades e 
estratégias de autocontrole, manejar seu ambiente e promover condições favorecedoras dos comportamentos de adesão (Casey, Johnson \& McClelland, 2002; Christensen, Moran, Wiebe, Ehlers \& Lawton, 2002; Tsay, 2003).

\subsection{Adesão à hemodiálise: considerações sobre os critérios e comparação com resultados de outros estudos}

Como foi visto, utilizaram-se dois critérios distintos para a classificação dos pacientes quanto à adesão ao tratamento. $\mathrm{O}$ primeiro critério, denominado Critério $\mathrm{HC}$, considerou $68,7 \%$ dos pacientes como "sem adesão" ao tratamento como um todo (Adesão Geral), enquanto que pelo segundo critério, denominado Critério da Literatura, apenas 15,62\% foram classificados como "sem adesão" ao tratamento como um todo. Esta diferença revelou que o Critério HC, adotado na unidade de diálise onde os dados foram colhidos, é bastante mais rígido do que o Critério da Literatura, frequentemente adotado em estudos anteriores, realizados em outros centros de tratamento. Esta divergência entre os critérios foi confirmada pelo Coeficiente Kappa, que avaliou a concordância entre os critérios como suave ou desprezível em todos os aspectos do tratamento. E o que isso significa?

Em primeiro lugar, esta diferença revela um problema já levantado por outros estudiosos da área: a ausência de parâmetros padronizados que permitam conclusões e comparações entre os resultados de pesquisas sobre a adesão de pacientes em hemodiálise (Iborra-Moltó et al., 2012; Denhaerynck et al., 2007; Kugler et al., 2005). Mostra-se necessária a validação de critérios que possam ser utilizados em diversas amostras de pacientes e que tornem as comparações possíveis.

Além disso, devem-se analisar as consequências de se adotar um critério mais rígido de adesão e de exigir dos pacientes um maior controle sobre seus comportamentos relacionados aos diferentes aspectos do tratamento. Vale ressaltar que, baseando-se nos parâmetros descritos como "Critério HC", todos os profissionais desta unidade realizavam suas orientações aos pacientes em busca de se atingir os níveis satisfatórios dos indicadores biológicos de adesão. Isto é, o paciente atendido na unidade era sempre, nas consultas com a equipe multiprofissional, estimulado e cobrado a manter (a) nível de fósforo sérico até 5,5, (b) GPID até $5 \%$ do PS aos finais de semana e até 3\% do PS durante a semana, (c) a nunca faltar das consultas médicas e (d) também nunca faltar das sessões de HD.

Supõe-se que, com a adoção destes parâmetros mais rígidos, a equipe da unidade busca melhorar o quadro clínico de seus pacientes e evitar agravos relacionados à IRC. 
Apesar de 68,75\% dos pacientes não terem atingido os critérios para ser considerados com adesão ao tratamento como um todo, os resultados obtidos em relação a variáveis clínicas, consideradas respostas clínicas ao tratamento, foram positivos: na amostra estudada, apenas cinco pacientes haviam apresentado intercorrências durante as sessões de HD e nenhum paciente havia passado por internações relacionadas à IRC no período de três meses anteriores à data da coleta.

Observa-se ainda que as taxas de adesão, obtidas segundo o Critério HC, para todos os aspectos do tratamento (HD, Controle Hídrico, Dieta e Medicação e Consultas) foram mais satisfatórias do que o aspecto geral do tratamento. De forma geral, houve prevalência de pacientes com adesão, exceto no aspecto Controle Hídrico, onde a distribuição entre pacientes com e sem adesão foi equilibrada. Talvez a exigência adotada neste estudo, de que para ser considerado com adesão geral um paciente deveria aderir a todos os aspectos do tratamento, tenha aumentado demasiadamente a rigidez do critério. Ainda assim, a adoção de exigências mais rígidas em relação ao tratamento desta amostra pareceu favorecer respostas clínicas satisfatórias nos pacientes estudados atingindo, portanto, o objetivo da equipe.

As exigências rígidas parecem ter também contribuído para a boa adesão destes pacientes se considerados os critérios utilizados em outros centros de diálise, já que os resultados encontrados na análise dos dados segundo o Critério da Literatura mostram que, nesta amostra, as taxas de adesão ao tratamento foram superiores a aquelas obtidas em outros estudos. Somente em relação à adesão às sessões de HD, analisada pelo número de faltas, a taxa observada neste estudo se assemelha a estudos anteriores. Na presente pesquisa o nível de adesão a este aspecto foi alto (96,87\% de adesão), semelhante aos resultados encontrados em estudos de Kimmel et al. (Kimmel et al., 1995; Kimmel et al. 1998b), em que respectivamente, 98,9 e 98,3\% das amostras apresentaram baixa porcentagem de faltas às sessões dialíticas.

Um aspecto comumente estudado e que se associa à adesão às sessões de HD é o chamado comportamento de "encurtamento" das sessões (shortening behavior) (Kimmel et al., 1995; Kimmel et al., 1998b; Kaveh \& Kimmel, 2001). Isto ocorre quando o paciente solicita a interrupção da sessão dialítica antes do cumprimento do tempo de sessão prescrito pelo médico (em geral, de 3 a 4 horas). Este aspecto não foi abordado neste estudo porque na unidade onde os dados foram colhidos, de forma geral, não é permitido o encurtamento da sessão a pedido do paciente. A sessão dialítica somente é interrompida em caso de intercorrência ou por prescrição do médico nefrologista. Sendo assim, esta medida não pode 
ser considerada como indicador de adesão neste contexto, já que não depende da emissão de comportamentos por parte do paciente e por isso não foi aqui incluída.

Com relação ao controle hídrico, medido a partir dos valores do GPID, obteve-se que 95,31\% dos participantes tinham adesão. Também com o uso do GPID como medida de adesão, Kluger et al. (2005) obtiveram que apenas 25,1\% dos pacientes tinham adesão ao controle hídrico, Iborra-Moltó et al. (2012) encontraram taxa de adesão de 73\% e Nerbass et al. (2011), obtiveram que $76 \%$ de sua amostra controlavam adequadamente seu GPID.

Quanto à adesão à dieta e medicação, avaliada pelo nível de fósforo sérico, a taxa encontrada na presente pesquisa $(89,06 \%$ de adesão) também foi superior a aquelas observadas em outros estudos. Sobre a adesão à dieta, da amostra do estudo de Kugler et al. (2005), apenas 18,6\% demonstraram adesão, pelo exame dos indicadores biológicos e de seus relatos. Com o uso dos valores do exame de fósforo sérico para avaliar adesão à dieta, Morales López, Burrowes, Gizis e Brommage (2007) encontraram taxas de 65 e $76 \%$ de adesão em seus grupos de pacientes, resultados também inferiores aos desta pesquisa.

Sobre a adesão ao tratamento farmacológico, os resultados de estudos anteriores também se mostram inferiores aos dados desta pesquisa: Theofilou (2013) encontrou $75 \%$ de boa adesão ao uso dos medicamentos, Arenas et al. (2010) obtiveram 60\% e Sgnaolim et al. (2012) identificaram que apenas 44,6\% da amostra aderiram a este aspecto do tratamento. Também com o objetivo de medir a adesão ao tratamento farmacológico, Terra et al. (2010) avaliaram uma amostra de 30 pacientes em hemodiálise e obtiveram que 16,66\% demonstraram baixa adesão.

Uma consideração importante se refere à diferença metodológica encontrada nos estudos sobre adesão ao uso de medicamentos: a maioria das pesquisas revisadas se baseou em escalas de adesão (Medication Adherence Rating Scale, Simplified Medication Adherence Questionnaire e Escala de Morisky) ou no relato dos próprios pacientes. Mas, considerando que o relato dos pacientes pode sofrer interferência de muitas variáveis e nem sempre corresponder à descrição da realidade, será que se pode confiar nesta fonte de dados?

O relato do paciente pode ser denominado "comportamento verbal", considerado por Skinner um comportamento também modelado pelo ambiente e mantido por suas consequências, como os comportamentos operantes. A principal diferença, entretanto, se dá pela necessidade de outras pessoas (ouvintes) na mediação entre indivíduo e ambiente (Skinner, 1957). Sendo considerado um comportamento controlado pelas consequências, o relato do paciente fica, então, sob controle das contingências atuantes (Hübner, 2001). 
Ou seja, ao relatar sobre algo, o paciente pode não estar sobre controle da realidade, do "algo" que pretende descrever. Ao invés disso, o comportamento pode estar sob controle do comportamento do ouvinte, ou da situação em que ambos estão inseridos. Ao invés de descrever a realidade, o paciente pode responder aquilo que, de acordo com experiências anteriores, sabe que será elogiado pelo entrevistador. Ou então pode responder aquilo que sabe que não causará impacto negativo no entrevistador, evitando uma possível repreensão. Este problema pode ser hipotetizado sobre os dados do estudo de Terra et al. (2010), em que $100 \%$ dos pacientes dialíticos entrevistados responderam que tomam a medicação prescrita diariamente, o que, de acordo com a experiência clínica com doentes crônicos, parece um tanto irreal.

Enfim, confiar somente no relato verbal do paciente pode enviesar dados de uma pesquisa, especialmente se o pesquisador não possuir treino adequado para manter, ao longo da entrevista, uma postura neutra e não punitiva, que diminua as chances do paciente responder somente o que for agradá-lo. É por isso que é comum e recomendável que estudos sobre o comportamento humano e, em particular, sobre a adesão de pacientes ao tratamento, se utilizem de métodos combinados de coleta de dados, como entrevistas e instrumentos e medidas objetivas (Kugler et al., 2005).

$\mathrm{Na}$ presente pesquisa, observa-se que o relato dos pacientes sobre sua adesão aos diferentes aspectos do tratamento correspondeu aos resultados obtidos com os indicadores objetivos de adesão segundo o Critério HC. Primeiramente, no que diz respeito à opinião dos pacientes sobre o aspecto mais difícil de aderir: os aspectos mais referidos foram o controle da ingestão de líquidos e o controle da alimentação. Também estes dois aspectos foram os únicos em que, na autoavaliação de adesão, as notas se concentraram entre 3 e 4, ao invés da nota máxima - predominante em todos os outros aspectos. Em concordância com estes resultados, quando observados os dados de adesão segundo o Critério HC, verifica-se que os aspectos Controle Hídrico e Dieta e Medicação foram aqueles em que a distribuição entre pacientes com e sem adesão foi mais equilibrada, sem o predomínio absoluto de pacientes com adesão (como ocorreu nos aspectos HD e Consultas). Ou seja, dentre todos os aspectos, estes dois foram os que obtiveram maior frequência de pacientes sem adesão.

Ainda para demonstrar a correspondência entre relato dos pacientes e resultados das medidas objetivas, destaca-se que o aspecto mais citado quando questionado qual deles é o mais fácil de aderir foi o aspecto Fazer hemodiálise / Comparecer às sessões (citado por $43,75 \%$ dos pacientes). Na autoavaliação de adesão, este também foi o aspecto em que a maior parte dos pacientes se atribuiu nota máxima $(87,50 \%)$. Observando os resultados 
obtidos com a utilização do Critério HC, no aspecto Adesão à HD, 84,37\% da amostra foram considerados aderentes. A porcentagem de pacientes com adesão só foi maior no aspecto Consultas $(87,50 \%)$, mas vale considerar que esta parte do tratamento somente foi lembrada por seis pacientes quando eles foram questionados sobre quais eram todos os aspectos que envolviam o tratamento de sua doença (seção "Conhecimento sobre a doença e tratamento", em Resultados).

Curiosamente, o aspecto Controlar a alimentação foi citado por 35,94\% dos pacientes como o mais fácil de aderir, tendo também sido bastante citado como o mais difícil (28,12\%). Isso talvez se deva ao fato de este aspecto do tratamento ter sido o mais lembrado pelos pacientes quando investigado seu conhecimento sobre o tratamento: 93,75\% sabiam que controlar a alimentação faz parte do tratamento. Sendo conhecido por grande parte dos pacientes, seria esperado que o aspecto Controlar a alimentação fosse também bastante citado nas respostas seguintes, sobre dificuldades e facilidades do tratamento.

Sendo assim, pode-se considerar que o relato dos pacientes nesta pesquisa correspondeu às informações obtidas através de exames bioquímicos e registros de prontuários, chamadas medidas objetivas de adesão. Esta correspondência é positiva, pois indica que a pesquisadora parece ter manejado as contingências adequadamente, no sentido de permitir aos pacientes a sensação de que poderiam responder com sinceridade e que não seriam punidos por suas respostas. Isso fortalece os dados desta pesquisa e aumenta a validade de seus resultados.

Passaremos, agora, a analisar os fatores relacionados com a adesão dos pacientes ao tratamento buscando identificar possíveis explicações para a superioridade das taxas encontradas neste estudo.

\subsection{A relação entre profissionais e pacientes como fator associado à adesão à hemodiálise}

Alguns fatores observados na amostra podem explicar a superioridade dos níveis de adesão encontrados neste estudo, e um deles é a relação entre os profissionais da equipe e os pacientes. Kovac et al. (2002) realizaram uma pesquisa com o objetivo de examinar a relação entre a satisfação dos pacientes com o cuidado vindo da equipe médica e a adesão ao tratamento. Entrevistas e avaliações psicométricas realizadas com 79 pacientes em hemodiálise revelaram uma associação entre a percepção de satisfação com o médico nefrologista e a adesão às sessões de HD (tanto pela redução do número de faltas quanto pelo 
aumento de sessões completas, sem encurtamento). Estes dados demonstram a importância da qualidade do atendimento médico e da relação médico-paciente e o impacto destes na adesão dos pacientes ao tratamento.

Isto assume importância ainda maior ao se falar de pacientes em hemodiálise, já que esta relação possui peculiaridades quando comparada a outros contextos de saúde. Como já foi dito, a vida do paciente renal crônico quando inicia a hemodiálise passa por grandes transformações e a partir daquele momento a unidade de diálise e a equipe que ali atua passam a fazer parte de suas rotinas. O paciente em hemodiálise comparece à unidade, no mínimo, três vezes por semana e permanece por muitas horas na companhia dos profissionais e outros pacientes em tratamento. Isso significa que muita interação social e muitas trocas de experiência ocorrem naquele ambiente, sendo que, frequentemente, estes são os únicos contatos sociais existentes na vida dos pacientes. Não é raro escutar destes doentes relatos do tipo: ñIsso aqui já é minha casa!ò ou ñSinto como eles fossem da minha famíliaò. Diante disso e da escassez de trabalhos sobre este tema, torna-se relevante o estudo da relação profissional da saúde / paciente em hemodiálise para buscar uma compreensão mais ampla deste fenômeno, bem como estudar seus efeitos sobre as respostas clínicas e psicológicas dos pacientes.

No presente estudo a satisfação dos pacientes com o atendimento da equipe não foi avaliada, mas sim a percepção da qualidade do relacionamento entre o paciente e os profissionais. Apesar de serem variáveis distintas, considerar que são associadas parece razoável. Na avaliação realizada, observou-se que $62,50 \%$ dos pacientes atribuíram nota máxima ao seu relacionamento com os médicos nefrologistas da unidade e isto pode explicar, ao menos em parte, os bons níveis de adesão obtidos com o Critério da Literatura.

Também foram bem avaliados os relacionamentos com os profissionais da Enfermagem e Nutrição, que podem ter funcionado como variável facilitadora dos comportamentos de adesão dos pacientes. Esta associação não foi encontrada em estudos na literatura com pacientes renais crônicos, mas pode ser observada em outros contextos, como o tratamento para o DM. Um estudo realizado em 2008 nos Estados Unidos avaliou os efeitos do suporte social vindo dos profissionais de saúde sobre os comportamentos de autocuidado em pacientes diabéticos e encontrou que o suporte de profissionais não médicos esteve associado com maiores chances de ocorrência de comportamentos como cuidado com os pés e adesão à dieta prescrita (Rosland et al., 2008).

Importa ressaltar que no presente trabalho, durante a entrevista em que foi feita a avaliação do relacionamento com a equipe, nenhum dos profissionais incluídos na avaliação 
(médicos, equipe de Enfermagem e Nutrição) estava presente. A investigação foi feita pela pesquisadora, que durante o período da coleta de dados atuava como Psicóloga da equipe. Em função disto, não foi abordada a questão "relacionamento com a Psicóloga", já que as respostas dos pacientes poderiam ser influenciadas pela presença desta profissional.

A qualidade da relação entre profisssional e paciente vem sendo analisada no âmbito da Análise do Comportamento e tem sido observada sua influência no processo de adaptação e mudança do paciente, considerando que o conhecimento técnico parece não ser mais suficiente para garantir o sucesso da terapêutica em saúde (Shinohara, 2000). Partindo do princípio de que o comportamento é instalado e mantido pelas suas consequências (Skinner, 1989), o profissional da saúde tem condições de modificar ou instalar novos comportamentos no repertório do paciente a partir do fornecimento de consequências adequadas às diferentes respostas deste.

Basicamente, se há alguma resposta que se deseja manter ou cuja frequência deva ser aumentada, deve-se fornecer consequências reforçadoras diante de sua ocorrência. Ao contrário disto, para respostas inadequadas ou prejudiciais ao paciente, estas consequências não devem ser fornecidas. Assim, comportamentos compatíveis com as prescrições do profissional da saúde (comportamentos de adesão) devem sempre ser reforçados, seja por reforços positivos (mais atenção, elogios, interações positivas com o paciente, gratificações e benefícios no contexto do tratamento) ou negativos (redução na quantidade de medicações, por exemplo).

Vale destacar que as consequências naturais das respostas de adesão ou não adesão ao tratamento têm poder maior para controlar o comportamento dos pacientes. Piora do quadro clínico e complicações advindas na baixa adesão são exemplos de consequências que poderiam exercer controle sobre o comportamento dos pacientes, fazendo-os aderir às prescrições. No entanto, no caso da doença renal estas complicações geralmente ocorrerão no futuro, temporalmente afastadas da emissão do comportamento e por isso perdem poder de controle. Sendo assim, é necessário que o ambiente social do indivíduo (no caso, os profissionais da saúde) forneça consequências reforçadoras contingentes à emissão dos bons comportamentos, para mantê-los (Malerbi, 2000).

Além de poder controlar comportamentos, o fornecimento de consequências reforçadoras pode produzir sentimentos de satisfação e confiança nos pacientes, melhorando a qualidade da relação. Tendo uma relação mais próxima, o profissional da saúde tem condições de compreender as percepções do paciente acerca de sua doença, conhecer sua realidade e seu 
padrão de comportamento, ouvir suas queixas e encontrar, junto com ele, estratégias que facilitem sua adaptação ao estilo de vida requerido pela doença (Caprara \& Rodrigues, 2004).

Ressalta-se, então, a necessidade de investir esforços na formação e treinamento de médicos para que estes desenvolvam as habilidades necessárias para um bom relacionamento interpessoal com seus pacientes. Na maioria das vezes, a formação fica restrita ao modelo biomédico, em que a relação se mantém assimétrica e centrada na doença, e não no paciente. Recomenda-se analisar criticamente este modelo para ampliar a visão sobre o paciente, considerar seu sofrimento como parte importante do tratamento e buscar uma nova prática em saúde, mais abrangente e humana (Campos \& Turato, 2003; Caprara \& Rodrigues, 2004).

\subsection{Fatores citados como facilitadores e obstáculos da adesão à hemodiálise: uma análise teórica e comparativa}

Investigou-se quais são os fatores que, segundo a percepção dos pacientes, dificultam ou facilitam a adesão aos diferentes aspectos do tratamento dialítico. Como fatores que dificultam a adesão, os mais citados foram os aspectos físicos / fisiológicos $(39,06 \%)$, os hábitos anteriores inadequados $(25 \%)$ e as características do tratamento $(15,62 \%)$. Este último fator inclui aspectos como "frequência e tempo destinado às sessões de HD" e "dor ou desconforto da punção da FAV", e também foi identificado por Madeiro et al. (2010) e por Griva et al., (2013) como um obstáculo à adesão ao tratamento.

Outros resultados observados por estes autores divergem dos achados da presente pesquisa. Por exemplo, fatores como "dificuldades de transporte", "distância" e "fatores financeiros" ficaram entre os mais citados no estudo de Madeiro et al. (2010) e na presente pesquisa, em que foram agrupados na categoria "dificuldades externas", foram mencionados por apenas $15,62 \%$ dos participantes. Deve-se considerar que a pesquisa acima citada foi realizada na cidade de Fortaleza / CE, em que as condições de transporte são diferentes das encontradas no estado de São Paulo. Além disso, observa-se que na amostra de nosso estudo, a maioria dos pacientes era residente de Ribeirão Preto $(71,88 \%)$, mesma cidade onde se localiza a clínica de diálise e, por isso, o fator “distância” foi pouco citado.

$\mathrm{O}$ aspecto mais citado neste estudo (aspectos físicos / fisiológicos) traz à tona uma ideia já exposta anteriormente sobre o impacto do tratamento hemodialítico sobre as necessidades humanas básicas. As restrições alimentares e hídricas limitam o acesso dos pacientes aos chamados reforços primários (comida e água), ou seja, aquelas consequências que são reforçadoras para todos os indivíduos, de todas as espécies, sem a necessidade de 
treino ou condicionamento. Comida e água são, de partida, importantes para manter uma série de comportamentos das pessoas e sua retirada pode funcionar como punição para muitas delas.

Além disso, o padrão alimentar dos indivíduos é construído por uma história de aprendizagem e a preferência por determinados alimentos sofre influência deste processo. Deve-se considerar, então, que se uma pessoa possui um padrão alimentar inadequado (preferência por alimentos ricos em sódio e com poucos nutrientes, por exemplo), isso significa que este padrão foi construído ao longo de sua história de vida, seja pelo contato com outras pessoas da família que se alimentavam assim, seja pela associação destes alimentos com outras situações prazerosas.

De qualquer forma, desconstruir este padrão alimentar e construir outro mais adequado à condição de doente renal crônico demanda tempo e esforço e novo processo de aprendizagem e condicionamento com outras consequências reforçadoras ao novo padrão alimentar. É por isso que a existência de hábitos anteriores muito diferentes do novo padrão desejável pode funcionar como obstáculo à adesão dos indivíduos e foi reconhecida como tal por $25 \%$ dos participantes.

Com relação aos fatores facilitadores da adesão ao tratamento, o mais citado pelos pacientes foi o aspecto referente às consequências negativas da não adesão. Este aspecto também foi o mais frequente no relato dos participantes da pesquisa de Madeiro et al. (2010), e também foi identificado em uma pesquisa qualitativa realizada com pacientes asiáticos (Griva et al., 2013). Na presente pesquisa, 25\% da amostra informaram que aderem ao tratamento para evitar complicações ou agravos da doença (estímulos aversivos). Chama-se, então, controle aversivo o controle que estes estímulos exercem sobre o comportamento destes pacientes (Moreira \& Medeiros, 2007).

Apesar de ser uma forma legítima e eficiente de controlar o comportamento, o controle aversivo possui uma série de efeitos colaterais, prejudiciais ao indivíduo. Dentre estes efeitos, está a eliciação de respostas emocionais desagradáveis, como culpa, medo e ansiedade (Moreira \& Medeiros, 2007). Assim, ainda que o paciente se mantenha aderindo ao tratamento para evitar a piora da doença ou até mesmo a morte, seu sofrimento emocional pode ser grande e sua qualidade de vida pode ficar prejudicada. Por isso, o ideal seria que os pacientes aderissem ao tratamento em função das consequências positivas que este lhes traz, como bem-estar e a sensação de saúde. Neste caso, apenas 14,06\% da amostra informaram que estes fatores os ajudam a aderir ao tratamento. 
A partir desta análise, há algumas contribuições que os profissionais que atendem pacientes em hemodiálise podem oferecer. Ao conversar com o paciente sobre o tratamento e orientar sobre quais comportamentos ele deve emitir, é importante ressaltar quais consequências positivas ele terá com a adesão a estas orientações. Ao invés de destacar todos os agravos que ele evitará, vale enfatizar que, aderindo às orientações, o paciente poderá sentir-se bem, ter disposição para realizar as atividades que gosta, viver por bastante tempo e presenciar momentos importantes com a família. Enfim, deve-se dar destaque aos possíveis ganhos que o paciente terá se aderir ao tratamento, ao invés de destacar as possíveis perdas no caso da má adesão. Fazendo isso, o profissional de saúde estará contribuindo para alterar o controle do comportamento do paciente e diminuir o controle aversivo em vigor, reduzindo assim as chances de problemas psicológicos e favorecendo a percepção do paciente sobre os efeitos benéficos do tratamento.

\subsection{Análise de outras associações observadas: o impacto da idade e da questão de gênero sobre a adesão ao tratamento}

Foi observada diferença estatisticamente significante entre a idade nos grupos com e sem adesão ao controle hídrico e ao tratamento como um todo, sendo que dentre os pacientes com adesão a média de idade foi superior à média do grupo de pacientes sem adesão. Ou seja, pacientes mais velhos pareceram aderir mais ao tratamento neste estudo. Esta mesma associação pôde ser observada em outros estudos, que testaram adesão a diferentes aspectos do tratamento (Kutner et al., 2002; Kugler et al., 2005; Sgnaolim et al., 2012; Iborra-Moltó, 2012).

Discute-se como possível explicação para esta associação o fato de que as pessoas idosas podem ter maior preocupação com a morte e, assim, seguir o tratamento para evita-la. Além disso, há autores que consideram que pessoas mais velhas possuem uma vida mais organizada e estruturada, na qual podem acomodar as demandas de um regime terapêutico (Snaolim et al., 2012). Entre pacientes mais jovens, pode ser comum o desejo de testar os limites do próprio corpo, adotando, para isso, comportamentos divergentes da orientação profissional (Kugler et al., 2005).

Outro aspecto importante relacionado à idade diz respeito ao autocontrole, ou seja, a capacidade do indivíduo controlar seu próprio comportamento diante de diferentes possibilidades, geralmente conflituosas. O autocontrole permite ao indivíduo fazer uma escolha que terá consequências positivas, para ele próprio ou para os outros, quando esta 
consequência está temporalmente afastada (Marchezini-Cunha \& Tourinho, 2010). Quando há autocontrole, o paciente consegue optar por tomar as medicações mesmo com a consequência imediata sendo ruim (gosto amargo, efeitos colaterais), pois fica sob controle da consequência que virá depois (bom estado de saúde, por exemplo).

Assim como toda habilidade comportamental, a capacidade de controlar seu próprio comportamento é aprendida e se desenvolve ao longo da vida dos indivíduos. Sendo assim, pode-se supor que um paciente com maior idade tenha maior probabilidade de ter sido exposto a contingências facilitadoras de autocontrole do que pacientes jovens. Ademais, com mais anos de vida, é mais provável que o paciente tenha vivido experiências em que suas escolhas diante de situações conflituosas tenham sido reforçadas e, assim, o autocontrole esteja mais bem estabelecido. No entanto, estas explicações são apenas suposições, já que não se pode afirmar se isto de fato ocorreu nesta amostra de pacientes. Para que se esclareçam quais variáveis fazem a mediação entre a idade e os comportamentos de adesão, tornam-se necessários estudos que busquem informações mais aprofundadas sobre a história de vida e aprendizagem dos pacientes mais jovens e mais idosos, bem como que coletem suas ideias e percepções sobre a doença e o tratamento.

Em relação à variável sexo, foram identificadas associações com a adesão aos aspectos HD e Dieta e Medicação. Os dados sugerem que pacientes do sexo masculino aderem mais à HD do que pacientes do sexo feminino e, ao contrário, pacientes mulheres apresentam mais adesão à dieta e medicação quando comparadas aos homens. Estes resultados contrariam os achados de Wileman et al. (2011), que avaliaram a adesão de pacientes renais crônicos aos quelantes de fósforo e identificaram que as mulheres tinham cinco vezes mais chances de não aderir ao uso desta medicação do que os homens. Em seu estudo sobre adesão à medicação em pacientes em hemodiálise, Theofilou (2012) não encontrou diferenças significantes entre os gêneros.

Não foram encontrados estudos brasileiros que avaliassem a associação entre o sexo e a adesão a estes aspectos do tratamento hemodialítico. É importante, no entanto, considerar que há no Brasil uma questão cultural que determina papéis sociais diferentes para homens e mulheres e que acaba refletindo na forma como estes dois grupos lidam com questões de saúde e doença.

Observando a caracterização sociodemográfica da amostra, nota-se um predomínio de pacientes sem atividade empregatícia $(78,13 \%)$. No caso dos homens, ter deixado de trabalhar (em função de aposentadoria ou incapacidade gerada pela doença) significa deixar de exercer seu principal papel social, já que a concepção de ser homem frequentemente está ligada ao 
trabalho (Figueiredo \& Schraiber, 2011). Sendo assim, muitas vezes o homem que não trabalha acaba também não exercendo outras funções e tendo, por isso, mais tempo livre. Ao contrário disso, a mulher - mesmo sem atividade empregatícia - é responsável por inúmeras outras tarefas, como o cuidado da casa, dos filhos e do marido. Isso porque socialmente, seu papel continua a ser o de responsável pelas tarefas domésticas e pelo bem-estar da família.

Esta questão de gênero pode indicar uma possível explicação para a diferença encontrada na adesão à HD. Ou seja, estando sem trabalhar e com mais tempo livre, os homens têm mais chances de não precisar faltar às sessões dialíticas. Em relação às mulheres, ainda que não trabalhem fora de casa, as tarefas domésticas e de cuidados com a família podem funcionar como concorrentes e aumentar as chances de faltas à HD.

Ainda sobre esta questão, a diferença encontrada entre homens e mulheres, no que diz respeito à adesão à dieta e medicação, vai de encontro a outras pesquisas brasileiras que avaliaram o padrão de cuidado com a própria saúde nestes dois grupos (Gomes, Nascimento \& Araujo, 2007; Knauth, Couto \& Figueiredo, 2012; Figueiredo \& Schaiber, 2011). No geral, encontra-se que mulheres exercem mais cuidado com a saúde e isso possivelmente se deve à sua forma de socialização. No geral, mulheres são estimuladas a cuidar de si e da família, tendo aceitas suas fragilidades, enquanto homens devem ser viris e fortes e, desde a infância, aprendem a desvalorizar fragilidades físicas. Assim, com relação aos cuidados com o tratamento que devem ser tomados em casa (como é o caso da dieta e da medicação), as mulheres parecem ter comportamento mais aderente.

A análise das diferenças no padrão de autocuidado entre os gêneros envolve, portanto, questões culturais bastante enraizadas que devem ser consideradas pelo profissional da saúde quando está diante de um paciente. Para que orientações e intervenções sejam eficazes, há que se considerar o contexto social e histórico em que o paciente está inserido já que ele é capaz de determinar como o paciente se comportará diante daquela nova condição, a de doente renal crônico.

\subsection{Prevalência de sintomas de ansiedade e depressão e percepção de suporte social: o que os dados indicam?}

A presença de sintomas de ansiedade foi observada em 25\% da amostra neste estudo, prevalência inferior aos resultados obtidos em trabalhos anteriores. Taskapan et al. (2005) avaliaram a presença de desordens psiquiátricas em uma amostra de 40 pacientes turcos em hemodiálise e identificaram a presença de transtorno de ansiedade em $30 \%$ dos pacientes. Nos 
Estados Unidos, os resultados obtidos por Cukor et al. (2008) mostraram que 45,7\% dos pacientes preencheram critério para transtorno de ansiedade, prevalência também superior à encontrada neste estudo. Analisando separadamente os aspectos traço e estado de ansiedade em pacientes renais crônicos submetidos à hemodiálise, Kohli, Batra e Aggarwal (2011) encontraram taxas elevadas: $73 \%$ dos pacientes com ansiedade-traço e $87 \%$ com ansiedadeestado. Apesar de a presença de sintomas de ansiedade observada neste estudo ter sido menor do que na literatura, ela é superior à prevalência de ansiedade na população geral desta região do país (6,9\%) (Almeida Filho et al., 1992 apud Munaretti \& Terra, 2007).

Alguns fatores relacionados ao tratamento dialítico podem facilitar o aparecimento de sintomas de ansiedade, tais como a perda de liberdade e controle sobre a vida devido à dependência da máquina, problemas de relacionamento social e deterioração do desempenho funcional (físico e mental) (Kohli, Batra \& Aggarwal, 2011). Há, também, a imprevisibilidade sobre o futuro, a possibilidade de intercorrências em todas as sessões e, por fim, a dor a que todo paciente em hemodiálise é submetido a cada punção da fístula. Ou seja, o contexto deste tratamento contém muitos elementos aversivos facilitadores de sintomas ansiosos e o conhecimento sobre formas adequadas de evitar ou tratar este problema prescinde de mais estudos, já que a literatura sobre o tema ainda é escassa.

Sobre a prevalência de sintomas de depressão, as taxas observadas neste estudo também são inferiores àquelas obtidas em pesquisas anteriores. Da amostra, apenas 12,5\% apresentaram sintomas depressivos, enquanto que em outros estudos os índices variaram de 25 a mais de $60 \%$. Su, Ng, Huang, Chi, Lee, Lai et al. (2012) avaliaram uma amostra de 320 pacientes no Taiwan e encontraram sintomas de depressão em 43,1\% dos pacientes em hemodiálise. Com o uso de notas de corte diferentes, Khalil et al. (2011) obtiveram taxas de depressão que variaram de 33 a 66\% na amostra de pacientes em hemodiálise da Jordânia. Rosenthal-Asher, Ver-Halen e Cukor (2012) avaliaram 130 pacientes de uma unidade norteamericana e identificaram que 44,61\% da amostra apresentaram depressão moderada ou grave.

No Brasil, Macuglia et al. (2010), em amostra de 49 pacientes em hemodiálise, obtiveram taxa de $28,6 \%$ de depressão leve ou moderada e em estudo realizado com 30 pacientes do sul do país, obteve-se taxa de depressão leve ou moderada de 33,3\% (Nifa \& Rudnicki, 2010). Ainda no sul do país, Finger et al. (2011) estudaram a prevalência de depressão em uma amostra de 64 pacientes em hemodiálise e observaram que 44,8\% dos pacientes apresentavam sintomas. 
A comparação dos resultados com a literatura deve ser feita de forma cautelosa, considerando-se as diferenças metodológicas identificadas nos estudos. A principal diferença se refere ao instrumento de avaliação psicológica utilizado: há uma diversidade de testes psicométricos que avaliam a presença de sintomas de ansiedade e depressão e, apesar de passarem por processos de validação e normatização, nem sempre a homogeneidade do constructo medido existe.

Na presente pesquisa optou-se por usar a Escala Hospitalar de Ansiedade e Depressão (HAD) em função dos tipos de sintoma que ela avalia em seus itens. Nesta escala, elaborada para o uso em situações de comorbidade física, não são incluídos itens sobre os sintomas físicos da ansiedade e depressão, como palpitação, desconforto no abdômen, tremores e perda de peso, por exemplo. Estes sintomas estão presentes em outras escalas, como as escalas Beck de ansiedade e depressão e no caso dos pacientes com IRC, podem ser confundidos com sintomas da própria doença. Sendo assim, optou-se pela utilização de um instrumento que abordasse os sintomas emocionais e cognitivos destes transtornos e por isso, a HAD pareceu mais apropriada.

O consenso sobre as medidas de avaliação psicológica mais adequadas para pacientes em hemodiálise depende ainda de novos estudos, especialmente no Brasil. Internacionalmente, tem havido grande preocupação relacionada a isto entre os estudiosos da área, mas os resultados são contraditórios. Cukor et al. (2008), em um estudo que comparou duas medidas de ansiedade - a Entrevista Clínica Estruturada para Diagnóstico do Eixo I do DSM-IV (SCID-I) e a HAD, não verificou concordância entre os resultados obtidos com os dois instrumentos e os autores concluíram que a HAD parece ter um fraco poder preditivo para o diagnóstico de ansiedade em pacientes renais crônicos. Entretanto, Preljevic et al. (2012), avaliaram três instrumentos de triagem de sintomas de ansiedade e depressão e concluíram que tanto o Inventário Beck de Depressão (BDI), quanto a SCID-I e também a HAD são ferramentas apropriadas para a identificação de sintomas de depressão e, no caso da subescala da HAD, de ansiedade, em pacientes em hemodiálise. Portanto, mostra-se necessário que novas pesquisas sejam realizadas a fim de testar a eficácia e a adequação destes instrumentos de avaliação psicológica na população de doentes renais.

Sobre as taxas de ansiedade e depressão obtidas neste estudo terem sido inferiores às encontradas na literatura, podem-se levantar algumas hipóteses que justifiquem estes achados. Primeiramente, verifica-se que alguns dados clínicos podem ter exercido influência sobre a taxa de prevalência. A média de tempo de tratamento na amostra foi elevada, de 65,38 meses ou mais de cinco anos. Isso indica que o período de adaptação, em que se vivencia com mais 
intensidade os sentimentos de medo e perdas, já havia passado para grande parte dos pacientes. Os resultados demonstram que a maior parte da amostra parece ter conseguido se adaptar ao tratamento, de forma que este não gerasse os sintomas de morbidade psicológica.

Outra variável clínica que pode ter contribuído para os baixos índices de sintomas ansiosos e depressivos é a taxa de intercorrências e hospitalizações no período analisado. Como já foi exposto, os registros nos prontuários médicos revelaram que apenas cinco pacientes haviam apresentado intercorrências durante as sessões dialíticas e nenhum havia sido hospitalizado devido à IRC. Sem definir o que é a causa e o que é a consequência, podese supor que estas variáveis estariam relacionadas com os resultados indicativos de boa saúde mental na maior parcela da amostra.

Além destas variáveis clínicas, deve-se analisar a variável suporte social, estudada a partir da avaliação do relacionamento com a equipe de saúde da unidade e também a partir da Escala de Apoio Social (MOS). A boa avaliação que os pacientes fizeram de seu relacionamento com a equipe médica, de enfermagem e nutrição da unidade indica que para este grupo de pacientes o apoio recebido pelos profissionais é satisfatório e contribui para a boa adaptação ao tratamento. Os resultados da escala MOS confirmam que a percepção de apoio social dos pacientes da amostra é alta, já que os resultados ficaram acima da média em todas as dimensões.

Não foram testadas estatisticamente as associações entre suporte social, ansiedade e depressão, nem foram comparados os grupos de pacientes com e sem sintomas psicológicos em relação às variáveis clínicas. Isso porque os objetivos deste estudo se focam na associação destas variáveis com a adesão dos pacientes ao tratamento. No entanto, futuramente novos testes podem ser aplicados a estas variáveis para buscar maior compreensão da caracterização psicológica e ampliar o conhecimento dos aspectos psicológicos em pacientes em hemodiálise.

O teste que investigou associações entre as variáveis ansiedade e depressão e a adesão ao tratamento revelou poucas associações estatisticamente significantes. Para a maior parte dos aspectos do tratamento não houve associação com estas variáveis psicológicas. Quando encontrada associação, esta foi inversa à hipótese que se tinha: a associação entre depressão e adesão ao controle hídrico indicou que no grupo de pacientes sem adesão, uma porcentagem significantemente maior de pacientes não apresentou sintomas de depressão.

Estes resultados contrariam os achados da literatura, que demonstram haver uma relação inversa entre sintomas depressivos e ansiosos e adesão ao tratamento (Kimmel et al., 1998b; Kutner et al., 2002; Zimmermann et al., 2004; Taskapan, et al., 2005; Akman et al., 
2007; Cé et al., 2008; Khalil \& Frazier, 2010). Esta diferença pode ser devida ao pequeno número de pacientes nos grupos com ansiedade e com depressão (16 e 8 , respectivamente). $\mathrm{Na}$ análise estatística, este pequeno tamanho amostral dos grupos pode ter influenciado os resultados dos testes. Para desfazer esta dúvida, sugere-se que estudos com maior número de participantes sejam realizados no Brasil, avaliando a relação das variáveis psicológicas com a adesão à hemodiálise.

De qualquer forma, ainda que tenham sido identificados menos casos de depressão e ansiedade do que na literatura, vale ressaltar a importância do diagnóstico e tratamento de transtornos psicológicos em pacientes renais crônicos, tendo em vista suas implicações sobre a qualidade de vida e respostas clínicas, como hospitalização e mortalidade destes indivíduos (Kimmel et al., 1998a; Almeida \& Meleiro, 2000; Zimmermann et al., 2004; Macuglia et al., 2010; Rosenthal-Asher et al., 2012).

Com relação ao apoio social, seu impacto sobre a adesão ao tratamento foi observado somente em relação à adesão à HD, em que os pacientes com adesão apresentaram escore de apoio social superior ao obtido pelos participantes sem adesão. Em pesquisas anteriores, observou-se associação entre apoio social e outros aspectos do tratamento, como dieta, medicação e controle hídrico (Cicolini et al., 2012; Untas et al., 2012).

As ideias levantadas por estes dados remetem, mais uma vez, à boa avaliação que os pacientes fizeram sobre seu relacionamento com a equipe de profissionais da unidade. Pacientes que comparecem mais às sessões de $\mathrm{HD}$, ou seja, que têm mais adesão a este aspecto do tratamento, acabam por conviver mais com estes profissionais e assim, podem se sentir mais apoiados por eles. Não se pode definir qual variável causa a outra, mas esta relação pode ser explicada pelo apoio social recebido dos profissionais da saúde, o qual pode estar incluído nas respostas à escala MOS, já que esta não restringe a fonte do apoio social percebido.

Incorporar nas avaliações e ações da equipe multidisciplinar a análise sobre a rede de apoio existente na vida dos pacientes é importante, pois amplia a visão sobre o indivíduo, enxergando-o também como um ser social. Ademais, o apoio social parece associado a respostas clínicas e qualidade de vida nesta população, conforme demonstraram os estudos de Rudnicki (2007), Spinale et al. (2008), Platinga et al. (2010) e Rambod e Rafii (2010).

\subsection{Em busca do bem estar biopsicossocial: estratégias de intervenção com pacientes renais crônicos em hemodiálise}


Tendo em vista a relevância destes aspectos psicológicos para a saúde e o bem estar dos pacientes em hemodiálise, alguns pesquisadores tem buscado encontrar estratégias eficazes de prevenção e tratamento aos distúrbios de ordem emocional. Duarte, Miyazaki, Blay e Sesso (2009) relataram uma experiência bem sucedida de intervenção psicológica para o tratamento de depressão em pacientes em hemodiálise. A terapia em grupo baseada na abordagem cognitivo-comportamental se mostrou eficiente para reduzir os escores de depressão em uma amostra de 41 pacientes brasileiros.

Esta mesma abordagem também tem se mostrado eficiente em intervenções que buscam elevar a adesão dos pacientes renais crônicos aos diferentes aspectos do tratamento. Uma revisão sistemática realizada por Matteson e Russell (2010) analisou estudos sobre este tipo de intervenção com pacientes adultos em hemodiálise. Os estudos foram variados, com diferentes tamanhos amostrais, características dos participantes e formações do profissional que conduzia as intervenções. Dos oito trabalhos que preencheram os critérios para inclusão, seis encontraram resultados significativos na melhora da adesão dos pacientes, tanto na adesão à dieta e medicação quanto na adesão ao controle hídrico e à hemodiálise. Estes seis estudos continham componentes cognitivos em suas estratégias, sendo que três deles se utilizavam de técnicas cognitivo-comportamentais. As autoras concluíram que as intervenções baseadas no modelo cognitivo ou cognitivo-comportamental parecem ser as mais promissoras, mas que novos estudos se fazem necessários (Matteson \& Russell, 2010).

Um modelo de intervenção cognitivo-comportamental para aumentar a adesão dos pacientes às restrições hídricas foi apresentado por Sharp, Wild, Gumley e Deighan (2005). As intervenções foram realizadas em grupos de três a oito pacientes, semanalmente, por quatro semanas, e conduzidas por um psicólogo. Possuíam componentes educativos (sobre a importância das restrições hídricas), comportamentais (com estratégias de automonitoramento, manejo de ambiente e autocontrole) e cognitivos (identificação de crenças e pensamentos). A análise longitudinal dos indicadores de adesão revelou que, após a intervenção grupal, houve redução na média de GPID, indicando melhora na adesão ao controle hídrico dos pacientes da amostra (Sharp et al., 2005).

Outro modelo de intervenção baseado em técnicas de autocontrole foi aplicado em pacientes com baixa adesão ao controle hídrico e descrito por Christensen et al. (2002). Partindo do princípio de que estratégias para aumentar o autocontrole incluem automonitoramento, autoavaliação e autorreforçamento, a intervenção grupal incluía tarefas de registro de comportamento, estabelecimento de metas e recompensas para o próprio comportamento. Como resultados, os autores observaram um aumento na adesão ao controle 
hídrico na avaliação de oito semanas após o término dos grupos, quando comparados aos pacientes do grupo controle (Christensen et al., 2002).

Vale considerar que estas ações, voltadas para o desenvolvimento de habilidades cognitivas e comportamentais para aumentar a adesão ao tratamento, devem ser planejadas para atender os pacientes em um momento anterior, antes de a doença renal ter avançado ao estágio mais grave. Em primeiro lugar, porque o controle das doenças de base pode prevenir o aparecimento da doença renal terminal. Também porque, nos casos em que a evolução para a IRC não puder ser evitada, o comportamento aderente ao tratamento da doença de base pode facilitar a adesão do paciente ao novo tratamento, de hemodiálise. Como se viu neste estudo, há uma associação entre a adesão dos pacientes à hemodiálise e a história de adesão a outros tratamentos. Entre os pacientes sem adesão ao tratamento dialítico, a maioria também não aderia ao tratamento da doença de base. Portanto, estratégias eficazes de atenção ao paciente pouco aderente devem ser adotadas em todos os contextos de saúde, no sentido de ampliar o repertório de autocuidado deste paciente e facilitar sua adesão a qualquer tipo de tratamento.

Apesar dos resultados animadores quanto à eficácia dos programas de intervenção, não se pode perder de vista o real objetivo do serviço prestado ao paciente renal: seu bem estar biopsicossocial. É claro que, se for observado que a falta de adesão ao tratamento é resultado de um déficit comportamental e de dificuldades de manejo que o próprio paciente deseja superar, deve-se empreender todos os esforços buscando auxiliá-lo na melhor adesão. No entanto, existem casos em que boa adesão e quadro clínico compensado não significam satisfação com a vida.

A visão de que a saúde física é a meta a ser alcançada pelos profissionais da saúde deve ser superada e substituída pela visão do indivíduo completo, com seus sentimentos, relações sociais, ideias sobre o que é ser saudável e sobre o que é viver bem. Deve-se lembrar que aderir ou não ao tratamento é uma escolha que cabe ao paciente. Aos profissionais, cabe oferecer condições para que ele faça esta escolha de forma consciente e responsável, considerando todos os riscos associados a ela. Quando não há perigo para a saúde pública (no caso de doenças altamente infecciosas, por exemplo), não se pode obrigar a pessoa doente a aceitar todas as propostas que, tecnicamente justificadas, lhe são feitas. Respeitar a autonomia do paciente é garantir seu direito de poder recusar e manifestar suas escolhas, ainda que estas não reflitam a opinião da equipe de saúde (Pinheiro, 2011).

Portanto, o estudo da adesão ao tratamento e de seus determinantes é muito importante, pois possibilita a ampliação do conhecimento sobre este complexo constructo, bem como a elaboração de estratégias eficazes de atendimento aos pacientes. Identificar 
características nos pacientes que possam ser indicadoras de dificuldades para aderir ao tratamento pode ser útil para programar assistência mais precoce e prevenir agravos relacionados à baixa adesão. No entanto, as conclusões devem ser tiradas com cautela, sem perder de vista as diferenças individuais e a necessidade de avaliação específica, para não correr o risco de agir com discriminação diante de um paciente que, a priori, apresente características comumente encontradas em pacientes com má adesão. Sabe-se que o comportamento humano é multideterminado, sofre influências da cultura, de fatores filogenéticos e de experiências passadas, e deve ser simplificado apenas para que se torne possível estudá-lo. 


\section{CONSIDERAÇÕES FINAIS}

Este trabalho teve o objetivo de medir a adesão ao tratamento de pacientes em hemodiálise e analisar sua relação com variáveis sociodemográficas, clínicas e psicológicas. A complexidade do tema foi evidenciada pelos resultados, que requerem extensa análise para o estabelecimento de conclusões. Foi possível observar que o paciente renal crônico encontra dificuldades para aderir totalmente ao tratamento de hemodiálise, pois este é composto por diferentes aspectos que exigem mudanças comportamentais distintas. Apesar de sua natureza quantitativa, este estudo permitiu conhecer a visão dos pacientes sobre as maiores dificuldades do tratamento e possibilitará, para o futuro, a elaboração de ações apropriadas às demandas levantadas por eles.

Entretanto, algumas limitações desta pesquisa devem ser consideradas. Primeiramente, o caráter descritivo do estudo não permite conclusões que descrevam relações de causa e efeito entre as variáveis. Tais conclusões são fruto de pesquisas experimentais, com maior controle de variáveis, que se mostraram, neste contexto, pouco viáveis. Enquanto estudo descritivo, este trabalho permitiu, no máximo, a possibilidade de se evidenciarem associações. Ademais, devido ao grande número de variáveis incluídas, não foi possível uma investigação mais aprofundada de suas relações, o que pode ser feito em estudos futuros. Por fim, vale destacar uma limitação inerente aos estudos sobre adesão ao tratamento, também presente nesta pesquisa: as medidas biológicas e comportamentais consideradas são apenas indicadoras de adesão. Não há como garantir que um paciente cujos indicadores são insatisfatórios, de fato não adere ao tratamento. Existem inúmeras variáveis, algumas pouco compreendidas, que tornam individuais as respostas biológicas à terapêtica. Por isso, o desafio de desenvolver técnicas mais eficazes de se avaliar a adesão ao tratamento permanece e também é sugestão para estudos futuros nesta área.

Apesar destas limitações, este trabalho contribui para ampliar a percepção do paciente renal crônico para além de suas necessidades físicas e biológicas, e a visão sobre a adesão ao tratamento para além de uma questão de "vontade" do paciente. É ressaltada a importância da boa relação terapêutica e do respeito aos sentimentos, preferências e à autonomia dos pacientes. Diante desta visão ampliada, destaca-se a importância das equipes interdisciplinares nas unidades de hemodiálise, com profissionais da Nutrição, Serviço Social, Terapia Ocupacional, Fisioterapia e Psicologia (Magacho et al., 2011). Particularmente, os psicólogos têm grande contribuição a oferecer ao paciente renal crônico, pois têm na sua formação treino para realizar escuta empática e não punitiva, validar e acolher expressão de 
sentimentos e modificar comportamentos que tragam prejuízos aos pacientes. Contribui de maneira especial o analista do comportamento, pois examina o ambiente do paciente e as relações que seu comportamento estabelece com este ambiente, manejando as contingências para promover melhor adaptação e mais satisfação.

É, portanto, necessário que a Psicologia, enquanto disciplina participante das equipes de Nefrologia, se fortaleça e amplie cada vez mais sua atuação frente a estes pacientes. Para isso, mais conhecimento precisa ser produzido - especialmente no Brasil - e a prática precisa ser sistematizada e testada, no sentido de se aprimorar e auxiliar os pacientes na busca pela qualidade de vida. 


\section{REFERÊNCIAS ${ }^{1}$}

Agresti, A. (1990). Categorical Data Analysis. New York: John Wiley.

Akman, B., Uyar, M., Afsar, B., Sezer, S., Ozdemir, F. N., \& Haberal, M. (2007). Adherence, depression and quality of life in patients on a renal transplantation waiting list. Transplant International, 20(8), 682-687.

Almeida, A. M., \& Meleiro, A. M. A. S. (2000). Revisão: depressão e insuficiência renal crônica: uma revisão. Jornal Brasileiro de Nefrologia, 22(1), 192-200.

Almeida Filho, N., Mari, J. J., Coutinho, E., França, J. F., Fernandes, J. G., Andreoli, S. B. et al. (1992). Estudo multicêntrico de morbidade psiquiátrica em áreas urbanas brasileiras (Brasília, São Paulo, Porto Alegre). Revista da Associação Brasileira de Psiquiatria, 14(3), 93-104.

Arenas, M. D., Malek, T., Gil, M. T., Moledous, A., Alvarez-Ude, F., \& Reig-Ferrer, A. (2010). Challenge of phosphorus control in hemodialysis patients: a problem of adherence? Journal of Nephrology, 23(5), 525-534.

Associação Brasileira de Transplante de Órgãos. Manual de Transplante Renal. Recuperado em 10 de maio de 2011, de http://www.abto.org.br.

Assunção, T. S., \& Ursine, P. G. S. (2008). Estudo de fatores associados à adesão ao tratamento não farmacológico em portadores de diabetes mellitus assistidos pelo Programa Saúde da Família, Ventosa, Belo Horizonte. Ciência \& Saúde Coletiva, 13(sup2), 2189-2197.

Biasoli-Alves, Z. M. M. (1998). A pesquisa psicológica: análise de métodos e estratégias na construção de um conhecimento que se pretende científico. In: G. Romanelli \& Z.M.M. Biasoli-Alves (Orgs), Diálogos metodológicos sobre prática de pesquisa, Ribeirão Preto.

Borges, L. R., \& Martins, D. G. (2001). Clínica de hemodiálise: existe qualidade de vida? Boletim de Iniciação Científica em Psicologia, 2(1), 42-58.

\footnotetext{
${ }^{1}$ De acordo com "Diretrizes para Apresentação de Dissertações e Teses da USP: documento eletrônico impresso - Parte II (APA)".
} 
Botega, N. J., Pondé, M. P., Medeiros, P., Lima, M. G., \& Guerreiro, C. A. M. (1998). Validação da Escala Hospitalar de Ansiedade e Depressão (HAD) em pacientes epilépticos ambulatoriais. Jornal Brasileiro de Psiquiatria, 47(6), 285-289.

Busnello, R. G., Melchior, R., Faccin, C., Vettori, D., Petter, J., Moreira, L. B. et al. (2001). Características associadas ao abandono do acompanhamento de pacientes hipertensos atendidos em um ambulatório de referência. Arquivos Brasileiros de Cardiologia, 76(5), 349-351.

Campos, C. J. G., \& Turato, E. R. (2003). A equipe de saúde, a pessoa com doença renal em hemodiálise e suas relações interpessoais. Revista Brasileira de Enfermagem, 56(5), 508-512.

Caprara, A., \& Rodrigues, J. (2004). A relação assimétrica médico-paciente: repensando o vínculo terapêutico. Ciência \& Saúde Coletiva, 9(1), 139-146.

Carlos, P. R., Palha, P. F., Veiga, E. V., \& Beccaria, L. M. (2008). Perfil de hipertensos em um núcleo de saúde da família. Arquivos de Ciências da Saúde, 15(4), 176-181.

Casey, J., Johnson, V., \& McClelland, P. (2002). Impact of stepped verbal and written reinforcement of fluid balance advice within an outpatient haemodialysis unit: a pilot study. Journal of Human Nutrition and Dietetics, 15, 43-47.

Castro, R. A. A., Moncau, J. E. C., \& Marcopito, L. F. (2007). Prevalência de Hipertensão Arterial Sistêmica na Cidade de Formiga - MG. Arquivos Brasileiros de Cardiologia, 88(3), 334-339.

Cavalcante, M. C. V., Lamy, Z. C., Lamy Filho, F., França, A. K. T. C., Santos, A. M., Thomaz, E. B. A. F., et al. (2013). Fatores associados à qualidade de vida de adultos em hemodiálise em uma cidade do nordeste do Brasil. Jornal Brasileiro de Nefrologia, 35(2), 79-86.

Cé, H. H., Kamile, Z. B., Ceza, M. R., \& Filla, S. (2008). Prevalência de transtornos depressivos em pacientes submetidos à hemodiálise em dois serviços de nefrologia na cidade de Criciúma. Arquivos Catarinenses de Medicina, 37(4), 12-15.

Christensen, A. J., Moran, P. J., Wiebe, J. S., Ehlers, S. L., \& Lawton, W. J. (2002). Effect of a behavioral self-regulation intervention on patient adherence in hemodialysis. Health Psychology, 21(4), 393-397. 
Cicolini, G., Palma, E., Simonetta, C., \& Di Nicola, M. (2012). Influence of family carers on haemodialyzed patients' adherence to dietary and fluid restrictions: an observational study. Journal of Advanced Nursing, 68(11), 2410-2417.

Cohen, J. A. (1960). Coefficient of Agreement for Nominal Scales. Educational and Psychological Measurement, 20, 37-46.

Conover, W.J. (1980). Practical Nonparametric Statistics. Second Edition. New York: Wiley.

Cukor, D., Coplan, J., Brown, C., Friedman, S., Newville, H., Safier, M., et al. (2008). Anxiety disorders in adults treated by hemodialysis: a single-center study. American Journal of Kidney Diseases, 52(1), 128-136.

De Figueiredo, R. M., Sinkoc, V. M., Tomazim, C. C., Gallani, M. C., \& Colombrini, M. R. (2001). AIDS patients' compliance with antiretroviral treatment: notified difficulties and measures for improvement at a teaching hospital. Revista Latino-Americana de Enfermagem, 9(4), 50-55.

Denhaerynck, K., Manhaeve, D., Dobbels, F., Garzoni, D., Nolte, C., \& de Geest, S. (2007). Prevalence and consequences of nonadherence to hemodialysis regimens. American Journal of Critical Care, 16(3), 222-236.

Duarte, P. S., Miyazaki, M. C., Blay, S. L., \& Sesso, R. (2009). Cognitive-behavioral group theraoy is na effective treatment for major depression in hemodialysis patients. Kidney International, 76, 414-421.

Durosa, C. L., Holdsworth, M., Watson, V., \& Przygrodzka, F. (2004). Knowledge of dietary restrictions and the medical consequences of noncompliance by patients on hemodialysis are not predictive of dietary compliance. Journal of the American Dietetic Association, 104(1), 35-41.

Feroze, U., Martin, D., Kalantar-Zadeh, K., Kim, J. C., Reina-Patton, A., \& Kopple, J. D. (2012). Anxiety and Depression in Maintenance Dialysis Patients: Preliminary Data of a Cross-sectional Study and Brief Literature Review. Journal of Renal Nutrition, 22(1), 207-210.

Figueiredo, W. S., \& Schraiber, L. B. (2011). Concepções de gênero de homens usuários e profissionais de saúde de serviços de atenção primária e os possíveis impactos na saúde da população masculina, São Paulo, Brasil. Ciência \& Saúde Coletiva, 16(Supl.1), 935944. 
Finger, G., Pasqualotto, F. F., Marcon, G., Medeiros, G. S., Abruzzi Junior, J., \& May, W. S. (2011). Sintomas depressivos e suas características em pacientes submetidos a hemodiálise. Revista da AMRIGD, 55(4), 333-338.

Girotto, E., Andrade, S. M., Cabrera, M. A. S., \& Matsuo, T. (2013). Adesão ao tratamento farmacológico e não farmacológico e fatores associados na atenção primária da hipertensão arterial. Ciência \& Saúde Coletiva, 18(6), 763-772.

Gomes, R., Nascimento, E. F., \& Araujo, F. C. (2007). Por que os homens buscam menos os serviços de saúde do que as mulheres? As explicações de homens com baixa escolaridade e homens com ensino superior. Cadernos de Saúde Pública, 23(3), 565574.

Griep, R. H., Chor, D., Faesrtein, E., \& Lopes, C. (2003). Apoio social: confiabilidade teste reteste de escala no estudo pró-saúde. Caderno de Saúde Pública, 19(2), 625-634.

Griep, R. H., Chor, D., Faerstein, E., Werneck, G. L., \& Lopes, C. S. (2005). Validade de constructo de escala de apoio social do Medical Outcomes Study adaptada para o português no Estudo Pró-Saúde. Caderno de Saúde Pública, Rio de Janeiro, 21(3), 703714.

Griva, K., Ng, H. J., Loei, J., Mooppil, N., McBain, H., \& Newman, S. P. (2013). Managing treatment for end-stage renal disease - a qualitative study exploring cultural perspectives on facilitators and barriers to treatment adherence. Psychology and Health, 28(1), 13-29.

Guedes, M. L. (2001). O comportamento governado por regras na prática clínica: um início de reflexão. In R. A. Banaco, et al. (Orgs.), Sobre comportamento e cognição: aspectos teóricos, metodológicos e de formação em análise do comportamento e terapia cognitivista. (pp.555). Santo André, SP: ESETec.

Gus, I., Harzheim, E., Zaslavsky, C., Medina, C., \& Gus, M. (2004). Prevalência, reconhecimento e controle da Hipertensão Arterial Sistêmica no estado do Rio Grande do Sul. Arquivos Brasileiros de Cardiologia, 83(5), 424-428.

Gusmão, J. L., \& Mion Junior, D. (2006). Adesão ao tratamento - conceitos. Revista Brasileira de Hipertensão, 13(1), 23-25.

Hartman, M., Dias-da-Costa, J. S., Olinto, M. T. A., Pattussi, M. P., \& Tramontini, A. (2007). Prevalência de hipertensão arterial sistêmica e fatores associados: um estudo de base 
populacional em mulheres no Sul do Brasil. Cadernos de Saúde Pública, 23(8), 18571866.

Hübner, M. M. C. (2001). Comportamento verbal e prática clínica. In: R.A. Banaco, et al. (Orgs.), Sobre comportamento e cognição: aspectos teóricos, metodológicos e de formação em análise do comportamento e terapia cognitivista. (pp.555). Santo André, SP: ESETec.

Iborra-Moltó, C., López-Roig, S., \& Pastor, M. A. (2012). Prevalence of adherene to fluid restriction in kidney patients in haemodialysis: objective indicator and perceived compliance. Revista Nefrologia, 32(4), 477-485.

Kaveh, K., \& Kimmel, P. L. (2001). Compliance in hemodialysis patients: multidimensional measures in search of a gold standard. American Journal of Kidney Disease, 37(2), 244266.

Khalil, A. A., \& Frazier, S. K. (2010). Depressive Symptoms and Dietary Nonadherence in Patients with End-Stage Renal Disease Receiving Hemodialysis: a review of quantitative evidence. Issues in Mental Health Nursing, 31, 324-330.

Khalil, A. A., Frazier, S. K., Lennie, T. A., \& Sawaya, B. P. (2011). Depressive symptoms and dietary adherence in patients with end-stage renal disease. Journal of Renal Care, $37(1), 30-39$.

Kimmel, P. L., Peterson, R. A., Wheis, K. L., Simmens, S. J., Boyle, D. H., Verme, D., et al. (1995). Behavioral compliance with dialysis prescription in hemodialysis patients. Journal of the American Society of Nephrology, 5, 1826-1834.

Kimmel, P. L., Thamer, M., Richard, C. M., \& Ray, N.F. (1998a). Psychiatric Illness in Patients with End-Stage Renal Disease. The American Journal of Medicine, 105, 214221.

Kimmel, P. L., Peterson, R.A., Weihs, K.L., Simmens, S.J., Alleyne, S., Cruz, I., et al. (1998b). Psychossocial factors, behavioral compliance and survival in urban hemodialysis patients. Kidney International, 54, 245-254.

Kimmel, P. L. (2001). Psychosocial factors in dialysis patients. Kidney International, $59,1599-1613$. 
Knauth, D. R., Couto M. T., \& Figueiredo, W. S. (2012). A visão dos profissionais sobre a presença e as demandas dos homens nos serviços de saúde: perspectivas para a análise da implantação da Política Nacional de Atenção Integral à Saúde do Homem. Ciência \& Saúde Coletiva,17(10), 2617-2626.

Kohli, S., Batra, P., \& Aggarwal, H. K. (2011). Anxiety, lócus of control and coping strategies among end-stage renal disease patientes undergoing maintenance hemodialysis. Indian Journal of Nephrology, 21(3), 177-181.

Kovac, J. A., Patel, S. S., Peterson, R. A., \& Kimmel, P. L. (2002). Patient satisfaction with care and behavioral compliance in end-stage renal disease patients treated with hemodialysis. American Journal of Kidney Diseases, 39(6), 1236-1244.

Koo, J. R., Yoon, J. W., Kim, S. G., Lee, Y. K., Oh, K. H., Kim, G. H., et al. (2003). Association of Depression With Malnutrition in Chronic Hemodialysis Patients. American Journal of Kidney Diseases, 41(5), 1037-1042.

Kugler, C., Vlaminck, H., Haverich, A., \& Maes, B. (2005). Nonadherence with diet and fluid restrictions among adults having hemodialysis. Journal of Nursing Scholarship, $1^{\text {st }}$ quarter, 25-29.

Kugler, C., Maeding, I., \& Russell, C. L. (2011). Non-adherence in patients on chronic hemodialysis: an international comparison study. Journal of Nephrology, 24(3), 366375 .

Kutner, N. G., Zhang, R., McClellan, W., \& Cole, S. A. (2002). Psychosocial predictors of non-compliance in haemodialysis and peritoneal dialysis patients. Nephrology Dialysis and Transplantation, 17(1), 93-99.

Landis, R. J., \& Koch, G.G. (1977) The Measurement of Observer Agreement for Categorical Data. Biometrics, 33, 159-174.

Law, M. (2002). Participation in the occupations everyday life. American Journal of Occupational Therapy, 56(6), 640-9.

Macuglia, G. R., Caillava, F., Teixeira, R. M. A. P., \& Giacomoni, C. H. (2010). Qualidade de vida e depressão de pacientes em hemodiálise. Revista Brasileira de Terapias Cognitivas, 6(2), 167-188. 
Madeiro, A. C., Machado, P. D. L. C., Bonfim, I. M., Braqueais, A. R., \& Lima, F. E. T. (2010). Adesão de portadores de insuficiência renal crônica ao tratamento de hemodiálise. Acta Paulista de Enfermagem, 23(4), 546-51.

Magacho, E. J. C., Ribeiro, L. C., Chaobah, A., \& Bastos, M. G. (2011). Adherence to drug therapy in kidney disease. Brazilian Journal of Medical and Biological Research, 44, 258-262.

Maldaner, C. R., Beuter, M., Brondani, C. M., Budó, M. L. D., \& Pauletto, M. R. (2008). Fatores que influenciam a adesão ao tratamento na doença renal crônica: o doente em terapia hemodialítica. Revista Gaúcha de Enfermagem, 29(4), 647-653.

Malerbi, F. E. K. (2000). Adesão ao tratamento. In R. R. Kerbauy (Org.), Sobre Comportamento e Cognição: conceitos, pesquisa e aplicação, a ênfase no ensinar, na emoção e no questionamento clínico (pp.305). Santo André, SP: ESETec.

Manley, M., \& Sweeney, J. (1986). Assessment of compliance in hemodialysis adaptation. Journal of Psychosomatic Research, 30(2), 153-161.

Marchezini-Cunha, V., \& Tourinho, E. Z. (2010). Assertividade e Autocontrole: interpretação analítico-comportamental. Psicologia: Teoria e Pesquisa, 26(2), 295-304.

Martins, M. R. I, \& Cesarino, C. B. (2005). Qualidade de vida de pessoas com doença renal cronica em tratamento hemodialítico. Revista Latino- americana de Enfermagem, 13(5), 670-676.

Matteson, M. L., \& Russell, C. (2010). Interventions to improve hemodialysis adherence: a systematic review of randomized-controlled trials. Hemodialysis International, 14, 370382

Menezes, C. L., Maia, E. R., \& Lima Junior, J. F. (2007). O impacto da hemodiálise na vida dos portadores de insuficiência renal crônica: uma análise a partir das necessidades humanas básicas. Nursing, 10(115), 570-576.

Miller, N. H., Hill, M., Kottke, T., \& Ockene, I. S. (1997). The multilevel compliance challenge: recommendations for a call to action. A statement for health care professionales. Circulation, 95, 1085-1090.

Ministério da Saúde (2009). Recuperado em 26 de junho de 2011, de http://www.saude.gov.br. 
Morales López, C., Burrowes, J. D., Gizis, F., \& Brommage, D. (2007). Dietary adherence in Hispanic patients receiving hemodialysis. Journal of Renal Nutrition, 17(2), 138-147.

Moreira, M. B., \& Medeiros, C.A. (2007). Princípios básicos da Análise do Comportamento. Porto Alegre: Artmed.

Munaretti, C. L., \& Terra, M. B. (2007). Transtornos de ansiedade: um estudo de prevalência e comorbidade com tabagismo em um ambulatório de psiquiatria. Jornal Brasileiro de Psiquiatria, 56(2), 108-115.

Nerbass, F. B., Morais, J. G., Dos Santos, R. G., Krüger, T. S., Koene, T. T., \& Da Luz Filho, H. A. (2010). Adesão e conhecimento sobre o tratamento da hiperfosfatemia de pacientes hiperfosfatêmicos em hemodiálise. Jornal Brasileiro de Nefrologia, 32(2), 149-155.

Nerbass, F. B., Morais, J. G., Dos Santos, R. G., Krüger, T. S., Koene, T. T., \& Da Luz Filho, H. A. (2011). Fatores relacionados ao ganho de peso interdalítico em pacientes em hemodiálise. Jornal Brasileiro de Nefrologia, 33(3), 300-305.

Nifa, S., \& Rudnicki, T. (2010). Depressão em pacientes renais crônicos em tratamento de hemodiálise. Revista da SBPH, 13(1), 64-75.

Organização Mundial de Saúde. (2003). Adherence to long-term therapies: evidence for action. Recuperado em 17 de janeiro de 2013, de http:/whqlibdoc.who.int/publications/2003/9241545992.pdf.

Passos, V. M. A., Barreto, S. M., \& Lima-Costa, M. F. F., The Bambuí Health and Ageing Study (BHAS) Group. (2003). Detection of renal dysfunction based on serum creatinine levels in a Brazilian community. The Bambuí Health and Ageing Study Brazilian Journal of Medical and Biological Research, 36, 393-401.

Pedroso, R. S, \& Sbardelloto, G. (2008). Qualidade de vida e suporte social em pacientes renais crônicos: revisão teórica. Psicópio: Revista Virtual de Psicologia Hospitalar e da Saúde, 4(7), 32-35.

Pinheiro, J. (2011). Autonomia e aderência na pessoa com doença renal crônica. Revista Bioética, 19(1), 219-229. 
Plantinga, L. C., Fink, N. E., Harrington-Levey, R., Finkelstein, F. O., Hebah, N., Powe, N. R., et al. (2010). Association of Social Support with Outcomes in Incident Dialysis Patients. Clinical Journal of The American Society of Nephrology, 5, 1480-1488.

Rambod, M., \& Rafii, F. (2010). Perceived Social Support and Quality of Life in Iranian Hemodialysis Patients. Journal of Nursing Scholarship, 42(3), 242-249.

Resende, M. C., Santos, F. A., Souza, M. M., \& Marques, T. P. (2007). Atendimento psicológico a pacientes com insuficiência renal crônica: em busca do ajustamento psicológico. Psicologia Clínica, 19(2), 87-99.

Ribeiro, M. C. S. A., Barata, R. B., Almeida, M. F., \& Silva, Z. P. (2006). Perfil sociodemográfico e padrão de utilização de serviços de saúde para usuários e nãousuários do SUS - PNAD 2003. Ciência \& Saúde Coletiva, 11(4), 1011-1022.

Romão Junior, J. E. (2004). Doença Renal Crônica: definição, epidemiologia e classificação. Jornal Brasileiro de Nefrologia, 26(3), 1-3.

Rosenthal-Asher, D., Ver-Halen, N., \& Cukor, D. (2012). Depression and nonadherence predict mortality in hemodialysis treated end-stage renal disease patients. Hemodialysis International, 16, 387-393.

Rosland, A. M., Kieffer, E., Israel, B., Cofield, M., Palmisano, G., Sinco, B., et al. (2008). When is social support important? The association of Family support and professional support with specific diabetes self-management behaviors. Journal of General Internal Medicine, 23(12), 1992-1999.

Rudnicki, T. (2007). Preditores de qualidade de vida em pacientes renais crônicos. Estudos de Psicologia (Campinas), 24(3), 343-351.

Sandri, J. V. A., \& Schmitz, J. (2011). Trajetória da família de portadores de insuficiência renal crônica: desafios e a emergência familiar. Nursing (São Paulo), 13(154), 138-143.

Sas Institute Inc. (1999). SAS/STAT ${ }^{\circledR}$ User’s Guide. Version 9.0. Cary, NC: SAS Institute Inc.

Schmid, H., Hartmann, B., \& Schiffl, H. (2009). Adherence to prescribed oral medication in adult patients undergoing chronic hemodialysis: A critical review of the literature. European Journal of Medical Research, 14, 185-190. 
Schwartz, E., Muniz, R. M., Burille, A., Zillmer, J. G. V., Silva, D. A., Feijó, A. M., et al. (2009). As redes de apoio no enfrentamento da doença renal crônica. REME Revista Mineira de Enfermagem, 13(2), 193-201.

Secretaria de Estado da Saúde. (2006). Epidemiologia da doença renal crônica no Brasil e sua prevenção. Recuperado em 11 de maio de 2011, de ftp.cve.saude.sp.gov.br.

Sesso, R. C., Lopes, A. A., Thomé, F. S., Lugon, J. R., \& Dos Santos, D. R. (2011). Relatório do censo brasileiro de diálise de 2012. Jornal Brasileiro de Nefrologia, 33(4), 442-447.

Sgnaolin, V., Prado, A. E., \& Figueiredo, L. (2011). Adesão ao tratamento farmacológico de pacientes em hemodiálise. Jornal Brasileiro de Nefrologia, 34(2), 109-116.

Sharp, J., Wild, M. R., Gumley, A. I., \& Deighan, C. J. (2005). A cognitive behavioral group approach to enhance adherence to hemodialysis fluid restrictions: a randomized controlled trial. American Journal of Kidney Diseases, 45(6), 1046-1057.

Sherbourne, C. D., \& Stewart, A. L. (1991). The MOS social suport survey. Social Science and Medicine, 38, 705-714.

Shinohara, H. (2000). Relação terapêutica: o que sabemos sobre ela? In R. R. Kerbauy (Org.), Sobre Comportamento e Cognição: conceitos, pesquisa e aplicação, a ênfase no ensinar, na emoção e no questionamento clínico (pp.305). Santo André, SP: ESETec.

Skinner, B. F. (1957). Verbal behavior. New York: Appleton.

Skinner, B. F. (1989). Recent issues in the analysis of behavior. Columbus, OH:Merrill.

Sociedade Brasileira de Nefrologia (2011). Recuperado em 03 de maio de 2011, de www.sbn.org.br.

Sociedade Brasileira de Nefrologia (2011). Censo de Diálise. Recuperado em 05 de fevereiro de 2013, de www.sbn.org.br.

Spinale, J., Cohen, S. D., Khetpal, P., Peterson, R. A., Clougherty, B., Puchalski, C. M., et al. (2008). Spirituality, Social Support, and Survival in Hemodialysis Patients. Clinical Journal of The American Society of Nephrology, 3, 1620-1627. 
Stamatakis, M. K., Pecora, P. G., \& Gunel, E. (1997). Factors influencing adherence in chronic dialysis patients with hyperphosphatemia. Journal of Renal Nutrition, 7(3), 144148.

Straub, R. (2005). Psicologia da Saúde (R.C. Costa, trad.). Porto Alegre: Artmed.

Strelec, M. A. A. M., Pierin, A. M. G., \& Mion Jr, D. (2003). A influência do conhecimento sobre a doença e a attitude frente à tomada dos remédios no controle da Hipertensão Arterial. Arquivos Brasileiros de Cardiologia, 81(4), 343-348.

Su, S. F., Ng, H. Y., Huang, T. L., Chi, P. J., Lee, Y. T., Lai, C. R., et al. (2012). Survey of depression by Beck Depression Inventory in Uremic Patients undergoing hemodialysis and hemodiafiltration. Therapeutic Apheresis and Dialysis, 16(6), 573-579.

Taskapan, H., Ates, F., Kaya, B., Emul, M., Kaya, M., Taskapan, Ç., et al. (2005). Psychiatric disorders and large interdialytic weight gain in patients on chronic haemodialysis. Nephrology, 10, 15-20.

Terra, F. S., Costa, A. M. D. D., Figueiredo, E. T., De Morais, A. M., Costa, M. D., \& Costa, R. (2010). Adesão ao tratamento farmacológico de uso diário de pacientes renais crônicos submetidos à hemodiálise. Revista Brasileira de Clínica Médica, 8(2), 119124.

Theofilou, P. (2013). Medication adherence in greek hemodialysis patients: the contribution of depression and health cognitions. International Journal of Behavioral Medicine, 20, 311-318.

Thomas, L. K., Sargent, R. G., Michels, P. C., Richter, D. L., Valois, R. F., \& Moore, C. G. (2001). Identification of the factors associated with compliance to therapeutic diets in older adults with end stage renal disease. Journal of Renal Nutrition, 11(2), 80-89.

Thomas, C. V., \& Alchieri, J. C. (2005). Qualidade de vida, depressão e características de personalidade em pacientes submetidos à Hemodiálise. Avaliação Psicológica, 4(1), 5764.

Tsay, S. L. (2003). Self-efficacy training for patients with end-stage renal disease. Journal of Advanced Nursing, 43(4), 370-375. 
Turkmen, K., Erdur, F. M., Guney, I., Gaipova, A., Turgut, F., Altintepe, L., et al. (2012). Sleep quality, depression, and quality of life in elderly hemodialysis patients. International Journal of Nephrology and Renovascular Disease, 5, 135-142.

Untas, A., Thumma, J., Rascle, N., Rayner, H, Mapes, D., Lopes, A. A., et al. (2011). The Associations of Social Support and Other Psychosocial Factors with Mortality and Quality of Life in the Dialysis Outcomes and Practice Patterns Study. Clinical Journal of The Amercian Society of Nephrology, 6(1), 142-152.

Untas, A., Rascle, N., Idier, L., Lasseur, C., \& Combe, C. (2012). Family relations, mental health and adherence to nutritional guidelines in patients facing dialysis initiation. Psychology and Health, 27(7), 753-766.

Vaiciuniene, R., Kuzminskis, V., Ziginskiene, E., Skarupskiene, I., \& Bumblyte, I. A. (2012). Adherence to treatment and hospitalization risk in hemodialysis patients. Journal of Nephrology, 25(5), 672-678.

Wileman, V., Chilcot, J., Norton, S., Hughes, L., Wellsted, D., \& Farrington, K. (2011). Choosing not to take phosphate binders: the role of dialysis patients' medication beliefs. Nephron Clinical Practice, 119, 205-213.

Zigmond, A. D., \& Snaith, R. P. (1983). The hospital anxiety and depression scale. Acta Psychiatrica Scandinavica, 67, 361-370.

Zimmermann, P. R., Carvalho, J. O., \& Mari, J. J. (2004). Impacto da depressão e outros fatores psicossociais no prognóstico de pacientes renais crônicos. Revista de Psiquiatria - Rio Grande do Sul, 26(3), 312-318. 


\section{APÊNDICE A - ROTEIRO DE ENTREVISTA SEMIESTRUTURADA}

\section{DATA:}

\section{Identificação e Dados Sociodemográficos}

Nome:

Registro:

Sexo: F ( ) M( ) Idade: Telefone: ( ) próprio ( ) recado

Cidade de procedência:

Grau de Escolaridade:
( ) Analfabeto
( ) Médio Incompleto
( ) Superior Completo
( ) Fundamental Incompleto
( ) Médio Completo
Anos de Estudo:
( ) Fundamental Completo
( ) Superior Incompleto
É praticante de alguma religião: ( ) sim ( ) não

$\begin{array}{llll}\text { Estado civil: } & (\text { ) solteiro (a) } & \text { ( ) casado (a) } & \text { ( ) amasiado (a) } \\ & (\text { ) separado (a) } & \text { ( ) viúvo (a) } & \text { ( ) outro: }\end{array}$

Atualmente está empregado (a)? ( ) sim （ ) não

Profissão:

Aposentadoria ( ) Auxílio doença ( )

Renda familiar mensal: ( ) Até 1 salário mínimo

Valor: R\$

( ) Entre 1 e 2 salários mínimos

( ) Entre 3 e 4 salários mínimos

( ) Entre 2 e 3 salários mínimos

( ) Acima de 4 salários mínimos

( ) Não sabe referir

Número de pessoas que dependem desta renda:

\section{Doença e Tratamento}

1. Tempo de hemodiálise (segundo prontuário médico):

2. Qual doença ocasionou a necessidade deste tratamento?

3. Você sabia que esta doença poderia prejudicar seus rins?

4. Você realizava o tratamento de sua doença que ocasionou a necessidade de hemodiálise da forma como o médico orientava?

5. Explique o que você sabe sobre a Insuficiência Renal Crônica. 
6. O que é recomendado pelo médico para o tratamento de uma pessoa com Insuficiência Renal Crônica? (investigar conhecimento sobre diferentes aspectos do tratamento a partir de perguntas como “e o que mais?")

6.a) E além disso? Tem mais alguma coisa que o médico fala que é necessário?

7. De todos os aspectos do tratamento, qual você acha o mais difícil de seguir? (pode citar mais de um)

8. O que torna isto difícil? (perguntar para cada aspecto citado na questão anterior)

9. Qual aspecto do tratamento você considera que segue corretamente? (pode citar mais de um)

10. O que torna este seguimento mais fácil? (perguntar para cada aspecto citado na questão anterior)

\section{Autoavaliação de adesão aos diferentes aspectos do tratamento}

11. Numere de 0 a 5 o quanto você realiza corretamente os seguintes aspectos do seu tratamento (sendo 0 se o que você faz é totalmente diferente do que é recomendado pelo médico e 5 se o que você faz é exatamente o que o médico orienta)

a) Tomar as medicações

\section{TOTALMENTE} DIFERENTE

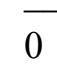

0

1

1

(2)

2

3

$4 \quad 5$

b) Comparecer às sessões de diálise 


\section{0}

1

2

3

4

5

c) Comparecer às consultas médicas mensais
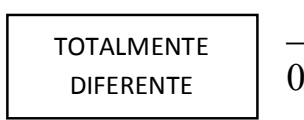

0

$\begin{array}{llll}1 & 2 & 3 & 4\end{array}$

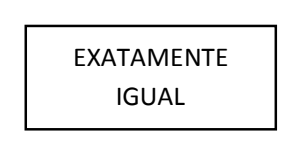

d) Controlar a ingestão hídrica

\begin{tabular}{|c|cccccc}
\hline $\begin{array}{c}\text { TOTALMENTE } \\
\text { DIFERENTE }\end{array}$ & 0 & 1 & 2 & 3 & 4 & 5 \\
\hline
\end{tabular}

EXATAMENTE

IGUAL

e) Controlar a alimentação

\begin{tabular}{|c|c|c|c|c|c|c|}
\hline $\begin{array}{l}\text { TOTALMENTE } \\
\text { DIFERENTE }\end{array}$ & 0 & 1 & 2 & 3 & 4 & 5 \\
\hline
\end{tabular}

EXATAMENTE

IGUAL

\section{Percepção da relação com a equipe de saúde}

12. Numere de 0 a 5 como você avalia a sua relação com os profissionais que te atendem, sendo 0 se você considera a relação péssima (não se sente acolhido e apoiado) e 5 se você acha que a relação é excelente (sente-se muito acolhido e apoiado).
a) Médicos

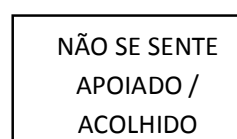

0

ACOLHIDO

b) Enfermeiros
NÃO SE SENTE
APOIADO /

ACOLHIDO

0

1

1

2

3

4

5

SENTE-SE MUITO

APOIADO/

ACOLHIDO

c) Nutricionistas

1

2

3

4

SENTE-SE MUITO APOIADO/ ACOLHIDO 


\section{APÊNDICE B - REGISTRO DE MEDIDAS FISIOLÓGICAS}

Nome do participante:

Registro:

Data da coleta:

Período considerado (últimos 3 meses):

I. Dados clínicos (colhidos do prontuário médico do participante)

a) Principais intercorrências durante a diálise:

b) Data da última internação:

c) Motivo da última internação:

II. Medidas objetivas de adesão (colhidas do prontuário médico do participante)

a) Número de faltas às sessões de hemodiálise nos últimos 3 meses:

b) Ganho de peso interdialítico:

\begin{tabular}{|c|l|l|l|l|l|l|l|l|l|l|l|l|l|}
\hline Sessões & 1 & 2 & 3 & 4 & 5 & 6 & 7 & 8 & 9 & 10 & 11 & 12 \\
\hline Mês 1 & & & & & & & & & & & & \\
\hline Mês 2 & & & & & & & & & & & & \\
\hline Mês 3 & & & & & & & & & & & & \\
\hline
\end{tabular}

c) Exames bioquímicos:

\begin{tabular}{|c|c|c|c|}
\hline & Mês 1 & Mês 2 & Mês 3 \\
\hline Fósforo (P) & & & \\
\hline Potássio (K) & & & \\
\hline
\end{tabular}




\section{APÊNDICE C - TERMO DE CONSENTIMENTO LIVRE E ESCLARECIDO}

\section{Obrigatório para Pesquisas Científicas com Seres Humanos Resolução $n^{\circ} 196 / 96$ - CNS}

Nome da Pesquisa: Avaliação de variáveis sociodemográficas e psicológicas associadas ao comportamento de adesão ao tratamento hemodialítico em pacientes renais crônicos

\section{Pesquisadores Responsáveis:}

Psicóloga Renata Tamie Nakao (CRP 06/96096)

Prof. Dr. Ricardo Gorayeb (CRP 06/05558)

Você está sendo convidado a participar de um estudo que tem por objetivo

avaliar

a adesão ao tratamento hemodialítico de pacientes renais crônicos, identificando possíveis relações entre o grau de adesão ao tratamento e variáveis sociodemográficas - como sexo, idade, escolaridade - e psicológicas - como depressão e ansiedade.

Este estudo se baseia na necessidade de uma melhor compreensão dos fatores associados à adesão e não-adesão dos pacientes ao tratamento, para que se possam desenvolver novas estratégias de atenção e cuidado à saúde. Busca-se, assim, auxiliar o individuo portador da doença renal crônica a adaptar-se ao tratamento hemodialítico de forma que este lhe possibilite viver mais e com qualidade.

Caso aceite participar desta pesquisa, você precisa saber que:

1. Você responderá uma entrevista com algumas questões sobre você, como seu nome, idade, endereço, escolaridade, estado civil, condição profissional e renda familiar. Além disso, serão realizadas perguntas a respeito da sua doença e tratamento, bem como sobre seu relacionamento com a equipe de saúde responsável pelo seu cuidado. Esta entrevista tomará, aproximadamente, 25 minutos do seu tempo.

2. Você responderá, também, a escalas psicológicas que investigam sua percepção de apoio social e a presença de sintomas de depressão e ansiedade. Esta etapa durará, aproximadamente, 15 minutos.

3. Seu prontuário médico será consultado para se obter informações sobre dados clínicos e resultados de exames bioquímicos relevantes para o estudo.

4. Todas as informações de ordem pessoal serão mantidas em sigilo e poderão ser utilizadas apenas para este estudo.

5. A entrevista será gravada por um gravador de voz para facilitar a posterior análise das respostas.

6. Não será possível identificá-lo (a), o que garante seu completo anonimato.

7. Caso seja identificada demanda para acompanhamento psicológico, este será fornecido pela psicóloga que atua na Unidade de Diálise.

8. Você está livre para desistir de participar do estudo a qualquer momento e isto não prejudicará seu atendimento no HCFMRP-USP. 
9. Não há nenhum risco significativo ao participar deste estudo.

$\mathrm{Eu}$,

aceito participar do estudo e declaro que li e compreendi as informações acima, sendo que minha participação é inteiramente voluntária.

Assinatura do Paciente

Assinatura pelo pesquisador responsável:

Renata Tamie Nakao

CRP 06/96096

Ribeirão Preto, de de

Caso haja necessidade de contato com quaisquer dos profissionais envolvidos nesta pesquisa, você pode entrar em contato com:

Serviço de Psicologia do HCFMRP-USP: (16) 3602-2547

Psicóloga Renata Tamie Nakao

Prof. Dr. Ricardo Gorayeb 


\section{APÊNDICE D - CATEGORIZAÇÃO DAS RESPOSTAS DO ROTEIRO DE ENTREVISTA SEMIESTRUTURADA}

Questão 8 ï O que torna isto difícil?

(1) Aspectos físicos/ fisiológicos:

Exemplos de respostas: "Muita sede"; "O calor"; "Sinto muita fome"; "A boca fica seca"; "É da natureza humana a pessoa sentir sede".

(2) Hábitos anteriores:

Exemplos de respostas: "O costume, hábito"; "Gostava muito de água, tomava muito líquido antes de começar a hemodiálise"; "Não gosto de comida sem sal"; "Gosto de comer comida forte. Gosto de beber cerveja e não posso".

(3) Características do tratamento:

Exemplos de respostas: "São muitos remédios"; "Ficar sentado 4 horas é muito ruim"; "São muitas restrições"; "Perde muito tempo".

(4) Dificuldades externas:

Exemplos de respostas: "É difícil ir à farmácia, tem muita fila"; "Meus filhos trabalham, não tem quem me trazer"; "Ter que depender da prefeitura"; "Trabalho à noite, fico cansado".

(5) Sentimentos negativos:

Exemplos de respostas: "Desânimo"; "As pessoas não entendem"; "É difícil ter disposição".

(6) Outros:

Exemplos de respostas: "Não sei ler".

Questão 10 ï O que torna este seguimento mais fácil?

(1) Consequências aversivas:

Exemplos de respostas: "Se não vier, vai dar problema"; "Para não passar mal na máquina"; "Passo mal, é pior pra mim"; "Sei que se faltar, vou sofrer uma consequência"; "Se eu não fizer certinho, quem vai sofrer sou eu"; "Ou faz ou morre".

(2) Aceitação da doença: 
Exemplos de respostas: "Pôr na cabeça que não pode abusar"; "Coloquei isso como prioridade"; "Coloquei como obrigação, como trabalho"; "Consciência"; "Acostumei, a gente acostuma"; "Tem que vir e acabou. Não tem outro jeito de tratar".

(3) Apoio Social:

Exemplos de respostas: “Ajuda da minha família"; "Apoio do meu marido"; "Ajuda dos médicos e dos meus filhos"; “Aqui me sinto em casa! É uma família!”.

(4) Estratégias comportamentais:

Exemplos de respostas: "Faço o controle da água com uma garrafa"; "Substituo o que não gosto"; "Uso temperos naturais"; "Deixo todos [os remédios] para tomar na mesma hora"; "Separo os remédios do dia".

(5) Sente que fica bem / Desejo de ficar bem:

Exemplos de respostas: "É para o meu bem estar"; "Pra eu ficar bem"; "Quero viver bem"; "O tratamento me dá uma vida muito boa. Vivo muito bem"; "A gente sai daqui bem mais aliviada".

(6) Bom conhecimento sobre a doença:

Exemplos de respostas: "Saber que não pode, ter informação"; "Porque sei que minha pressão é muito alta"; "As orientações"; "Sei das complicações".

(7) Outros:

Exemplos de respostas: "Trabalhar fora"; "Venho de carro, não dependo da ambulância"; "Nunca fui de comer porcaria"; "Não sinto fome porque meu estômago fica embrulhado". 


\section{ANEXO 1 - ESCALA HOSPITALAR DE ANSIEDADE E DEPRESSÃO - HAD}

Este questionário nos ajudará a saber como você está se sentindo. Leia todas as frases. Marque com um ñXò a resposta que melhor corresponder a como você tem se sentido na ÚLTIMA SEMANA. Não é preciso ficar pensando muito em cada questão. Neste questionário as respostas espontâneas têm mais valor do que aquelas em que se pensa muito. Marque apenas uma resposta para cada pergunta.

1) Eu me sinto tenso ou contraído:

( ) A maior parte do tempo

( ) Boa parte do tempo

() De vez em quando

( ) Nunca

2) Eu ainda sinto gosto pelas mesmas coisas de antes:

() Sim, do mesmo jeito que antes

( ) Não tanto quanto antes

( ) Só um pouco

( ) Já não sinto mais prazer em nada

3) Eu sinto uma espécie de medo, como se alguma coisa ruim fosse acontecer:

( ) Sim, e de um jeito muito forte

( ) Sim, mas não tão forte

( ) Um pouco, mas isso não me preocupa

( ) Não sinto nada disso

4) Dou risada e me divirto quando vejo coisas engraçadas:

( ) Do mesmo jeito que antes

() Atualmente um pouco menos

( ) Atualmente bem menos

( ) Não consigo mais

5) Estou com a cabeça cheia de preocupações:

( ) A maior parte do tempo

( ) Boa parte do tempo

( ) De vez em quando

( ) Raramente

6) Eu me sinto alegre:

() Nunca

( ) Poucas vezes

() Muitas vezes

( ) A maior parte do tempo

7) Consigo ficar sentado à vontade e me sentir relaxado:
( ) Sim, quase sempre
( ) Muitas vezes
() Poucas vezes
( ) Nunca

8) Eu estou lento para pensar e fazer as coisas:

( ) Quase sempre

() Muitas vezes

() De vez em quando

( ) Nunca

9) Eu tenho uma sensação ruim de medo, como um frio na barriga ou um aperto no estômago:

() Nunca

( ) De vez em quando

( ) Muitas vezes

( ) Quase sempre

10) Eu perdi o interesse em cuidar da minha aparência:

() Completamente

( ) Não estou mais me cuidando como deveria

( ) Talvez não tanto quanto antes

( ) Me cuido do mesmo jeito que antes

11) Eu me sinto inquieto, como se eu não pudesse ficar parado em lugar nenhum:

( ) Sim, demais

( ) Bastante

() Um pouco

( ) Não me sinto assim

12) Fico esperando animado as coisas boas que estão por vir:

( ) Do mesmo jeito que antes

( ) Um pouco menos do que antes

( ) Bem menos do que antes

() Quase nunca

13) De repente, tenho a sensação de entrar em pânico:

( ) A quase todo momento

() Várias vezes

( ) De vez em quando

( ) Não sinto isso

14) Consigo sentir prazer quando assisto a um bom programa de televisão, de rádio ou quando leio alguma coisa:

( ) Quase sempre

() Várias vezes

( ) Poucas vezes

() Quase nunca 
ANEXO 2 - ESCALA DE APOIO SOCIAL - MOS

As seguintes questões fazem referência ao apoio social ou ajuda com a qual você pode contar quando necessita. Se você precisar, com que frequência dispõe de cada um dos seguintes tipos de apoio?

\begin{tabular}{|c|c|c|c|c|c|c|}
\hline & & Nunca & Raramente & Às vezes & $\begin{array}{l}\text { Quase } \\
\text { Sempre }\end{array}$ & Sempre \\
\hline 1 & Alguém que o ajude, se ficar de cama & 1 & 2 & 3 & 4 & 5 \\
\hline 2 & Alguém para lhe ouvir, quando você precisa falar & 1 & 2 & 3 & 4 & 5 \\
\hline 3 & $\begin{array}{l}\text { Alguém para lhe dar bons conselhos em uma } \\
\text { situação de crise }\end{array}$ & 1 & 2 & 3 & 4 & 5 \\
\hline 4 & Alguém para levá-lo(a) ao médico & 1 & 2 & 3 & 4 & 5 \\
\hline 5 & Alguém que demonstre amor e afeto por você & 1 & 2 & 3 & 4 & 5 \\
\hline 6 & Alguém para se divertir junto & 1 & 2 & 3 & 4 & 5 \\
\hline 7 & $\begin{array}{l}\text { Alguém para lhe dar informação que o(a) ajude a } \\
\text { compreender uma determinada situação }\end{array}$ & 1 & 2 & 3 & 4 & 5 \\
\hline 8 & $\begin{array}{l}\text { Alguém em quem confiar ou para falar de você ou } \\
\text { sobre seus problemas }\end{array}$ & 1 & 2 & 3 & 4 & 5 \\
\hline 9 & Alguém que lhe dê um abraço & 1 & 2 & 3 & 4 & 5 \\
\hline 10 & Alguém com quem relaxar & 1 & 2 & 3 & 4 & 5 \\
\hline 11 & $\begin{array}{l}\text { Alguém para preparar suas refeições, se você não } \\
\text { puder prepará-las }\end{array}$ & 1 & 2 & 3 & 4 & 5 \\
\hline 12 & Alguém de quem você realmente quer conselhos & 1 & 2 & 3 & 4 & 5 \\
\hline 13 & Alguém com quem distrair a cabeça & 1 & 2 & 3 & 4 & 5 \\
\hline 14 & $\begin{array}{l}\text { Alguém para ajudá-lo nas tarefas diárias, se você } \\
\text { ficar doente }\end{array}$ & 1 & 2 & 3 & 4 & 5 \\
\hline 15 & $\begin{array}{l}\text { Alguém para compartilhar suas preocupações e } \\
\text { medos mais íntimos }\end{array}$ & 1 & 2 & 3 & 4 & 5 \\
\hline 16 & $\begin{array}{l}\text { Alguém para dar sugestões sobre como lidar com } \\
\text { um problema pessoal }\end{array}$ & 1 & 2 & 3 & 4 & 5 \\
\hline 17 & Alguém com quem fazer coisas agradáveis & 1 & 2 & 3 & 4 & 5 \\
\hline 18 & Alguém que compreenda seus problemas & 1 & 2 & 3 & 4 & 5 \\
\hline 19 & $\begin{array}{l}\text { Alguém que você ame e que faça você se sentir } \\
\text { querido }\end{array}$ & 1 & 2 & 3 & 4 & 5 \\
\hline
\end{tabular}




\section{ANEXO 3}

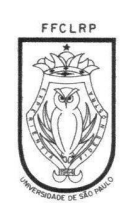

Universidade de São Paulo

Faculdade de Filosofia, Ciências e Letras de Ribeirão Preto

_Campus" de Ribeirão Preto

\section{Of.CEtP/FFCLRP-USP/156/-jsI}

Ribeirão Preto, 21 de novembro de 2011.

Prezada Pesquisadora,

Comunicamos a V. Sa. que o trabalho intitulado "VARIÁVEIS SOCIODEMOGRÁFICAS E PSICOLÓGICAS ASSOCIADAS AO COMPORTAMENTO DE ADESÃO AO TRATAMENTO HEMODIALítICO EM PACIENTES RENAIS CRÔNICOS" foi analisado pelo Comitê de Ética em Pesquisa da FFCLRP-USP, em sua $102^{a}$ Reunião, realizada em 17.11.11, e enquadrado na categoria: APROVADO, de acordo com o Processo CEP-FFCLRP n 601/2011 - 2011.1.2238.59.7.

Atenciosamente,

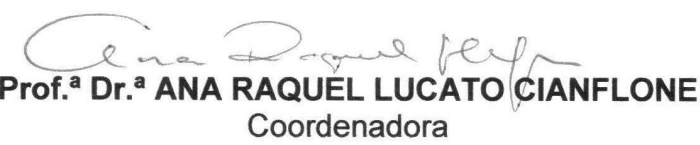

À Senhora

Renata Tamie Nakao

Mestranda do Programa de Pós-Graduação em Psicologia da FFCLRP - USP

Com cópia para o orientador:

Prof. Dr. Ricardo Gorayeb

Departamento de Neurociências e Ciências do Comportamento da FMRP - USP

CEP - Comitê de Ética em Pesquisa da FFCLRP

Fone: (16) 3602-4811

Fax: (16) 3633-2660 (direto) ou 3633-5015

Avenida Bandeirantes, 3900 - bloco 3 - sala 16 - 14040-901 - Ribeirão Preto - SP - Brasil

Homepage: http://www.ffclrp.usp.br - e-mail: coetp@ffclrp.usp.br 


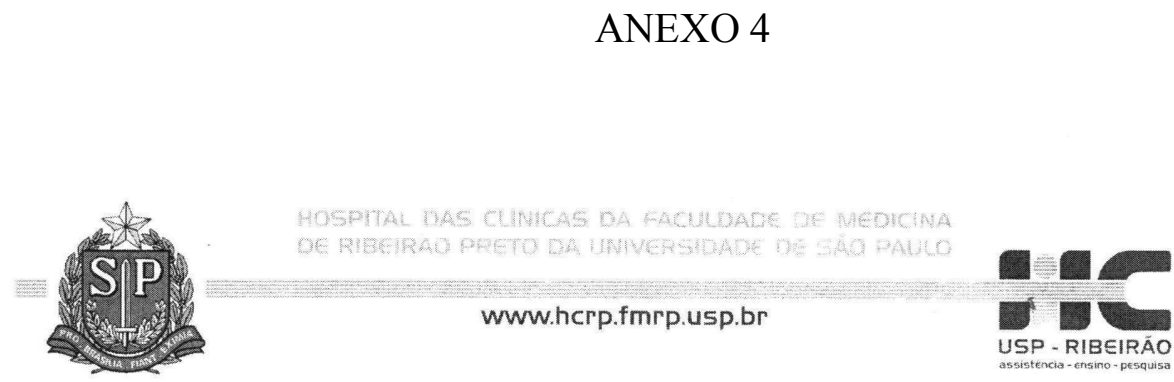

Ribeirão Preto, 14 de dezembro de 2011

Projeto de pesquisa: "Variáveis sociodemográficas e psicológicas associadas ao comportamento de adesão ao tratamento hemodialítico em pacientes renais crônicos" Pesquisadoras responsáveis: Prof Dr Ricardo Gorayeb (Orientador) e Renata Tamie Nakao (mestranda)

Instituição Proponente: Faculdade de Filosofia, Ciências e Letras de Ribeirão Preto da Universidade de São Paulo

"O CEP do HC e da FMRP-USP concorda com o parecer ético emitido pelo CEP da Instituição Proponente, que cumpre as Resoluções Éticas Brasileiras, em especial a Resolução CNS 196/96. Diante disso, o HCFMRP-USP, como instituição co-participante do referido projeto de pesquisa, está ciente de suas co-responsabilidades e de seu compromisso no resguardo da segurança e bem-estar dos sujeitos desta pesquisa, dispondo de infra-estrutura necessária para a garantia de tal segurança e bem-estar".

Ciente e de acordo:

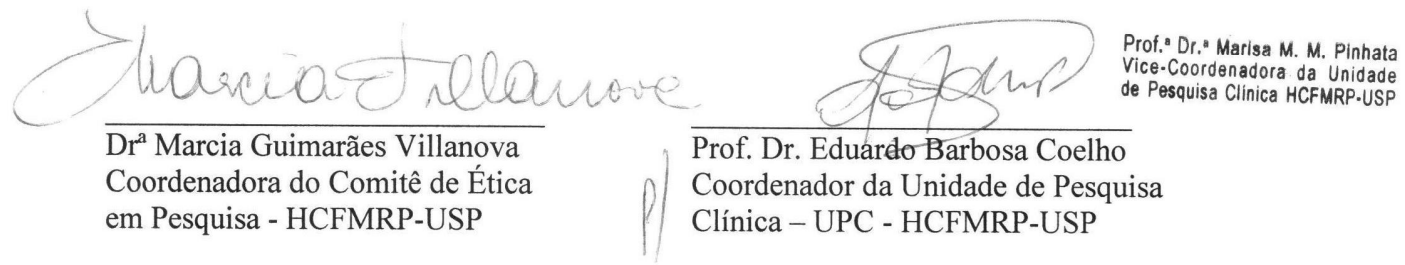

